\title{
LA FAMILIA JUNCACEAE EN MÉXICO
}

\author{
Henrik Balslev $^{1,3}$ y Rodrigo Duno de Stefano²
}

${ }^{1}$ Aarhus University, Department of Bioscience, Ecoinformatics and Biodiversity, Ny Munkegade 114-116, DK-8000 Aarhus C., Dinamarca.

${ }^{2}$ Centro de Investigación Científica de Yucatán, A.C., Mérida, Yucatán, México.

${ }^{3}$ Autor para la correspondencia: henrik.balslev@biology.au.dk.

\section{RESUMEN}

Se presenta un tratamiento de la familia Juncaceae Juss. para la flora de México. La familia incluye dos géneros en dicho país: Juncus L. y Luzula DC. El primero comprende 31 especies y el segundo cinco. Se proporciona una clave para la identificación de los taxones, descripciones morfológicas, notas taxonómicas e información sobre la distribución geográfica, así como ilustraciones de algunas especies. Una especie es endémica: Juncus chiapasensis Balslev crece exclusivamente en el estado de Chiapas. Otra, J. textilis Buchenau, es un endemismo local que se encuentra en el estado de Baja California y en el estado de California en los Estados Unidos de América.

Palabras clave: Juncus, Luzula, Poales, taxonomía.

\begin{abstract}
A treatment of the family Juncaceae Juss. for the flora of Mexico is presented. The family includes two genera in this country: Juncus L. and Luzula DC. The first genus consists of 31 species and the second one of five. Keys for identification of the taxa, morphological descriptions, taxonomic notes, and information about the geographic distribution are provided, as well as some illustrations. One species is endemic: Juncus chiapasensis Balslev occurs only in the state of Chiapas. A second species, J. textilis Buchenau, is a local endemism, occurring in the state of Baja California as well as in the state of California in the United States of America.
\end{abstract}

Key words: Juncus, Luzula, Poales, taxonomy. 


\section{INTRODUCCIÓN}

La mayoría de los taxones que pertenecen a la familia Juncaceae son hierbas parecidas a poáceas y ciperáceas con culmos herbáceos, hojas lineares, usualmente con inflorescencias con muchas flores glumáceas. Una excepción en la forma del hábito corresponde a los miembros de Distichia Nees \& Meyen, el cual está adaptado a elevadas altitudes a través de la concentración de sus internodosy crece en forma de densos cojines o almohadones. Las juncáceas difieren de las poáceas y ciperáceas en sus hojas y culmos lisos (más o menos pilosos en Luzula DC.) sin incrustaciones de sílice. También difieren en la estructura floral (Fig. 1 A y B) que cuenta con dos verticilos de tres tépalos cada uno y usualmente dos verticilos de tres estambres cada uno (solo tres estambres en las poáceas y ciperáceas). El gineceo cuenta con tres carpelos (uno solo en poáceas y dos o tres en ciperáceas pero fusionados y entonces un solo lóculo) que luego se transforma en una cápsula (cariopsis en las poáceas y aquenio en las ciperáceas) con 3 semillas en Luzula y muchas en el resto de los taxones (una sola en poáceas y ciperáceas).

Las juncáceas incluyen siete géneros y cerca de 440 especies distribuidas en todo el mundo pero la mayoría está confinada a regiones templadas y frías (Kirschner, 2002a). En los trópicos americanos crecen en tierras elevadas, usualmente por encima de los 2000 metros sobre el nivel de mar pero a veces tan bajo como 800 metros. En el Nuevo Mundo se encuentran siete géneros. Marsippospermum Desv. se restringe a Nueva Zelanda y el extremo meridional de Sur América (Patagonia). Rostkovia Desv., Patosia Buchenau y Oxychloe Phil. son fundamentalmente de regiones templadas del hemisferio sur, incluyendo los trópicos de Sur América. Por último, Distichia está restringida a los trópicos de Sur América. Juncus L. y Luzula DC. son los taxones más cosmopolitas y diversos.

Quince taxones de Juncaceae fueron incluidos en Species Plantarum por Linnaeus (1753). Aunque este autor no estudió ningún material proveniente del Nuevo Mundo, seis de ellos prosperan en esta parte del planeta. La publicación de Mexico's Juncaceer (Liebmann, 1850) requiere una especial consideración ya que incluyó la descripción de cinco especies nuevas de Juncus y Luzula en México e información de otras descritas previamente (Buchenau, 1873). Buchenau (1875) publicó una primera clasificación infragenérica y reconoció ocho subgéneros en Juncus y tres en Luzula. Posteriormente, este mismo autor publicó un primer tratamiento para Sur América (Buchenau, 1879), para México y Centro América (Buchenau, 1886), así como dos trabajos a nivel global (Buchenau, 1880, 1906). Esta última obra en la serie Pflanzenreich de Engler (Buchenau, 1906) resume 40 años de investigación, incluyendo abundante información morfológica, anatómica e ilustraciones detalladas 

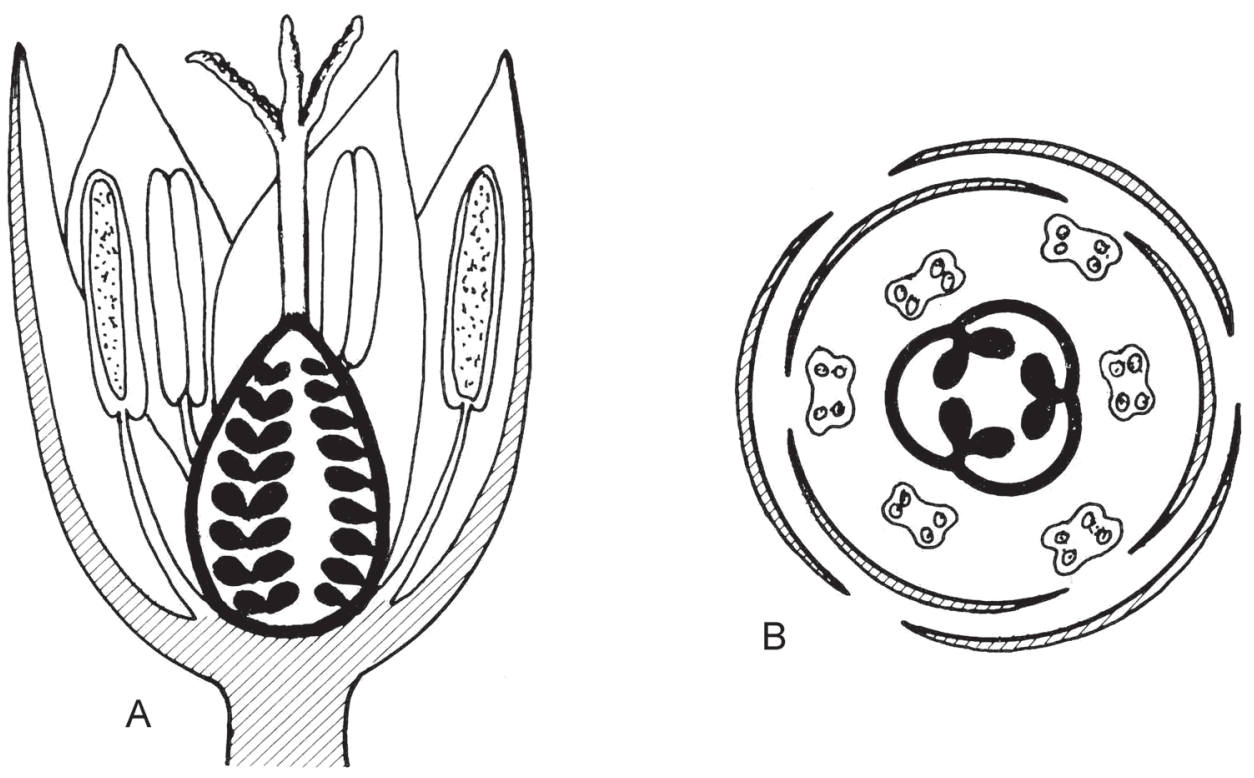

Fig. 1. Morfología floral en Juncus. A. diagrama en sección longitudinal mostrando cuatro tépalos: uno completo del verticilo externo junto con dos medios tépalos y un tépalo completo del verticilo interior; cuatro estambres: dos del verticilo externo y dos del verticilo interno; ovario unilocular con placentación parietal y muchos óvulos, un estilo simple prolongado en tres estigmas. B. diagrama de la sección transversal de una flor de Juncus mostrando dos verticilos con tres tépalos cada uno, dos verticilos de tres estambres cada uno, un ovario tricarpelar, unilocular con placentación parietal y muchos óvulos. Este diagrama es el mismo para toda la familia con la excepción de Luzula que solo tiene tres óvulos y tres semillas en un ovario unilocular, triseptado hasta trilocular.

de un buen número de taxones. La clasificación de Buchenau $(1875,1906)$ ha sido utilizada hasta fechas recientes, por ejemplo en la revisión para la Península Ibérica (Fernández-Carvajal, 1981, 1983), la Flora Neotropica (Balslev, 1996) o como referencia básica en la Flora Intermontana (Cronquist et al., 1977). Kirschner (2002a, b, c) publicó una actualización de la familia a nivel mundial.

En el caso particular de México, las obras de Liebmann (1850) y Buchenau $(1879,1880,1906)$ abordan taxones mexicanos al igual que la revisión de Juncus en Norte América (Engelmann, 1866, 1868). En Flora Neotropica (Balslev, 1996) se incluye la mayoría de los taxones aquí discutidos, menos siete que crecen exclusivamente por encima del Trópico de Cáncer (aproximadamente 23 grados latitud norte). En la Flora del Bajío y de Regiones Adyacentes (Galván-Villanueva, 2002) 
se provee información de once especies de Juncus y tres de Luzula, mientras que la Flora Nova Galiciana (McVaugh, 1993) incluye información de ocho especies de Juncus y tres de Luzula.

Las juncáceas fueron ubicadas por Cronquist (1981) en la subclase Commelinidae y el orden Juncales junto con Thurniaceae. Sin embargo, el uso de marcadores moleculares y de estudios con enfoque filogenético han cambiado nuestra visión de la familia. Un análisis pionero de Plunkett et al. (1995) relacionó a Juncaceae con la familia Cyperaceae. Otras filogenias, utilizando diversos marcadores moleculares (Drábková et al., 2006, Drábková y Vlček, 2007, 2009), han evaluado las relaciones genéricas, en especial las del género Juncus, demostrando para este caso la necesidad de profundos cambios en su clasificación.

En resumen, el orden Juncales desapareció para quedar integrado en el Poales junto con otras quince familias (APG 1998, 2003, 2009). Los análisis filogenéticos han comprobado la monofilia de Juncaceae, una vez excluido Prionium, género arbustivo monotípico del sur de África, y transferido finalmente a Thurniaceae (Munro y Linder, 1998). Juncaceae y Cyperaceae son grupos hermanos, mientras que a su vez Thurniaceae es el grupo hermano del clado Juncaceae-Cyperaceae. También se ha comprobado la monofilia de Luzula y la parafilia de Juncus. Si la clasificación es reorganizada, aceptando solo clados monofiléticos, la taxonomía de las Juncaceae requiere profundos cambios (Drábková et al., 2003). En el caso de Juncus, Drábková et al. (2006) y Drábková y Vlček (2009) encontraron que la mayoría de las especies se agrupan en tres clados que corresponden a los subgéneros Agathryon Raf. y Juncus L. (apoyados morfológicamente por la presencia o ausencia de bractéolas y la inflorescencia tipo cima o racimo respectivamente) y un clado denominado Hemisferio Sur que incluye a varios miembros de Juncus pero también a representantes de Distichia, Marsippospermum, Patosia, Rostkovia y Oxychloe (Drábková et al., 2003, 2004, 2006; Drábková y Vlček, 2007).

\section{MATERIALES Y MÉTODOS}

Este trabajo está basado en el estudio de la morfología y anatomía de caracteres derivados de material herborizado. Se estudiaron especímenes de los siguientes herbarios: AAU, ARE, ARIZ, B, BM, C, CAS, CHAPA, CHARL, CU, DAV, DS, DUKE, ENCB, F, FI, G, GH, GOET, HAL, HBG, IEB, JEPS, K, L, LL, MA, MEXU, MICH, MIN, MO, MY, NCU, NY, P, PMA, PH, PR, PRC, QMEX, S, SD, UC, UPS, US, W y XAL. Las muestras fueron estudiadas con un microscopio estereoscópico. 
Este trabajo tiene su origen en la investigación original del primer autor en la familia Juncaceae iniciado con el tratamiento para la Flora de Ecuador (Balslev, 1979), varias novedades taxonómicas (Balslev, 1983, 1988; Balslev y Lægaard, 1986), la disertación para obtener el grado de doctor en filosofía en la Universidad de Nueva York (Balslev, 1982) y los estudios de la familia para la Flora Mesoamericana (Balslev, 1994), Flora Neotropica (Balslev, 1996) y la Flora de Colombia (Balslev y Zuluaga, 2009). Ninguno de estos trabajos incluyó aquellas especies de la familia que crecen por encima del Trópico de Cáncer desde el altiplano central de México hacia el norte.

México cuenta con una extensión territorial de cerca de dos millones de kilómetros cuadrados, y su ubicación y forma revisten características notables como lo apunta Rzedowski (1978). Sus extremos meridional y boreal alcanzan los paralelos $14^{\circ} 30^{\prime} \mathrm{N}$ y $32^{\circ} 42^{\prime} \mathrm{N}$, respectivamente, y el territorio queda más o menos distribuido equitativamente a cada lado del trópico de Cáncer. El país cuenta además con un relieve muy accidentado. Solo $35 \%$ del territorio presenta elevaciones menores de los 500 metros sobre el nivel del mar y la cumbre más alta, el pico de Orizaba, alcanza los 5653 metros. Su ubicación geográfica determina que el país forme parte de dos reinos biogeográficos: el Neotropical y el Holártico. Por tal motivo, el presente tratamiento taxonómico aborda todos los taxones incluidos en la Flora Neotropica (Balslev, 1996), y además los que crecen exclusivamente por encima del Trópico de Cáncer como Juncus bryoides F.J. Herm., J. cooperi Engelmann, J. dubius Engelm., J. longistylis Torrey, J. macrophyllus Coville, J. textilis Buchenau, J. tiehmii Ertter, $J$. torreyi Coville y J. xiphioides E. Mey.

La sinonimia en el género Juncus es bastante extensa para algunos taxones y solo se incluyen sinónimos relevantes para México. Para una sinonimia actualizada se debe consultar los tres volúmenes de Species Plantarum: Flora of the World (Kirschner et al., 2002a, b, c).

\section{TRATAMIENTO TAXONÓMICO}

Juncaceae Juss., Gen P1. 43.1789 (“Junci”). Tipo: Juncus L.

Hierbas perennes y usualmente rizomatosas, rara vez anuales, glabras o con los márgenes de las hojas pilosos. Rizomas rastreros, ascendentes o erectos, ramificados o no, desnudos o cubiertos por escamas o las bases de las hojas partidas; culmos erectos, ascendentes o rara vez procumbentes, teretes, lisos o longitudinal- 
mente dentados, desnudos o llevando hojas. Hojas lineares o filiformes, con una vaina abierta o cerrada a veces auriculada, espiraladas o rara vez dísticas; láminas a veces reducidas, glabras o pilosas en los márgenes. Inflorescencias terminales, a veces pseudo-laterales, compuestas, cimosas o racemosas, usualmente en cabezuelas o grupos parecidos a espigas, rara vez reducidos a una flor solitaria. Flores generalmente pequeñas, perfectas o imperfectas, actinomorfas. Perianto con seis segmentos o en dos verticilos de tres, de menos de $8 \mathrm{~mm}$ de largo, glumáceos, iguales o casi iguales. Estambres seis, dos verticilos de tres, opuestos a los segmentos del perianto, el verticilo interior a veces reducido; filamentos filiformes o algo aplanados y más engrosados en la base; anteras oblongas o lineares, basifijas, obtusas o mucronadas, dehiscentes por dos ranuras longitudinales. Ovario súpero con tres carpelos connados, unilocular pero claramente triseptado o trilocular; estilo uno, hasta $10 \mathrm{~mm}$ de largo, pero usualmente más corto; estigmas tres, teretes y del mismo diámetro desde la base hasta el ápice o a veces atenuados hacia el ápice, volubles, con papilas en la superficie adaxial. Fruto una cápsula loculicida o circuncísil, orbicular a oblonga o elipsoidal, trilobada, redonda o trígona. Semillas usualmente muchas por cápsula, a veces tres; cubierta seminal externa hialina, de color blanquecino o ligeramente castaño, a veces terminando en un apéndice en forma de cola, frecuentemente con una ornamentación distintiva; cubierta seminal interna de color castaño claro, castaño o amarillo.

Clave para los géneros de la familia Juncaceae en México

1. Vainas foliares abiertas; láminas completamente glabras; cápsula con muchas semillas, hasta 120 Juncus

1. Vainas foliares cerradas; láminas con márgenes pelosos; cápsula con solo tres semillas Luzula

Juncus L., Sp. Pl. 1: 325. 1753. Tipo: Juncus acutus L.

Cephaloxys Desv., J. Bot. (Desvaux) 1: 321. 1809, nom. illeg.

Tipo: C. flabellata Desv. nom. illeg.; J. repens Michaux.

Hierbas anuales o perennes, rizomatosas, glabras, parecidas a gramíneas y/o ciperáceas; culmos usualmente erectos, rara vez procumbentes o ascendentes. Tallos teretes a aplanados y ocasionalmente algo alados. Hojas alternas, divididas en vaina y lámina, con forma de escamas en los rizomas, catáfilos (hojas reducidas) a veces 
en la base de los culmos y brácteas en las inflorescencias; vainas abiertas fluctuando en largo y ancho, a veces prolongadas por encima de la unión con la vaina en un par de aurículas; láminas variando en la sección transversal desde aplanadas con márgenes elevados y ligeramente acanaladas abajo, caniculadas, redondas hasta elípticas o completamente planas, glabras. Inflorescencias generalmente en cimas o racimos, con brácteas que decrecen en tamaño desde la base hacia arriba, las inferiores en general conspicuamente diferentes del resto. Flores bisexuales, a veces abrazadas por dos bractéolas en el pedicelo. Tépalos generalmente seis, en dos series iguales o los internos ligeramente más cortos, lanceolados, enteros, persistentes, de color pajizo o castaño, a veces verde pálido. Estambres tres o seis, persistentes; filamentos alargados, filiformes o aplanados, a veces ensanchados en la base; anteras lineares u oblongas, obtusas. Ovario sésil, generalmente tricarpelar, con un estilo corto o evidente; estigmas tres, filiformes, volubles, papilosos. Fruto una cápsula generalmente trilocular, triseptada o unilocular. Semillas hasta 120, elipsoidales, oblongas u ovoides, lisas, rugosas o a veces con un patrón reticulado, de color amarillento o castaño, diminutamente apiculadas, y a veces prolongadas en cada extremo en un apéndice delicado de textura suave que puede llegar a ser más largo que el cuerpo de la semilla.

El nombre Juncus se deriva del verbo latino jungo que significa unir, probablemente refiriéndose al antiguo uso de la planta para sujetar cosas.

Distribución general. El género Juncus es cosmopolita con cerca de 315 especies, la mayoría de las cuales se encuentran en regiones templadas del hemisferio norte pero con alguna proliferación en partes templadas del hemisferio sur. En los trópicos está ausente en tierras bajas pero presente usualmente arriba de los 2000 metros sobre el nivel del mar (Kirschner, 2002b, c). Juncus cuenta con 41 especies en el Neotrópico (Balslev, 1996) y 31 en México. Solo Juncus chiapasensis es considerada endémica del país, y Juncus textilis como un endemismo local que incluye el noroeste de México (Baja California) y el suroeste de los Estados Unidos de América (California).

Clave para las especies de Juncus en México

1. Inflorescencia racemosa; flores no abrazadas por un par de bractéolas; flores generalmente en cabezuelas o agrupadas, rara vez solitarias (Juncus subgénero Juncus) 
2. Hojas teretes con apariencia de tallos, todas basales y no septadas; haces vasculares dispersos a lo largo de un corte transversal; brácteas inferiores aparentemente formando una prolongación del tallo (Juncus sección Juncus)

3. Anteras amarillas; cápsula tan larga como los tépalos, elipsoidal hasta estrechamente elipsoidal, con 60-70 semillas ............................... J. cooperi

3. Anteras amarillas pero tornándose marrones o de color rojo castaño con el tiempo; cápsula conspicuamente más larga que los tépalos, esférica hasta anchamente elipsoisal, con 80-120 semillas...... J. acutus subsp. leopoldii

2. Hojas planas, comprimidas, canaliculadas o de ser teretes usualmente septadas sin apariencia de tallos, basales o caulinares; haces vasculares por lo general en posición epidérmica; brácteas inferiores usualmente sin formar una prolongación del tallo

4. Hojas unitubulosas o pluritubulosas, perfectamente septadas, de ser pluritubulosas (no bitubulosas) e imperfectamente septadas, entonces teretes o aplanadas pero dispuestas perpendicularmente al tallo (Juncus sección Ozophyllum)

5. Plantas no cespitosas; rizomas estoloníferos y/o con ramas ascendentes .. J. nodosus

5. Plantas laxa a densamente cespitosas; rizomas rastreros o densamente ramificados

6. Estambres tres; cápsula conspicuamente más larga que el perianto

7. Plantas 60-90 cm de largo; vaina de las hojas 4-8 cm de largo; cápsula usualmente $4-4.5 \mathrm{~mm}$ de largo ................. J. chiapasensis

7. Plantas $15-50 \mathrm{~cm}$ de largo; vaina de la hojas de $1-5 \mathrm{~cm}$ de largo; cápsula usualmente $3 \mathrm{~mm}$ de largo J. debilis

6. Estambres seis, rara vez tres; cápsula más corta o igual de largo que el perianto

8. Anteras 1.5 o más veces más largas que los filamentos

9. Tallo usualmente densamente papiloso-ruguloso, rara vez liso; aurículas 1-4.9 mm de largo, redondeadas y membranosas; inflorescencia difusa, decompuesta, flores pediceladas, hasta $2 \mathrm{~mm}$ de largo J. dubius

9. Tallo liso; aurículas $0.5-5 \mathrm{~mm}$ de largo, obtusas, escariosas; inflorescencia una antela compuesta, flores sésiles

J. ebracteatus

8. Anteras más cortas, iguales o apenas más largas que los filamentos 10. Plantas densamente cespitosas, rizomas muy cortos o cortos y entonces densamente ramificados 
11. Cápsula ovoide; trilobada en sección transversal J. acuminatus

11. Cápsula elipsoidal a obovoide, redonda en sección transversal y trilobada en la base J. microcephalus

10. Plantas laxamente cespitosas, rizomas largos y rastreros

12. Tépalos internos iguales o ligeramente más cortos que los tépalos externos, (3-)3.4-4.6 mm de largo .......... J. torreyi

12. Tépalos internos hasta dos veces más largos que los externos, 2-6 mm de largo J. liebmannii

4. Hojas aplanadas o con los márgenes elevados, no septadas o bitubulosas y septadas, o lateralmente comprimidas y pluritubuladas e imperfectamente septadas (y entonces dispuestas perpendicularmente al tallo), si unitubulosas y perfectamente septadas entonces las anteras claramente exsertas

13. Plantas anuales (Juncus sección Caespitosi)

14. Culmo con varias flores, inflorescencia una cabezuela terminal; tépalos rectos, no curvados sobre la cápsula; semillas con crestas longitudinales prominentes J. tiehmii

14. Culmo terminando en una sola flor; tépalos curvados sobre la cápsula; semillas sin crestas longitudinales prominentes J. bryoides

13. Plantas perennes

15. Hojas lateralmente comprimidas, pluritubulosas, imperfectamente septadas, dispuestas perpendicularmente al tallo (Juncus sección Iridifolii)

16. Planta con rizoma trepador; flores con tres estambres

J. ensifolius

16. Planta con rizomas ascendentes u horizontales; flores con seis estambres

17. Plantas hasta $55 \mathrm{~cm}$ de alto; aurículas ausentes; hojas $1.5-3$ (-4.5) $\mathrm{mm}$ de ancho; tépalos lanceolados y cápsula oblongoelipsoidal J. saximontanus

17. Plantas hasta $110 \mathrm{~cm}$ de alto; aurículas ausentes o presentes; hojas 4-9 mm de ancho; tépalos estrechamente lanceolados y cápsula oblongo-cilíndrica J. xiphioides

15. Hojas dorsiventralmente comprimidas o más o menos caniculadas, no septadas, dispuestas con la cara abaxial plana hacia el tallo (Juncus sección Graminifolii) 
18. Plantas 5-15 cm de alto, frecuentemente con largos estolones con fascículos de hojas uniformemente espaciados; cápsula linear a lanceolada, trígona J. repens

18. Plantas 20-100 cm de alto, sin estolones largos, éstos de estar presentes entonces cortos; cápsula obovoide a elipsoidal, trilobada hasta circular en sección transversal

19. Tépalos externos 2-2.8(-3) mm de largo; estambres tres, anteras usualmente más cortas que los filamentos; cápsula circular en sección transversal, rostro ausente J. marginatus

19. Tépalos externos 4.5-6 mm de largo; estambres seis, anteras más largas que los filamentos; cápsula trilobada en sección transversal, rostro presente

20. Plantas laxamente cespitosas; cápsula obovada, emarginada J. longistylis

20. Plantas densamente cespitosas; cápsula estrechamente obovoide J. macrophyllus

1. Inflorescencia cimosa; flores abrazadas por un par de bractéolas; flores solitarias o en inflorescencias laxas (Juncus subgénero Agathryon)

21. Plantas anuales; rizomas ausentes (Juncus sección Tenageia) ....... J. bufonius 21. Plantas perennes; rizomas presentes

22. Inflorescencias pseudolaterales; brácteas inferiores de la inflorescencia teretes, erectas, pareciendo una continuación del tallo; hojas basales sin láminas; hojas caulinares más o menos ausentes; vástagos estériles que parecen tallos (Juncus sección Juncotypus)

23. Tallos rectos o flexuosos; tépalos externos 3-5.5 mm de largo

J. balticus

23. Tallos generalmente tortuosos o flexuosos; tépalos externos 2-5 mm de largo

24. Estambres seis

25. Flor abrazada por un par de bractéolas 1.5-2 mm de largo; cápsula obovoide-obtusa ........................................................ J. textilis

25. Flor abrazada por un par de bractéolas 0.7-1 mm de largo; cápsula elipsoidal J. patens

24. Estambres tres

26. Flor abrazada por un par de bractéolas $0.8-1 \mathrm{~mm}$ de largo; tépalos exteriores de color castaño, 2-3.5 mm de largo 
26. Flor abrazada por un par de bractéolas de 0.7-2 mm de largo; tépalos de color estramíneo o castaño, 2-5 mm de largo

J. effusus

22. Inflorescencias obviamente terminales; brácteas inferiores de la inflorescencia aplanadas, caniculadas o teretes, no pareciendo una continuación del tallo; algunas hojas basales con láminas bien desarrolladas; vástagos estériles que no parecen tallos (Juncus sección Steirochloa)

27. Rizomas no ramificados, rastreros; internodos cortos; tallos dispuestos en densas filas J. imbricatus

27. Rizomas densamente ramificados, usualmente no rastreros; internodos de longitud variable; tallos usualmente dispuestos en densas macollas, no en fila

28. Aurículas 2-6 mm de largo, membranosas J. tenuis

28. Aurículas de menos $2 \mathrm{~mm}$ de largo, escariosas a cartilaginosas

29. Aurículas coriáceas, amarillentas; anteras 0.6-1 mm de largo J. dudleyi

29. Aurículas escariosas, blanquecinas; anteras usualmente 0.4-0.8 mm de largo

30. Cápsula usualmente 2.8-3.5 mm de largo, de color café claro a profundamente café J. dichotomus

30. Cápsula usualmente 3.8-4.7 mm de largo, de color blanco J. interior

1. Juncus acuminatus Michx., F1. Bor.-Amer. 1: 192. 1803.

三Juncus acuminatus var. legitimus Engelm., Trans. Acad. Sci. St. Louis 2: 463. 1868. nom inval.

Tipo: ESTADOS UNIDOS DE AMÉRICA. Carolina, Georgia, A. Michaux s.n. (holo-: P-MICHAUX!).

Hierbas perennes, cespitosas, $30-100 \mathrm{~cm}$ de alto. Rizomas densamente ramificados, 2-4 mm de diámetro, con escamas delgadas e inconspicuas; culmos agrupados, erectos, 1-3 mm de diámetro, teretes, lisos; catáfilos 1-3 por cada culmo, hasta $10 \mathrm{~cm}$ de largo, verdes o con matices rojizos, con los márgenes membranáceos distintivos. Hojas basales 1-3 por cada culmo, hasta $30 \mathrm{~cm}$ de largo; vainas de hasta $10 \mathrm{~cm}$ de largo, con márgenes membranáceos en dos vueltas, aurículas 1.5-5 mm de largo; láminas 1-2 mm de diámetro, teretes, conspicuamente septadas. Inflorescencia una antela compuesta, (3-)5-15(-20) × 3-8 cm, 3-35 cabezuelas, 10-40 flores, de color pajizo, úl- 
timas cabezuelas con ramas de menos de $0.4 \mathrm{~mm}$ de diámetro; brácteas inferiores de las inflorescencias 1-5 cm de largo, mucho más cortas que las inflorescencias, con una lámina reducida, terete, brácteas distales más cortas, brácteas florales acuminadas, hasta $3 \mathrm{~mm}$ de largo, membranáceas. Tépalos más o menos iguales, 2.5-3.5 $\mathrm{mm}$ de largo, linear-lanceolados, agudos a acuminados, los externos cóncavos o con forma de $\mathrm{V}$ en sección transversal, los internos planos. Estambres tres, ocasionalmente 6, 1.5-2 $\mathrm{mm}$ de largo; filamentos filiformes, $0.5-0.6 \mathrm{~mm}$ de largo; anteras oblongas a lineares, 0.5-0.7 mm de largo, más cortas que los filamentos. Ovario con el estilo de 0.2-0.3 $\mathrm{mm}$ de largo; estigmas $0.3-0.7 \mathrm{~mm}$ de largo. Cápsula más o menos del mismo tamaño que los tépalos, ovoide, trígona, 3-3.5 × 0.9-1.3 mm, rostro de ca. $0.3 \mathrm{~mm}$ de largo, de color castaño claro o pajizo, unilocular, los márgenes de los carpelos involutos cuando dehiscente. Semillas oblongo-elipsoidales, apiculadas, 0.3-0.5 $\times 0.2-0.25 \mathrm{~mm}$, reticuladas, de color amarillo-castaño, con cubierta seminal pajiza. $2 \mathrm{n}=40$ (Harriman y Redmond, 1976; Harriman, 1979).

Distribución general. Juncus acuminatus está presente en los Estados Unidos de América, en la mayor parte de la costa este, desde Maine hasta Georgia, y en forma más o menos dispersa en la costa oeste y las tierras altas de México y Centro América hasta Costa Rica. Ha sido introducida en Nueva Zelanda y Chile. En México se distribuye en Chihuahua, Distrito Federal, Durango, Guanajuato, Guerrero, Hidalgo, Jalisco, Estado de México, Michoacán, Querétaro, San Luis Potosí, Sinaloa y Sonora. McVaugh (1993) la menciona para Aguascalientes, Nayarit, Veracruz y posiblemente Zacatecas.

Hábitat y fenología. Juncus acuminatus crece en ciénegas, acequias, bancos de ríos y en afloramientos rocosos. En México se encuentra en bosques de encino o de pino-encino, en orillas de arroyos o de sitios encharcados al fondo de cañadas, además en los márgenes de presas, zanjas o ciénagas y en zonas con matorral entre los 550-2600 m de altitud. Juncus acuminatus es simpátrica con otras especies del género como J. microcephalus y J. tenuis. Juncus acuminatus florece y fructifica a lo largo de todo el año excepto en diciembre y enero.

Nombres vernáculos y usos. Desconocidos.

Afinidades. Juncus acuminatus es miembro del subgénero Juncus sección Ozophyllum, con 84 especies y solo nueve de ellas en México: J. chiapasensis, J. debilis, Juncus dubius, J. ebracteatus, J. liebmannii, J. microcephalus, J. nodosus y J. 
torreyi. Juncus acuminatus es similar a J. microcephalus en su hábito y se distingue por tener la cápsula obovoide, trígona y aguda (no ovoide, redonda y acuminada). Ambas especies son mayormente alopátricas pero se sobrelapan en el sur de México y Centro América (Guatemala, Honduras y Costa Rica).

Especímenes examinados. CHIHUAHUA: Majalca, 24.VII.1936, H. LeSueur 1123 (GH, UC, US); Cascada Basaseachic, Rancho San Lorenzo, 2150 m, 26-27. VIII.1986, P. S. Martin s.n. (ARIZ). GUANAJUATO: Irapuato, 8.VIII.1947, L. A. Kenoyer 1864 p.p. (GH, mezclado con J. nodosus). GUERRERO: Taxco de Alarcón, 2000 m, M. A. Gómez 50 (CHAPA). HIDALGO: El Banco, 10 km E of Metzquititlan, 1900 m, 28.III.1981, R. Hernández M. 5720 (MO); Nr. Tulancingo on road to Pachuca, 2200 m, 18.XI.1946, H. E. Moore, Jr. 2059 (GH, US); between Tepeoco and Tianguistengo, 2200 m, 19.III. 1947, H. E. Moore Jr. 2351 (GH); Lake Texca, below Molango, 24.VI.1947, H. E. Moore Jr. 3474 (GH); Barranca below Trinidad Iron Works, 29.VII.1904, C. G. Pringle 13226 (ARIZ, C, F, GH, K, MO, SI, UC, US). JALISCO: Santa Lucía, Zapopan, 1625 m, Guzmán \& de Puga 931 (ENCB). ESTADO DE MÉXICO: Las Mesas, Temascaltepec, 2000 m, 25.IV.1933, G. B. Hinton 3726 (F, GH, MO, NY, US); Ypericones, 1500 m, 5.VIII.1933, G. B. Hinton 3905 (GH); Peñón, 1700 m, 24.II.1934, G. B. Hinton 5601 (F, K, MO, NY, US); Puente Calderón, Ixtapan de la Sal, 1800 m, 21.II.1954, E. Matuda 30410 (US). MICHOACÁN: Umécuaro, $40 \mathrm{~km}$ al sur de Morelia, $2177 \mathrm{~m}, 26 . V I I I .1999$, A. Novelo \& L. Ramos 3696 (MO); Lago Zirahuén a 16 km al suroeste de Pátzcuaro, 2095 m, 8.VIII.2000, A. Novelo $R \&$ \& . Ramos 3994 (MO); valley of Zamora, $1660 \mathrm{~m}, 24 . V .1901, C$. G. Pringle 9464 (GH). NAYARIT: Santiago Ixc. Mexcaltitán, VII.1924, I. G. Ortega 5542 (GH, K, PH, US). QUERÉTARO: 3 km al E de El Puerto de Las Alegrías 2100 m, 16.V.1986, M. Medina \& M. A. Barrios 3067 (MO). SAN LUIS POTOSÍ: $22^{\circ}$ N. lat., 1800-2400 m, 1878, C. C. Parry \& E. Palmer 893 (MO, PH, US); $22^{\circ}$ N. lat., 1800-2400 m, 1878, C. C. Parry \& E. Palmer 895 (MO); San Luis Potosí, 1879, J. G. Schaffner 217 (C, CM, F, GOET, M, NY, P, US-2 exsicatas, una mezclada con $J$. tenuis). SONORA: Chiribo, Río Mayo Region, Sierra Sahuaribo, $17 \mathrm{~km}$ SE of San Bernardo, 1400 m, 24.VIII.1993, P. S. Martin s.n. (ARIZ). VERACRUZ: Tlalnelhuayocan, $1 \mathrm{~km}$ from Rancho Viejo on Río Pixquiac, 30.III.1976, W. Márquez R. 837 (F); Jalapa, 17-22.V.1899, J. N. Rose \& W. Hough 4309 (GH, US).

El siguiente especímen tiene la cápsula más larga que los tépalos pero la plantas es más robusta que $J$. debilis con la que comparte una cápsula más larga que los tépalos. CHIAPAS: D. E. Breedlove 10871 (CAS, WIS). 
2. Juncus acutus L. subsp. leopoldii (Parl.) Snogerup, Bot. Not. 131: 187. 1978. $\equiv$ Juncus leopoldii Parl., Giorn. Bot. Ital. 2: 324. 1846 Juncus acutus var. leopoldii (Parl.) Buchenau, Abh. Naturwiss. Ver. Bremen 4: 421. 1875. Lectotipo (designado por Snogerup, 1993): SUDÁFRICA. Sommerset, Stellenbosch, C. F. Ecklon \& C. Zeyher 4308 (FI, n.v.; iso-: S, n.v., W, n.v.).

Hierbas perennes, densamente cespitosas, $50-150 \mathrm{~cm}$ de alto. Rizomas densamente ramificados y produciendo vástagos en las axilas de las hojas, así que la planta se engrosa en la base; culmos rígidamente erectos, teretes, $2-5 \mathrm{~mm}$ de diámetro, longitudinalmente estriados, fuertemente esclerificados, con perforaciones parenquimatosas con haces vasculares dispersos a través de la sección transversal. Hojas 40-120 cm de largo, 5-7 por cada culmo, todas basales; vainas de 5-30 cm de largo, con márgenes delgados membranáceos gradualmente estrechándose hacia arriba y terminando en una hendidura adaxial de pocos centímetros de largo; láminas teretes, rígidas con el ápice duro pareciendo una espina, médula parenquimatosa con haces vasculares dispersos a través del corte transversal. Inflorescencia una panícula compuesta de glomérulos, de solo $3 \times$ $3 \mathrm{~cm}$ o más laxa hasta de $20 \times 10 \mathrm{~cm}$, las ramas alternando entre vástagos cortos y largos, así que la inflorescencia frecuentemente tornándose subdividida; brácteas inferiores de la inflorescencia de la mitad de largo o tan largas como la inflorescencia, rara vez más largas, rígidas, erectas con una vaina ancha y una lámina terete con el ápice duro y puntiagudo. Flores agrupadas en glomérulos de 2-4 flores y abrazadas por brácteas que yacen en la base del pedicelo, pero sin bractéolas insertadas en el pedicelo. Tépalos más o menos iguales, de ca. $2 \mathrm{~mm}$ de largo, los externos agudos u obtusos con los márgenes escariosos, terminando en dos pequeñas aurículas, con forma de $\mathrm{V}$ en corte transversal, los internos mucronados a obtusos con grandes aurículas escariosas, con forma de $\mathrm{U}$ en corte transversal. Estambres seis, 1.5-2 $\mathrm{mm}$ de largo, iguales a ligeramente más largos que los tépalos; filamentos cortos y anchos en la base; anteras varias veces más largas que los filamentos, amarillas tornándose de color rojo castaño con el tiempo. Ovario con estilo de ca. $0.5 \mathrm{~mm}$ de largo; estigmas $1 \mathrm{~mm}$ de largo. Cápsula casi dos veces más larga que los tépalos, obovoide hasta casi globular, cortamente mucronada, redonda en sección transversal, 3.5-4 × 3-3.5 mm, de color castaño claro a oscuro, triseptada. Semillas $80-120$ por fruto, con formas irregulares, usualmente algo curvadas, 0.9-1.1 $\times$ 0.3-0.4 mm, con extensiones transparentes de la cubierta seminal en cada extremo. 2n = 46, 48 (Dalgaard, 1991; Snogerup, 1993; Druskovic, 1995). 
Distribución general. Juncus acutus subsp. leopoldii se distribuye en el sur de África, en regiones templadas de Sur América, el suroeste de Norte América y varias islas del Océano Atlántico. Las poblaciones de Norte América crecen a lo largo del condado de San Luis Obispo (California) hacia el sur de Baja California Sur y Sonora, tierra adentro en el desierto de Colorado y Arizona. Existe una población disyunta en Puebla (México).

Hábitat y fenología. Juncus acutus subsp. leopoldii es común en suelos húmedos y alcalinos a lo largo de los márgenes de ríos, planicies salinas y playas arenosas con hierbas y arbustos tolerantes a la salinidad, a veces creciendo en lugares con una costra de carbonato y sales sulfurosas y en áreas con aguas subterráneas. En Baja California se desarrolla a elevaciones entre 0-900 metros sobre el nivel del mar y en la única localidad de Puebla entre 1000-1500 metros sobre el nivel del mar. Ha sido colectada en flor entre mayo y junio, y en fruto todo el año.

Nombres vernáculos y usos. Forrajera (Mudie 824, SD).

Afinidades. Juncus acutus y J. cooperi son los únicos miembros del subgénero Juncus sección Juncus en México y se diferencian porque la primera tiene rizomas cortos y tépalos internos que son cimbiformes, con una pequeña aurícula en el ápice, mientras que $J$. cooperi tiene rizomas robustos y tépalos internos oblongos con el ápice redondeado.

Especímenes examinados. BAJA CALIFORNIA: Cantillas (Tajo) Canyon, 20.VII.1955, C. F. Harbison s.n. (SD); N of windmill San Quintín, 8.VI.1973, A. Johnson \& J. Rutherford IV-5-3 (SD); 2 km N of village, 22.IV.1948, R. Moran 2967 (UC); Tajo Cañon, E side of Sierra Juárez, 760 m, 9.IX.1957, R. Moran 6097 (SD); ex misión Santa Maria, 550 m, 7.I.1964, R. Moran 11491 (SD, UC); Las Palomas, 50 m, 1.IV.1970, R. Moran 17165 (ARIZ, SD); 2 km SW of Redondo Station, $220 \mathrm{~m}$, 14.VI.1970, R. Moran 17842 (SD); Cañada las Palmas, S side Valle de las Palmas, 400 m, 16.X.1977, R. Moran 25152 (SD); Cañada el Yaqui, S to Valle las Palmas, 460 m, 13.XII.1981, R. Moran 29924 (SD); Cedros Island, 18-20.III.1889, E. Palmer 676 (C, F, GH, NY, US); Cedros Island, 14.IV.1963, R. Moran 10597 (UC); Cerros (sic!) Island, 18.VII.1905-1906, A. Stewart s.n. (GH); Tijuana, 25 m, 28.VII.1912, H. H. Smith 5194 (F, US); $48 \mathrm{~km}$ N of Ensenada near Predio Belen, N of Guadalupe, 500 m, 30.VI.1983, R. F. Thorne et al. 56042 (SD). BAJA CALIFORNIA SUR: San Juanico, V-VI.1897, A. W. Anthony 419 (F, GH, SD, US); Malarrimo Beach, Vizcaino 
Peninsula, 4.III.1986, D. E. Breedlove 62553 (MO); San Juanico Bay, 52 km NW of La Purisima, 6.I.1948, A. Carter et al. 2492 (UC); Bahia Trinidad, 0 m, 20.III.1971, I. R. Hastings 71-88 (ARIZ, SD). PUEBLA: W of Río Salado on and around Petlanco, 1000-1500 m, 12.VII.1961, C. E. Smith et al. 3675 (F, G, GH, MO, NY, US); Canyon Calamajue, 15 miles south of Las Rastras, 25.V.1960, I. L. Wiggins \& D. B. Wiggins 15948 (GH). SONORA: Gran Desierto, La Salina, ca. $3.5 \mathrm{~km}$ inland from beach at SW end of Bahia Adair (Punta Borrascosa), 14.VII.1982, M. Equina s.n. (ARIZ); NW of La Salina, 12.XII.1986, R. S. Felger 86-538 (ARIZ); La Salina, 2 m, 6.I.1993, E. S. Felzer 93-17 (ARIZ).

Una serie de especímenes de $J$. acutus subsp. leopoldii son atípicos porque tienen cápsulas pequeñas de solo $3 \mathrm{~mm}$ de largo (no 3.5-4 $\mathrm{mm}$ ) y mucho más delgadas (no obovoides hasta casi globulares). El aspecto general de estos ejemplares es el de Juncus littoralis C. A. Meyer, la cual se encuentra a lo largo de la costa norte del mar Mediterráneo, Mar Negro y el Mar Caspio: R. S. Felger \& I. M. Cooper 15262, H. S. Gentry 7770, C. E. Smith et al. 3675, I. L. Wiggins \& D. B. Wiggins 15948.

3. Juncus aemulans Liebm., Mexic. Juncac. 38. 1850.

$\equiv$ Juncus effusus var. aemulans (Liebm.) Buchenau en Engler, Pflanzenreich IV, 36 (Heft 25): 136. 1906.

Lectotipo (designado por Balslev, 1996): MÉXICO. Veracruz, Cerro León cerca Perote, 2150 m, VII.1841, F. M. Liebmann s.n. (C!; iso-: C!, K!, P!, fragmento, MO!).

Hierbas perennes, densamente cespitosas, $50-110 \mathrm{~cm}$ de alto. Rizomas rastreros, 2-4 mm de diámetro, densamente cubiertos con escamas de color castaño, con ápices agudos, internodos muy cortos y los culmos surgiendo en grupos o en cortas filas densamente coronadas; culmos erectos, teretes, 0.7-1.7 mm de diámetro, longitudinalmente estriados por trazas de esclerénquima subepidérmicos; médula continua, aerénquima con células asteriformes; catáfilos usualmente tres por cada culmo, densamente cubiertos, hasta $14 \mathrm{~cm}$ de largo, con láminas aciculares, rudimentarias, hasta $5 \mathrm{~mm}$ de largo, basalmente de color castaño, de color pajizo o verde pálido. Hojas laminares ausentes. Inflorescencia pseudolateral con muchas flores, usualmente laxa, compuesta de muchas cimas de un solo lado y en las partes apicales con drepanios unilaterales; brácteas inferiores de la inflorescencia apareciendo en forma continua a partir del culmo, $10-17 \mathrm{~cm}$ de largo, usualmente constituyendo 1/7 o más de la altura total de la planta, ligeramente unidas a los culmos, brácteas superiores membranáceas, progresivamente más cortas hacia arriba, las últimas de 
hasta $4 \mathrm{~mm}$ de largo. Flor abrazada por dos bractéolas acuminadas, 0.8-1 $\mathrm{mm}$ de largo. Tépalos desiguales, lanceolados, acuminados, de color castaño pero verde a lo largo de la nervadura media cuando jóvenes, los externos 2-3.5 mm de largo, cóncavos, los internos ligeramente más cortos, aplanados. Estambres tres, 1.2-1.5 mm de largo; filamentos filiformes; anteras oblongas a lineares, 0.5-0.7 $\mathrm{mm}$ de largo, de color amarillo. Cápsula obovoide, trígona a trilobada, de ca. $2 \times 1 \mathrm{~mm}$, de color castaño, triseptada. Semillas no vistas. $2 \mathrm{n}=$ desconocido.

Distribución general. Juncus aemulans se distribuye en México y Guatemala. En México se encuentra en los estados de Chiapas, Distrito Federal, Hidalgo, México, Oaxaca y Veracruz.

Hábitat y fenología. Juncus aemulans forma densas macollas en áreas húmedas y campos herbáceos, a lo largo de ríos y claros de bosques de Abies, Alnus, Carya, Ilex, Ficus, Podocarpus, Prunus y Quercus, y a veces en áreas rocosas perturbadas. Crece entre 2200-3600 metros sobre el nivel del mar. Juncus aemulans ha sido colectada en flores y frutos en enero, desde abril hasta junio y luego en septiembre y noviembre.

Nombres vernáculos y usos. Tule (Matuda, 1960).

Afinidades. Juncus. aemulans forma parte del subgénero Agathryon sección Juncotypus junto con J. balticus, J. effusus, J. patens y J. textilis. Está más cercanamente relacionada con $J$. effusus pero es distinguible por la combinación de tépalos cortos (2-3.5 mm), de color castaño oscuro y culmos delicados (0.7-1.7 mm de diámetro). También se parece a $J$. hesperius (Piper) Lint, presente en la costa occidental de Estados Unidos de América, pero con catáfilos lisos y delgados y usualmente con menos tallos.

Especímenes examinados. CHIAPAS: Tenejapa, Colonia Achlum, 15.V.1967, $2800 \mathrm{~m}$, A. Shilom Ton 2360 (CAS, DS, DUKE, NY, WIS). DISTRITO FEDERAL: El Pantano, Desierto de los Leones, Cuajimalpa, 3000 m, 20.XI.1979, R. Galván 612 (GH, NY); Llanos de Narvarte, s.f., E. Lyonnet $287 b$ p.p. (MEXU). HIDALGO: Peñas Largas, near Tezoantla, Real del Monte, 2750 m, 21.IV.1966, J. Rzedowski 22180 (NY). MÉXICO: 3 km E of San Rafael, Tlalmanalco, 2750-2900 m, Cisneros 1645 (WIS); Río Frío, C. L. Gilly \& E. B. Sharp 21 (CAS); Tepexpan, Valle de México, 2300 m, 2.VII.1950, E. Matuda 19141 (F, NY); 3 km al E de San Rafael, 2700 m, 27.V.1965, J. Rzedowski 19897 (GH); Lago Zumpango, San Juan, 9.XI.1975, V. 
Lopez H. 1083 (GH). OAXACA: Highway 179 to Pochutla $24 \mathrm{~km} \mathrm{~S}$ of Miahuatlan, 2200 m, 21.I.1979, T. B. Croat 46199 (MO, NY); 2 km NW of Calpulalpan, $1000 \mathrm{~m}$, 22.II.1987, T. B. Croat 65654 (AAU, MO); Ixtlán, 5 km E of Ixtlán de Juárez, 2200 m, 5.IV.1981, G. I. Martin 476 (MO); 31 km SW of Oaxaca, 2300-2900 m, 10-20. IX.1894, E. W. Nelson 1335a (US). VERACRUZ: Calcahualco, $3 \mathrm{~km}$ NE of Nueva Vaquería, entrada por Coscomatepec, 2600 m, 24.IV.1980, J. I. Calzada 5927 (F, $\mathrm{NY}$ ); $3.5 \mathrm{~km}$ N of Vaqueria, $0.8 \mathrm{~km}$ from junction with Coscomatepec-Escola-Jacal road, $12 \mathrm{~km} \mathrm{~W}$ of Escola, Calcahualco, 15.XI.1981, M. Nee 23156 (F, MO, NY).

4. Juncus balticus Willd., Ges. Naturf. Freunde Berlin Mag. Neuesten Entdeck. Gesammten Naturk. 3: 298. 1809.

Tipo: ALEMANIA. An den sandigen Meeresufern bei Warnemünde, 1809, G. G. Detharding s.n. (holo-: B-WILLDENOW!; iso-: K!).

Hierbas perennes, 20-170 cm de alto, con tallos rectos o flexuosos. Rizomas rastreros, 2.5-10 $\mathrm{mm}$ de diámetro, ramificados, pero también con largos segmentos no ramificados, internodos cortos o más frecuentemente de hasta $4 \mathrm{~cm}$ de largo, la inserción de los culmos agrupada o espaciada, a veces con una parte rastrera con largos internodos y ramas laterales con internodos cortos; culmos erectos, 1-7 mm de diámetro, lisos o ligeramente arrugados a estriados, muy rara vez con crestas longitudinales; catáfilos 2-3 por cada culmo, los inferiores 1-8 cm de largo, los distales 3-25 cm de largo, usualmente con láminas rudimentarias de hasta $3 \mathrm{~mm}$ de largo, aciculares, mucronados, de color amarillo o castaño pálido. Hojas laminares ausentes, solo presentes en J. balticus var. mexicanus y entonces 1-2 por cada culmo; láminas teretes, lateralmente comprimidas, muy cortas o igualando al culmo. Inflorescencia pseudolateral, con pocas a muchas flores, usualmente laxa y entonces $15 \times 7 \mathrm{~cm}$, a veces aglomerada y solo $2.5 \times 2 \mathrm{~cm}$, cima compuesta, formada de varias cimas aglomeradas, las últimas en forma de drepanios unilaterales; brácteas inferiores de la inflorescencia apareciendo como un continuo desde el culmo, (2-)5-15(-25) cm de largo, o usualmente constituyendo entre $1 / 10$ y $1 / 5$ del total del tamaño de la planta, a veces menos, brácteas distales progresivamente más cortas, membranáceas, cada flor abrazada por dos bractéolas membranáceas, 1.5-2.5 mm de largo, ápice agudo. Tépalos iguales o los externos más largos, lanceolados, de color pajizo o castaño, a veces más claros en el nervio medio al menos en los internos, frecuentemente con márgenes membranáceos, los externos 3-5.5 mm de largo, cóncavos, acuminados, los internos 3-5 mm de largo, planos a cóncavos, ápices agudos. Estambres seis, 1.5-3 $\mathrm{mm}$ de largo; filamentos planos, ensanchados hacia la base; anteras lineares, 0.7-2.5 
mm de largo, 1-6 veces más largas que los filamentos. Ovario con estilo 0.5-1.5 mm de largo; estigmas 1.5-3 mm de largo. Cápsula elipsoidal a ovoide, apiculada, redonda a trígona o ligeramente trilobada, 2.5-4.5 $\times 1.5-2 \mathrm{~mm}$, de color castaño claro a castaño, frecuentemente más clara en la base y oscura en el ápice, brillante, triseptada. Semillas elipsoidales, oblongas, ovoides, o con formas irregulares, cortamente apiculadas, 0.6-0.8 $\times$ 0.2-0.5 mm, rugosas, de color castaño pálido a castaño y la cubierta seminal hialina. $2 \mathrm{n}=80$ (Harriman y Redmond, 1976).

Distribución general. Juncus balticus es una especie extremadamente variable con una distribución cosmopolita. En México hay tres subespecies.

Clave para las subespecies de Juncus balticus en México

1. Culmos con una o dos hojas laminares; culmos comprimidos, usualmente retorcidos J. balticus subsp. mexicanus

1. Culmo sin hojas laminares, solo con catáfilos; culmos teretes

2. Tépalos de color castaño J. balticus subsp. andicola

2. Tépalos de color pajizo o al menos con el nervio medio más claro

J. balticus subsp. ater

4.1. Juncus balticus Willd. subsp. andicola (W. J. Hooker) Snogerup en S. Snogerup, P. F. Zika \& J. Kirschner, Preslia 74: 258: 2002. Figura 2 A.

$\equiv$ Juncus andicola Hook., Icon. Pl., ser. 2(8): pl. 714. $1848 \equiv$ Juncus arcticus var. andicola (Hook.) Balslev, Brittonia 35: 308. 1983.

Tipo: ECUADOR. Pichincha, Andes of Quito, W. Jameson 51 (holo-: K!; iso-: BM!, G!).

Hierbas perennes, 20-170 cm de alto. Rizomas cortos o largamente rastreros, 2.5$10 \mathrm{~mm}$ de diámetro, de color amarillo pálido a castaño, con escamas delgadas, membranáceas o gruesas y duras, internodos 1-4 cm de largo; culmos teretes, $1-10 \mathrm{~mm}$ de diámetro, no torcidos. Hojas laminares ausentes. Inflorescencia con 20 o hasta varios cientos de flores, 2-15 × 2-10 cm. Tépalos más o menos iguales, 3.5-5.5 mm de largo, lanceolados, acuminados, escariosos, de color castaño, los internos agudos a acuminados, a veces subobtusos y mucronados. Estambres seis, 1.5-2.5 mm de largo; filamentos de ca. $0.4 \mathrm{~mm}$ de largo; anteras lineares, $0.7-2 \mathrm{~mm}$ de largo. Ovario con estilo 1-1.5 mm de largo; estigmas 1-1.5 mm de largo. Cápsula elipsoidal a obovoide, aguda a truncada, apiculada, $2.5-5 \mathrm{~mm}$ de largo, igual o más corta que los tépalos. $2 \mathrm{n}=$ desconocido. 
Acta Botanica Mexicana 111: 61-164 (2015)


Fig. 2. Juncus balticus subsp. andicola y J. effusus. A. hábito de J. balticus subsp. andicola (colección). B. hábito de J. effusus (Prescott 694, NY). Originalmente publicado en Balslev, 1979, 1996, respectivamente. 
Distribución general. Juncus balticus subsp. andicola se distribuye en la región central de México y Guatemala y en Sur América en los Andes desde Colombia hasta la Patagonia.

Hábitat y fenología. Juncus balticus subsp. andicola crece en lugares húmedos a lo largo de ríos, lagunas y bosques entre los 2300-4000 metros sobre el nivel del mar. Ha sido colectada en flor en noviembre, diciembre y mayo, y en fruto en diciembre.

Nombres vernáculos y usos. Tule (Matuda, 1960).

Afinidades. Juncus balticus forma parte del subgénero Agathryon sección Juncotypus junto con J. aemulans, J. effusus, J. patens y J. textilis (ver J. aemulans).

Especímenes examinados. ESTADO DE MÉXICO: Zempoala lake district, $20 \mathrm{~km}$ NW of Cuernavaca, 9.XII.1950, N. C. Fassett 28462 (F, GH, US); Laguna Seca, Parque Nacional Lagunas de Zempoala, 3000 m, 15.XI.1980, R. Galván $710 b$ (US). MORELOS: Valle de México, Lago Zempoala, 3000 m, 7.X.1951, E. Matuda 25606 (NY). PUEBLA: Laguna Preciosa, 450 m, 18.XII.1958, R. Dickerman 1045 (MIN); Lago cráter Tecuitlapa, 15 km E of San Salvador El Seco, 2300 m, 13.V.1980, P. Ramírez 18 (MO).

4.2. Juncus balticus subsp. ater (Rydb.) Snogerup en S. Snogerup, P. F. Zika \& J. Kirschner, Preslia 74: 258. 2002.

$\equiv$ Juncus ater Rydb., Fl. Rocky Mts. 1060. $1917 \equiv$ Juncus arcticus Willd. subsp. ater (Rydb.) Hultén, Kongl. Svenska Vetenskapsakad. Handl. IV, 8(5): 24. $1962 \equiv$ Juncus balticus Willd. var. montanus Engelm., Trans. Acad. Sci. St. Louis 2: $442.1866 \equiv$ Juncus arcticus var. montanus (Engelm.) Welsh, Anderson's Flora of Alaska 611. $1974 \equiv$ Juncus arcticus Willd. var. montanus (Engelm.) Balslev, Brittonia 35: 308. 1983, superfl. comb.

Lectotipo (designado por Balslev, 1996): ESTADOS UNIDOS DE AMÉRICA. Rocky Mountain Flora, 1862, E. Hall \& I. P. Harbour 567 (MO; iso-: MO).

Hierbas perennes, 40-120 cm de alto. Rizomas rastreros, 3-7 mm de diámetro, de color castaño claro con escamas esparcidas, membranosas, internodos $1-3 \mathrm{~cm}$ de largo; culmos teretes, 1.5-4 mm de diámetro, no torcidos. Hojas laminares ausentes. Inflorescencia usualmente con más de 20 flores, 5-10 × 2-4 cm. Tépalos más o me- 
nos iguales, 3.5-5 mm de largo, más o menos estrechamente lanceolados, acuminados, de color castaño con verde o gris en el nervio medio, de color pajizo cuando el fruto está maduro, los internos subobtusos y mucronados o agudos. Estambres seis, 1.5-2.5 mm de largo, anteras 1.2-1.8 mm de largo, lineares. Ovario con estilo de ca. 1 $\mathrm{mm}$ de largo; estigmas de ca. $2 \mathrm{~mm}$ de largo. Cápsula elipsoidal a ovoide, apiculada, 3.5-4.5 mm de largo, más corta que o igual a los tépalos. $2 \mathrm{n}=$ desconocido.

Distribución general. Juncus balticus subsp. ater se distribuye en el oeste de Norte América desde Alaska hasta México y Guatemala. En México se encuentra en Baja California, Chihuahua, Hidalgo, Estado de México, Michoacán, Puebla, Sonora y Tlaxcala.

Hábitat y fenología. Juncus balticus subsp. ater crece en lugares húmedos, pantanosos, frecuentemente alcalinos, en los valles y llanuras. En México es posible hallarla entre 1800 y 2300 metros sobre el nivel del mar. En Michoacán es simpátrica con $J$. balticus subsp. mexicanus, la cual es más común y forma poblaciones más densas (Galván-Villanueva, 2002). Juncus balticus subsp. ater se encontró en floración en agosto y octubre, con frutos en octubre.

Nombres vernáculos y usos. Desconocidos.

Afinidades. Juncus balticus subsp. ater se diferencia de J. balticus subsp. mexicanus por ser más alta y más robusta y carecer de hojas laminares. Las flores son similares a las de J. balticus subsp. mexicanus, pero su inflorescencia es usualmente más larga y con más flores.

Especímenes examinados. BAJA CALIFORNIA: Ensenada, 27.VIII.1893, J. S. Brandegee s.n. (UC); NE of Valle Redondo, 30.V.1932, F. R. Fosberg. 8386 (PH); Sierra San Pedro Mártir, La Grulla, 2100 m, 22.VIII.1967, R. Moran \& R. F. Thorne 14490 (SD); Tecate River near Monument no. 245, 23.VI.1894, L. Schoenfeldt 3722 (US). CHIHUAHUA: Near Chihuahua, 1300 m, 8-27.IV.1908, E. Palmer 33 (F, GH, MO, NY, US); $5 \mathrm{~km}$ W of Camargo, $1200 \mathrm{~m}, 2-5$. VIII.1939, S. S. White 2278 (GH, US). HIDALGO: Tula de Allende, Tula, 2000 m, 9.X.1946, H. E. Moore, Jr. 1368 (GH, MEXU, UC, US). ESTADO DE MÉXICO: near Tlalnepantla, 6.VI.1905, J. N. Rose et al. 8377 (GH); valley of México, VII.1855, W. Schaffner 523 (MO). MICHOACÁN: presa La Lagunita, $0.5 \mathrm{~km}$ al $\mathrm{N}$ de la desviación Ucareo-Maravatío, carretera Morelia-México, M. J. Jasso 430 (ENCB). PUEBLA: Lago de Quechulac, Los Llanos, 2.X.1953, N. C Fassett 29095 
(F, UC); Puebla Highway 190, 2 km E of Cholula, 2200 m, Sanders 74086 (LL). SONORA: Río Sonoyta, ca. $0.5 \mathrm{~km}$ S of Cerro El Huérfano, ca. 23 airline km WNW from Sonoyta, 280 m, 25.X.1992, R. S. Felger 92-979 (ARIZ). TLAXCALA: El Carmen, 2450 m, M. A. Lane 2550 (TEX); El Carmen, 24.IX.1953, E. R. Sohns 632 (US).

4.3. Juncus balticus subsp. mexicanus (Willd. ex Schult. \& Schult. f.) Snogerup en S. Snogerup, P. F. Zila \& J. Kirschner, Preslia 74: 257. 2002.

$\equiv$ Juncus mexicanus Willd. ex Schult. \& Schult. f., Syst. Veg. 7: $178.1829 \equiv$ Juncus balticus Willd. var. mexicanus (Willd. ex Schult. \& Schult. f.) Kuntze, Revis. Gen. Pl. 3(2): 320. 1898 इ Juncus balticus Willd. fo. mexicanus (Willd. ex Schult. \& Schult. f.) Parish, Muhlenbergia 6: 119. $1910 \equiv$ Juncus arcticus var. mexicanus (Willd.) Balslev, Brittonia 35: 308. 1983.

Tipo: MÉXICO. Chapultepec, San Agustín de las Cuevas and Real del Monte, $A$. von Humboldt \& A. Bonpland s.n. (holo-: $\mathrm{B}$ !; iso-:, $\mathrm{P}$ !).

= Juncus compressus Kunth, Nov. gen. sp. 1: 235. 1816, nom illeg., non Jacq., 1762. = Juncus complanatus Roem. \& Schult., Syst. Veg. 7: 185. 1829.

Tipo: MÉXICO. Estado de México, Chapultepec, San Agustin de las Cuevas and Real del Monte, A. von Humboldt \& A. Bonpland s.n. (holo-: P; iso-: B).

= Juncus orizabae Liebm., Mexic. Juncac. 39. 1850.

Tipo: MÉXICO. Veracruz: Mt. Orizaba, 3650 m, IX.1841, F. M. Liebmann s.n. (holo-: C!; fragmento, W).

= Juncus balticus Willd. var. durangensis Buchenau en Engler, Pflanzenreich IV, 36 (Heft 25): 146. 1906.

Lectotipo (designado por Balslev, 1996): MÉXICO. Durango, Durango, IV-XI.1896, E. Palmer 188 (W; iso-: F, G, GH, K, MO, NY, UC, US).

Hierbas perennes (5-)15-30(-70) $\mathrm{cm}$ de alto. Rizomas rastreros, 2-6 $\mathrm{mm}$ de diámetro, internodos muy cortos hasta $2 \mathrm{~cm}$ de largo, los culmos densos o espaciados, frecuentemente con cortas ramas laterales, con cortos internodos dando origen a densos culmos; culmos 0.5-2 mm de diámetro, lateralmente comprimidos, con frecuencia torcidos. Hojas laminares 1-2 por cada culmo; láminas similares a los culmos pero frecuentemente más cortas. Inflorescencia pequeña, usualmente menos de 20 flores y menos de $3 \times 2 \mathrm{~cm}$. Tépalos $4-5.5 \mathrm{~mm}$ de largo, de color castaño, la costilla media verde o gris, tornándose más corta y pajiza con la madurez del fruto. Estambres seis, 2-3 mm de largo con anteras lineares, 1.5-1.8 mm de largo. Ovario con estilo 1-1.5 $\mathrm{mm}$ de largo; estigmas 1.5-3 mm de largo. Cápsula elipsoidal, apiculada, 3.5-4.5 mm de largo, ligeramente más corta o tan larga como los tépalos. $2 \mathrm{n}=$ desconocido. 
Distribución general. Juncus balticus subsp. mexicanus se distribuye en el oeste de Estados Unidos de América, el sur de México y Guatemala, y en Sur América en los Andes desde el sur de Perú hasta la Patagonia. En México crece en los estados de Chihuahua, Coahuila, Distrito Federal, Durango, Hidalgo, Jalisco, Michoacán, Morelos, Oaxaca, Puebla, Querétaro, San Luis Potosí, Sonora, Tamaulipas, Tlaxcala y Zacatecas. McVaugh (1993) también la menciona para Baja California Sur, Estado de México, Guanajuato y Veracruz.

Hábitat y fenología. En México, J. balticus subsp. mexicanus crece en elevaciones entre 1800-3200 metros sobre el nivel del mar, en ciénagas, arroyos y lagunas, a veces prospera en pantanos salinos y puede ser maleza y encontrarse en bancos de camino, áreas de pastoreo, áreas de cultivo, e incluso creciendo en las grietas del pavimento. En general se le observa en lugares soleados. Juncus balticus subsp. mexicanus florece de abril a noviembre, con frutos desde julio hasta diciembre.

Nombres vernáculos y usos. Desconocidos.

Afinidades. La presencia de hojas laminares en J. balticus subsp. mexicanus es excepcional ya que el resto de las especies del subgénero carece de ellas. Las láminas son ovaladas en sección transversal, lateralmente comprimidas sin márgenes afilados, lineares con una médula aerenquimatosa y pueden tornarse tan largas como los culmos. La presencia de hojas laminares sugiere que esta variedad es primitiva dentro del subgénero y que está estrechamente relacionada con el subgénero Agathryon, el cual normalmente se distingue del subgénero Juncus por la presencia de hojas laminares. McVaugh (1993) menciona que no existe acuerdo con relación al estatus taxonómico de esta especie (variedad de J. articus o J. balticus) y sigue la opinión de Hermann (1975) de reconocerla como una especie distinta.

Especímenes examinados. BAJA CALIFORNIA: San Isidoro, $900 \mathrm{~m}$, 2.VI.1975, R. Moran 22252 (SD); Sierra Blanca, 675 m, 15.VI.1976, R. Moran 23176 (SD); SW of Rancho el Catorce, Valle Ojos Negros, 670 m, 28.IV.1980, R. Moran 28371 (SD); El Rosario, 16.III.1956, J. T. Howell 31040 (SD); Distrito Norte, Misión de San Borja, 16.XI.1950, A. Carter \& L. Kellog 2808 (SD, UC); Sierra de Juárez, 2.5 km NW of Rancho Marcos, 1675 m, 4.IX.1966, R. Moran 13484 (SD); Sierra de Juárez, 3.5 km S of Agua Hechicera, 1200 m, 18.IX.1971, R. Moran 18491 (SD); Sierra de Juárez, 2 km WNW of La Tableta, 1575 m, 1.VIII.1976, R. Moran 23694 (SD); Sierra San Pedro Mártir, 2 km SE of Yerba Buena, 2450 m, 4.IX.1978, R. Moran 
26248 (SD); bank of La Sanca creek, about 5 mi. NW of La Grulla, Sierra San Pedro Mártir, 2230 m, 17.VIII.1930, I. L. Wiggins \& D. Demaree 4859 (GH). CHIHUAHUA: El Cima, 29.VI.1936, H. LeSueur 1121 (GH, UC, US). COAHUILA: La Casita, Coale, 21.VIII.1948, L. A. Kenoyer \& Crum 2936 (GH); Saltillo, V.1898, E. Palmer 201 (B, F, GH, MO, NY, UC, US); Del Carmen Mts, 9.VIII.1936, E. G. Marsh 743 (F). DISTRITO FEDERAL: San Borjes, Mixcoac, 2600 m, 15.VIII.1914, G. Arsène 10991 (NY, US); Puerto de las Cruces, Cuajimalpa, 3000 m, 20.VII.1980, R. Galván 638 (MO); La Piedad, VII.1927, E. Lyonnet 42 (US); Llanos de Narvarte, IX.1929, E. Lyonnet 287 (US); Tlalpan, 17.VI.1897, C. G. Pringle 7517 (GH, US); Valley of Mexico, Tlalpan, 15.VII.1901, J. N. Rose \& R. Hay 5471 (US); Paraje de Sompoli, delegación de Milpa Alta, 2850 m, 7.VII.1976, A. Ventura 1832 (ARIZ). DURANGO: $11 \mathrm{~km}$ E of Durango, entronque a Parras de la Fuente, $1850 \mathrm{~m}$, 24.IX.1982, $S$. González \& R. Fernández 2230 (NY); 39 km NE of Durango, route \# 31, 25.VII.1958, D. S. Correll \& J. M. Johnston 20173 (NY). GUANAJUATO: N of San Miguel de Allende, 15.VIII.1947, L. A. Kenoyer 2147 (GH). HIDALGO: Rancho Nuevo, 2700 m, R. C. West K-9 (WIS); Santa Julia near Venta Prieta, 17.VI.1947, H. E. Moore, Jr. 3081 (GH); Pachuca-Tulancingo road, Hacienda Cuyamaloya, 2500 m, 6.IX.1948, H. E. Moore \& C. E. Wood, Jr. 4862 (GH); near Ixmiquilpan, 1905, J. N. Rose et al. 9065 (US). ESTADO DE MÉXICO: Valle de México, Ahuehueta, Texcoco, $2250 \mathrm{~m}$, 25.XI.1951, E. Matuda 25863 (NY); Valle de México, Actopan, 2400 m, 5.V.1952, E. Matuda 26156 (NY); Laguna de Zumpango, 2250 m, 5.V.1963, J. Rzedowski 16593 (ARIZ, MO, SD); MICHOACÁN: ver Galván-Villanueva (2002). MORELOS: Lagunas de Zempoala, 3000 m, ter Weijden 16 (AAU). OAXACA: Sierra, $2150 \mathrm{~m}, H$. G. Galeotti 5845 p.p. (P). PUEBLA: Camino Oriental-Zacatepec, 30.X.1971, 1700 m, $W$. Boege 2014 (US); Zacatepec, 1.X.1953, N. C. Fassett 22769 (F); Iztaccihuatl, al sur de la montaña, 3960 m, 1.VIII.1958, J. H. Beaman 1994 (GH). QUERÉTARO: lagunita a las afueras del poblado Huimilpan, a $31 \mathrm{~km}$ al S de Querétaro rumbo a Amealco, municipio de Huimilpan, 27.IX.1999, A. Novelo y L. Ramos 3770 (IEB). SAN LUIS POTOSÍ: San Luis Potosí, 1876, J. G. Schaffner 554 (GH, K, MEXU); $22^{\circ} \mathrm{N}$ lat., 1878, 1800-2400 m, C. C. Parry \& E. Palmer 895 1/2 (MO). SONORA: Highway 15 just $\mathrm{N}$ of settlement, 22.IV.1986, A. M. Rea 1185 (SD); Tucson river, 8.VI.1855, A. Schott 3 (F). TAMAULIPAS: Between Marcella and Hermosa, 22.VII.1949, L. R. Stanford et al. 2671 (NY, US). TLAXCALA: Carmen, 2300 m, VII.1976, G. Ramos E. et. al. 35 (MEXU). VERACRUZ: Llano Grande above Acultzingo, 3150 m, 28.VII.1944, A. J. Sharp 44113 (GH, NY); Acajete, La Joya, 10.IV.1972, 2020 m, E. Ventura A. 5200 (MO). ZACATECAS: Atotonilco, M. González 111 (MEXU); Sierra HermosaZacatecas road, Villa de Cos, 4-5.IX.1938, I. M. Johnston 7431 (GH). 
5. Juncus bryoides F. J. Herm., Lefl. W. Bot. 5: 117. 1948. Tipo: ESTADOS UNIDOS DE AMÉRICA. California, San Bernardino Co., Bear Valley, San Bernardino Mts., 3-16.VI.1886, 1800 m, S. B. Parish 1859 (holo-: US!; iso-: DS!, F!, GH!, JEPS!, MICH!, MO!, NY!).

Hierbas anuales muy pequeñas, $10-25 \mathrm{~mm}$ del alto. Hojas hasta de $9 \mathrm{~mm}$ de largo, usualmente más cortas que los culmos que llevan las flores; cada planta con hasta 150 culmos, cada culmo de 10-22 mm de largo y 0.1-0.2 mm de grosor. Flor solitaria; brácteas (1-)2, 0.3-0.9 mm de largo, ovadas a lanceoladas, ápice agudo, no pigmentadas, hialinas. Tépalos usualmente seis pero a veces cuatro u ocho, subiguales, lanceolados, curvados sobre la cápsula, ápice agudo, 1.2-2.3 mm de largo, 0.4-0.6 mm de ancho, iguales o los tépalos internos ligeramente más largos, hasta $2.5 \mathrm{~mm}$ de largo, ápice agudo a acuminado. Estambres usualmente tres pero a veces dos o cuatro, de 0.5-0.9 $\mathrm{mm}$ de largo o de la mitad de largo de los tépalos, anteras de $0.15-0.25 \mathrm{~mm}$ de largo o hasta de la mitad del largo de los filamentos. Ovario con estilo muy corto o ausente; estigmas 0.2-0.3 mm de largo. Cápsula ovoide a elipsoidal, terete, redondeada, más corta que los tépalos y usualmente oculta por ellos. Semillas hasta 40 por cápsula, ovoides a globosas, ligeramente apiculadas o umbonadas, sin crestas longitudinales, 0.3-0.5 mm de largo, lisas o con débiles líneas transversales. $2 \mathrm{n}=38$ (Ertter, 1986).

Distribución general. Juncus bryoides se distribuye en el oeste de Estados Unidos de América (Colorado, Idaho, Nevada, Oregon, Utah y California), alcanzando la Sierra San Pedro Mártir en Baja California (México).

Hábitat y fenología. Juncus bryoides crece en lugares húmedos, praderas, áreas de regadío y afloramientos rocosos, la mayoría de las veces en suelos arenosos pero también en los arcillosos. Juncus bryoides ha sido colectada en flor y fruto entre abril a agosto.

Nombres vernáculos y usos. Desconocidos.

Afinidades. Juncus bryoides y J. tiehmii son los únicos miembros mexicanos del subgénero Juncus sección Caespitosi pero J. bryoides es más pequeña en todas sus partes desde el tamaño general de la planta hasta el fruto. El carácter más distintivo son los tépalos incurvados sobre la cápsula.

Especímenes examinados. BAJA CALIFORNIA: Oak Pasture turnoff, Sierra San Pedro Mártir, 1725 m, 31.V.1976, R. Moran 23340 (DAV, GH, MICH, 
NCU, SD, UC); 3 km E of El Socorro, Sierra San Pedro Mártir, 1450 m, 8.V.1978, R. Moran 25700 (NY, SD); 5 km W of La Rumorosa, Sierra de Juárez, 14.IV.1979, $1310 \mathrm{~m}$, R. Moran 27013 (MO, NY, SD, US); $0.5 \mathrm{~km} \mathrm{~S}$ of El Condor, $1300 \mathrm{~m}$, 15.IV.1979, R. Moran 27031 (ARIZ, SD); 8 km S of Los Gavilanes, Sierra de Juárez, 1675 m, 28.V.1979, R. Moran 27501 (SD); $1 \mathrm{~km} \mathrm{~S}$ of Cerro Monje and $12 \mathrm{~km}$ SW of La Rumorosa, 1325 m, 8.V.1982, R. Moran 30612 (SD); Laguna Hanson, Constitución National Park, Sierra de Juárez, 1610 m, 28.V.1983, R. E. Thorne \& al. 55744 (SD).

6. Juncus bufonius L., Sp. Pl. 1: 328.1753.

Lectotipo (designado por Cope and Stace, 1978): EUROPA. Sin localidad exacta, Van Royen s.n. (L904145-433, n.v.; para-: L, n.v.). Figura 3 A, B.

Hierbas anuales, cespitosas, 5-40 cm de alto. Rizomas ausentes; culmos erectos, rastreros o ascendentes, teretes, lisos, 0.5-1.5 mm de diámetro, a veces produciendo vástagos foliares en las axilas de los tallos rastreros; catáfilos ausentes o rara vez uno por cada culmo y entonces inconspicuos, membranáceos, 7-12 mm de largo. Hojas laminares 1-5 basales, 1-3 caulinares por cada culmo, 4-15 cm de largo; vaina 0.5-3 cm de largo, con márgenes membranáceos no prolongados en aurículas; láminas aplanadas con márgenes elevados, ligeramente acanalados abajo, 0.5-1.5 mm de ancho. Inflorescencia usualmente ocupando más de la mitad de la altura total de la planta, laxa, compuesta, consistiendo de varias cimas unilaterales (drepanios) con las flores insertadas individualmente y alejadas unas de otras, rara vez 2-4 flores agrupadas, drepanios individuales hasta $10 \mathrm{~cm}$ de largo; brácteas inferiores de la inflorescencia semejantes a hojas caulinares, 4-15 cm de largo, brácteas distales progresivamente más cortas, la última de $5 \mathrm{~mm}$ de largo y membránaceas. Flor abrazada por dos bractéolas, 1.5-2.5 mm de largo. Tépalos desiguales, lanceolados, acuminados, de color verde pálido con márgenes membranáceos, que se tornan de color castaño en la madurez del fruto, los externos de 4-6(-7) $\mathrm{mm}$ de largo, los internos de 3.5-5(-6) mm de largo. Estambres seis, 1.3-2.2(-2.6) $\mathrm{mm}$ de largo; anteras lineares u oblongas, 0.3-1(-1.5) $\mathrm{mm}$ de largo. Ovario con el estilo de $0.4-0.5 \mathrm{~mm}$ de largo; estigmas patentes, 1-1.5 mm de largo. Cápsula elipsoidal, trígona, truncada y mucronada, 3-4 × 1.5-2 mm, estilo persistente, $0.1-0.3 \mathrm{~mm}$ de largo, de color castaño en la madurez, dehiscente apicalmente, trilocular. Semillas oblongas, apiculadas, 0.4-0.6 $\times 0.2-0.3 \mathrm{~mm}$, lisas a ligeramente rugosas, de color amarillo-castaño. $2 \mathrm{n}=$ 34, ca. 70, 80, ca. 100, 100-110, 106, ca. 108 (Uhrikova, 1974; Harriman y Redmond, 1976; Love y Love, 1980, 1981; Cope y Stace, 1985; Druskovic, 1995). 

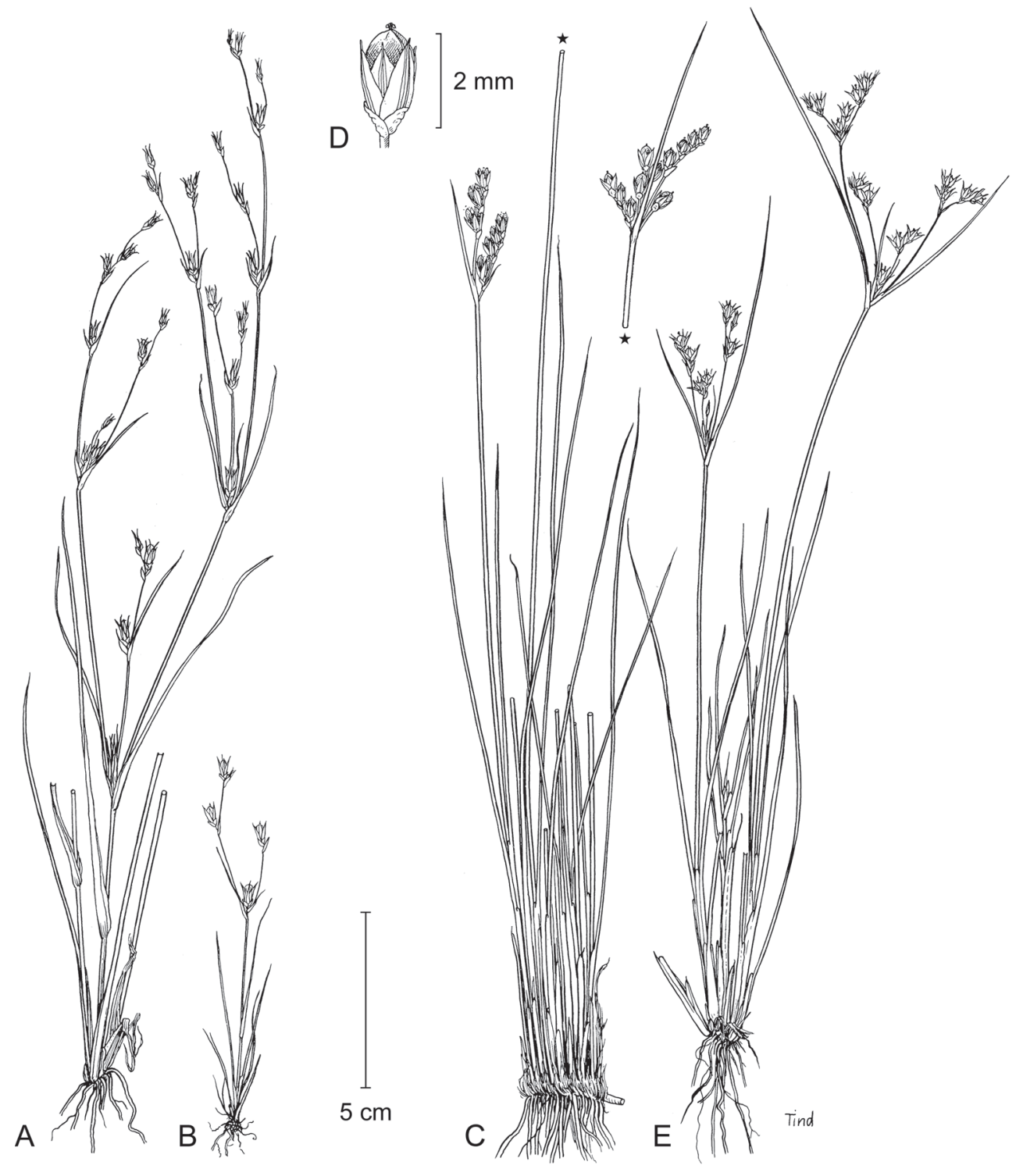

Fig. 3. Juncus bufonius, J. imbricatus y J. tenuis. A y B. hábito de J. bufonius (Holm-Nielsen \& Jeppesen 1537, NY; B, Holm-Nielsen \& Jeppesen 1168). C. hábito y D. flor de J. imbricatus (Asplund 6996, S). E. J. tenuis (Asplund 6997, US). A y B. Originalmente publicado en Balslev, 1979; C y D. Originalmente publicado en Balslev, 1996. 
Distribución general. Juncus bufonius es una especie cosmopolita, más común en las regiones templadas del hemisferio norte. También se encuentra en porciones templadas del hemisferio sur y en partes elevadas y frías de todas las áreas intertropicales. En México se encuentra en Baja California, Chiapas, Coahuila, Distrito Federal, Hidalgo, Estado de México, Michoacán, Oaxaca, Puebla, Querétaro, San Luis Potosí, Sonora, Tlaxcala y Veracruz.

Habitat y fenología. Juncus bufonius es una maleza y en México se encuentra creciendo entre 0 y 2900 metros sobre el nivel del mar, más frecuentemente en suelos abiertos y expuestos a lo largo de caminos, acequias, arroyos, orillas de lagos, marismas, prados, etc. Florece entre abril y septiembre, y fructifica entre abril y noviembre.

Nombres vernáculos y usos. Sacate de manzo (R. Moran 29366 SD).

Afinidades. Juncus bufonius es el único miembro mexicano del subgénero Agathryon sección Tenageia Dumort., un grupo con once especies con centro de diversificación en el oeste de la región Mediterránea y con algunas especies de amplia distribución (Kirschner, 2002c). Morfológicamente J. bufonius es variable y en Europa y el Medio Oriente ha sido tratada como un complejo de microespecies estrechamente relacionadas (Cope y Stace, 1978; Snogerup, 1971, 1980).

Especímenes examinados. BAJA CALIFORNIA: Melpomene drainage, 300 m, 28.X.1957, R. Moran 6152 (SD); Below lower Circus, 900 m, 25.IV.1958, R. Moran 6646 (SD); near principal spring, $1000 \mathrm{~m}, 26 . I V .1958, R$. Moran 6663 (SD); NE slope of El Picacho, 450 m, 29.IV.1958, R. Moran 6753 (SD); mouth of Long Canyon, 50 m, 16.IV.1970, R. Moran 17364 (SD); Boca San José, 25 m, 29.V.1966, R. Moran 13193 (SD); SE of La Misión, 250 m, 20.IV.1969, R. Moran 15802 (SD, UC); N slope Cerro Blanco, 875 m, 15.VI.1969, R. Moran 16148 (PH, SD); Sierra San Pedro Mártir, Rancho el Potrero, 875 m, 5.VII.1969, R. Moran 16336 (SD); SE of Cerro León, 1225 m, 31.V.1970, R. Moran 17718 (SD); Cañada Ancha, N slope of Sierra Blanca, 650 m, 15.V.1976, R. Moran 23194 (SD); $1 \mathrm{~km} \mathrm{~S}$ of Santo Tomas, km 2.3 on Chocolate road, 300 m, 11.III.1979, R. Moran 26658 (SD); Sierra de Juárez, 5 km S of Los Gavilanes, 1675 m, 28.V.1979, R. Moran 27508 (SD); Sierra de Juárez, 6 km N of Laguna Hanson, 1670 m, 28.V.1979, R. Moran 27520 (SD); SE side of Laguna Mormona, 7 km NW of San Quintin Nuevo, 0 m, 7.VII.1980, R. Moran 29014 (SD); Guadalupe Island, 1875, E. Palmer 93 (GH); Sierra San Pedro Mártir, Rancho La Suerte, 1130 m, 4.VI.1963, 
R. F. Thorne 32060 (SD); W of Lobster Camp, 29.IV.1958, I. L. Wiggins \& W. R. Ernst 208 (UC); Lower California sin localidad, C. R. Orcutt 1165 (GH, US); El Cajon Canyon, foot of Sierra San Pedro Mártir at western edge of San Felipe desert, south-west of village of San Felipe, 830 m, I. L. Wiggins 9828 (GH). CHIAPAS: Tenejapa, Paraje Matsab, 2600 m, 25.V.1966, A. Shilom Ton 964 (CAS, F, GH, NY). COAHUILA: Saltillo, VI.1898, E. Palmer 263 (GH, US). DISTRITO FEDERAL: Puerto de las Cruces, $3100 \mathrm{~m}$, J. Rzedowski 35358 (AAU); at edge of river La Gavia, 2930 m, 9.VII.1944, A. J. Sharp 44294 (GH). HIDALGO: Pachuca, 2650 m, Medina 1399 (AAU). ESTADO DE MÉXICO: Santo Tomás Atzingo, 1 km al NE del poblado, $2 \mathrm{~km}$ al E de la carretera Tlalmanalco-Amecameca, $2550 \mathrm{~m}, 20 . X I .1981$, J. García P. 1570 (MO, NY); Temascaltepec, Los Hornos, 2600 m, 17.IV.1933, G. B. Hinton 3702 (F, GH, MO, NY, US); Villa de Allende, 1800 m, 5.X.1952, E. Matuda 26425 (NY); San Nicolás Tlamincas, Texcoco, 2300 m, 9.IV.1983, E. Ventura 720 (ARIZ). MICHOACÁN: $19 \mathrm{~km}$ al E de Queréndaro, sobre la carretera a Maravatío, $2300 \mathrm{~m}$, 15.II.1987, J. Rzedowski 42456 (MEXU). OAXACA: Cerro Pelón, 2900 m, 23.X.1977, J. Rzedowski 35448 (AAU). PUEBLA: El Zapote, Barranca de los Membrillos, 1860 m, 6.IV.1983, P. Tenorio et al. 3828 (MO). QUERÉTARO: Barranca de Amealco, 2100 m, III.1980, E. Argüelles 1355 (MEXU). SAN LUIS POTOSÍ: San Luis Potosí, 1876, J. G. Schaffner 556 (GH, PH), 1877, J. G. Schaffner 211, 223 (C, F, M, NY, US). SONORA: Hermosillo, 5.III.1910, J. N. Rose et al. 12392 (NY, US); Magdalena, 25.IV.1910, J. N. Rose et al. 15109 (NY, US). TLAXCALA: San Juan Quetzalcuapan, 2500 m, 11.II.1981, H. Vibrans 657 (MEXU). VERACRUZ: Perote, Caja de Agua, 2350 m, 25.XI.1972, F. Ventura A. 7465 (AAU, MO).

7. Juncus chiapasensis Balslev, Ann. Missouri Bot. Gard. 75: 379-380. 1988.

Tipo: MÉXICO. Chiapas: Lagunas de Montebello near Guatemala border, $30 \mathrm{~km}$ (air) E of La Trinitaria, 1200 m, 6-7.VIII.1965, K. Roe, E. Roe \& S. A. Mori 966 (holo-; DS-584358!; iso-: F!, WIS!). Figura 4 A, B, 5.

Hierbas perennes, cespitosas, $60-90 \mathrm{~cm}$ de alto. Rizomas $3 \mathrm{~mm}$ de diámetro; culmos erectos, 2-3 mm de diámetro, teretes, lisos o finamente estriados; catáfilos basales ausentes o uno por cada culmo, hasta $7 \mathrm{~cm}$ de largo. Hojas laminares 1-2 basales y 1-2 caulinares por cada culmo, $10-45 \mathrm{~cm}$ de largo; vainas de 4-8 $\mathrm{cm}$ de largo con márgenes membranosos, terminando en dos aurículas, las aurículas 2-3 mm de largo y redondeadas; láminas 1.5-3 mm de diámetro, redondas en sección transversal, conspicuamente septadas transversalmente. Inflorescencia una antela compuesta, $10-20 \times 5-12 \mathrm{~cm}$, con 8-17 flores por cabezuela, éstas globosas, 10-13 

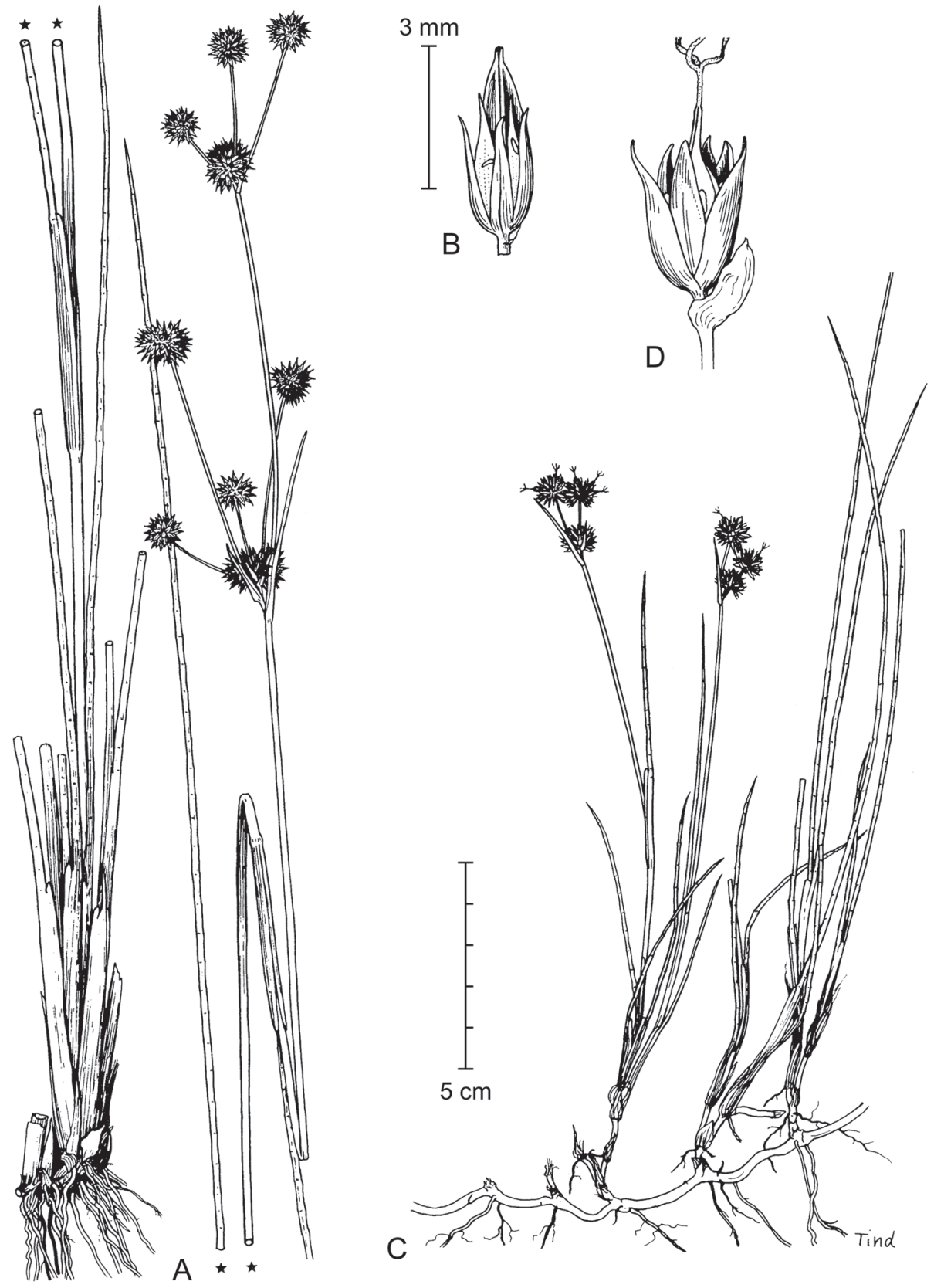

Fig. 4. Juncus chiapasensis y J. ebracteatus. A. hábito y B. flor con una cápsula casi madura de J. chiapasensis (Roe et al. 966, DS). C. hábito y D. flor de J. ebracteatus (Steinbach 8814, US). A y B. Originalmente publicados en Balslev, 1988; C y D. Originalmente en Balslev, 1979). 
mm de diámetro, 10-35 flores, de color castaño, las últimas cabezuelas con ramas de ca. 0.5 mm de grueso; brácteas inferiores de la inflorescencia 3-7 cm de largo, mucho más cortas que las inflorescencias, semejantes a las hojas basales y caulinares, brácteas distales progresivamente más cortas, brácteas florales acuminadas, de ca. $0.2 \mathrm{~mm}$ de largo, membranáceas. Tépalos casi iguales, 2.5-3 $\mathrm{mm}$ de largo, lanceolados, agudos, los externos con forma de $\mathrm{V}$ en sección transversal, los internos planos. Estambres tres, 1.8-2.5 mm de largo; filamentos lineares; anteras oblongas, 0.6-0.8 $\mathrm{mm}$ de largo, cerca de la mitad del largo de los filamentos. Cápsula 4-4.5 × 1-1.2 $\mathrm{mm}$, conspicuamente más larga que los tépalos, obclavada, trígona, aguda, gradualmente estrechándose hacia el ápice, de color castaño, unilocular. Semillas $1 \times 0.2$ $\mathrm{mm}$, elipsoidales, apiculadas, reticuladas, de color amarillo-marrón, con cubierta seminal gruesa e hialina. $2 \mathrm{n}=$ desconocido.

Distribución general. Juncus chiapasensis es endémica del estado de Chiapas en México, con una colecta realizada muy cerca de la frontera con Guatemala.

Hábitat y fenología. Juncus chiapasensis crece en elevaciones entre 12002200 metros sobre el nivel del mar, en pantanos y orillas de lagos.

Nombres vernáculos y usos. Desconocidos.

Afinidades. Juncus chiapasensis es miembro del subgénero Juncus sección Ozophyllum que en México incluye nueve especies (ver $J$. acuminatus). Es afín y simpátrica con Juncus ebracteatus E. Mey., ambas con una cápsula más larga que los tépalos, pero J. chiapasensis es mucho más grande en todas sus dimensiones.

Especímenes examinados. CHIAPAS: La Trinitaria, Lagunas de Montebello, 1500-1525 m, 23.X.1972, D. E. Breedlove \& R. E. Thorne 21247 (DS); San Cristóbal valley, $2200 \mathrm{~m}, 23 . X .1972, D$. E. Breedlove \& R. E. Thorne 21285 (DS, mezclado con J. ebracteatus; MICH, MO).

8. Juncus cooperi Engelm., Trans. Acad. Sci. St. Louis 2: 590. 1868.

Tipo: ESTADOS UNIDOS DE AMÉRICA. California, San Bernardino Co., Camp Cady, I. G. Cooper 1861 (holo-: US!). Figura 5.

Hierbas perennes, densamente cespitosas, $50-120 \mathrm{~cm}$ de alto. Rizomas densamente ramificados y produciendo vástagos en las axilas de las hojas laminares; 
culmos rígidamente erectos, teretes, $2-5 \mathrm{~mm}$ de diámetro, longitudinalmente estriados, fuertemente esclerificados, médula parenquimatosa con haces vasculares esparcidos a través de la sección transversal. Hojas 30-100 cm de largo, 5-7 por cada culmo, todas basales; vaina 5-15 cm de largo, con márgenes estrechamente membranáceos, gradualmente estrechándose hacia el ápice y terminando en una hendidura estrecha de pocos centímetros; láminas teretes, rígidas con el ápice espiniforme, médula parenquimatosa con haces vasculares dispersos a través de la sección transversal. Inflorescencia una panícula compuesta, aglomerada y solo $3 \times 3 \mathrm{~cm}$ o más, laxa, hasta $15 \times 7 \mathrm{~cm}$, las ramas alternando entre vástagos cortos y vástagos largos, así que la inflorescencia frecuentemente parece subdividida; brácteas inferiores de la inflorescencia igualando el largo de la inflorescencia o más largas, rígidamente erectas con una vaina ancha, terete y una lámina con el ápice duro y puntiagudo. Flores agrupadas en glomérulos de 2-6 flores cada uno y abrazadas por brácteas que yacen en la base del pedicelo, pero sin bractéolas insertas en los pedicelos. Tépalos de color verde a pajizo, 5-6 mm de largo, los externos acuminados a aristados con márgenes escariosos, con forma de $\mathrm{V}$ en sección transversal, los internos acuminados con márgenes escariosos, con forma de $U$ en sección transversal. Estambres seis, 2-3 mm de largo, conspicuamente más cortos que los tépalos; filamentos cortos y anchos en la base; anteras muchas veces más largas que los filamentos, amarillas. Ovario con estilo de ca. $0.5 \mathrm{~mm}$ de largo; estigmas $1 \mathrm{~mm}$ de largo. Cápsula tan larga como los tépalos, elipsoidal a estrechamente elipsoidal, cortamente mucronada, trígona, 4-5 × 2-2.5 mm, de color verde a pajizo, tornándose castaño apicalmente en la madurez, trilocular. Semillas $60-70$ por fruto, de formas variadas e irregulares, usualmente algo curvas, $1.2-1.6 \times 0.4-0.5 \mathrm{~mm}$, con extensiones transparentes de la cubierta seminal en cada extremo. $2 \mathrm{n}=$ desconocido.

Distribución general. Juncus cooperi se distribuye en el oeste de Estados Unidos de América y México. Crece desde el Valle de la Muerte hasta el Golfo de California, en el Delta del Río Colorado (California, Utah y Arizona) y en el flanco oriental de la Sierra de Juárez (Sonora). En México solo ha sido reportada en el estado de Sonora.

Hábitat y fenología. Juncus cooperi crece en humedales y pantanos, frecuentemente en suelos salinos; puede emerger en aguas someras y desarrollarse en densos rodales a lo largo de márgenes de charcos temporales que en verano acumulan una costra de sal por evaporación, a veces se encuentra esparcida a lo largo de arroyos salinos. Localmente es muy común, mezclada con gramíneas y 
ciperáceas. Se encuentra entre 0-100 metros sobre el nivel del mar. Florece entre abril y mayo.

Nombres vernáculos y usos. Desconocidos.

Afinidades. Juncus cooperi se relaciona con J. acutus, ambas pertenecen al subgénero Juncus sección Juncus pero la primera se diferencia por sus tépalos más largos, de 4-6 mm de largo, de color verde a pajizo y cápsula estrechamente elipsoidal y trilocular.

Especímenes examinados. SONORA: Gran Desierto, La Salina, ca. $3.5 \mathrm{~km}$ inland from beach at SW end of Bahia Adair (Punta Borrascosa), 14.VII.1982, E. Ezcurra s.n. (ARIZ, SD); Laguna Prieta, Gran Desierto, NE Sonora, 20.IV.1985, E. Ezcurra s.n. (MO, NY); Punta Borrascosa, La Salina, 24.III.1989, E. Ezcurra s.n. (ARIZ); 20 miles $\mathrm{N}$ of El Golfo de Santa Clara on road from San Luis, then 0.3 miles W, 13.III.1975, R. S.

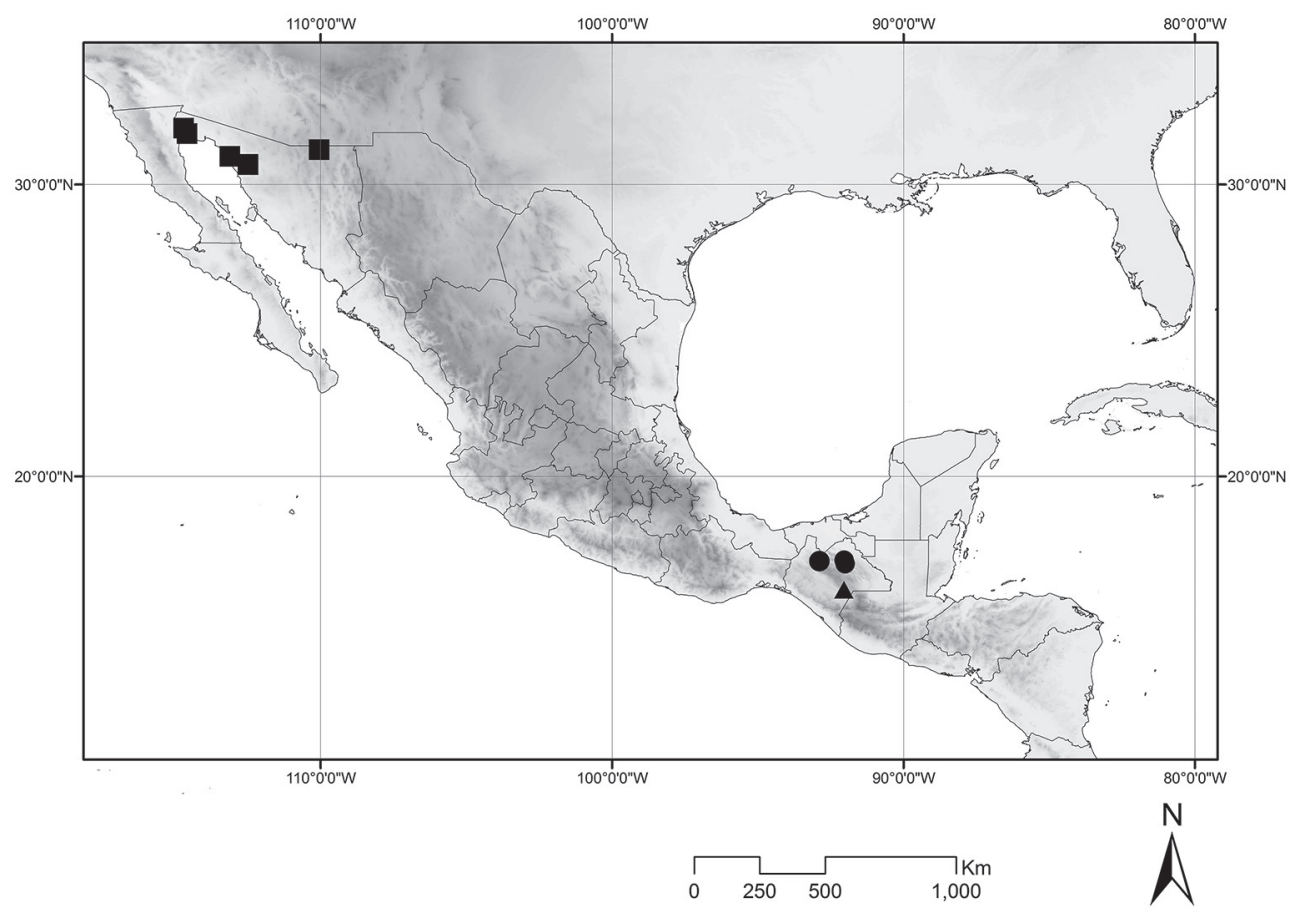

Fig. 5. Mapa de distribución de los especímenes examinados de Juncus chiapasensis ( $\mathbf{\Delta}), J$. debilis $(\bullet)$ y $J$. cooperi $(\mathbf{\bullet})$. 
Felger 75 (ARIZ); Laguna Prieta, ca. 20 km SE of San Luis Río Colorado, 14.V.1985, $R$. S. Felger 85-757 (ARIZ, SD); $5 \mathrm{~km} \mathrm{~S}$ of El Doctor (35 km S of Rillito, or $80 \mathrm{~km} \mathrm{~S} \mathrm{of} \mathrm{San}$ Luis Río Colorado), 6.X.1985, R. S. Felger 85-1053 (ARIZ); Río Colorado 1 km NW of Estación el Octubre, 0 m, 22.XI.1992, R. S. Felger 92-994 (ARIZ); ciénega de Santa Clara, 5 m, 21.XI.1992, R. S. Felger 92-9858 (ARIZ); Delta region of the Río Colorado, ca. $1 \mathrm{~km} \mathrm{~N}$ of Ejido El Octubre, 23.III.1993, R. S. Felger 93-250B (ARIZ); 20 miles SE of San Luis, Río Colorado at Laguna Prieta, 7.VI.1959, V. Roth 2 (ARIZ).

9. Juncus debilis A. Gray, Manual 506. 1848.

三Juncus acuminatus Michx. var. debilis (A. Gray) Engelm. en Manual ed. 5, 542. 1867. Lectotipo (designado por Engelmann, 1868): ESTADOS UNIDOS DE AMÉRICA. Kentucky, Crab Orchad, 1.VIII.1835, C. W. Short s.n. (lecto-: PH!). Figura 5.

= Juncus radicans Schltdl., Linnaea 18: 442. 1844. nom. rej. en favor de Juncus debilis A. Gray, nom. cons. (referencia TROPICOS y Kirschner et al., 2002).

Lectotipo (designado por Balslev, 1996): MÉXICO. Veracruz, Río Jalapa, 28.V.1828, C. J. W. Schiede s.n. (HAL).

Hierbas laxamente cespitosas, delicadas, $15-50 \mathrm{~cm}$ de alto. Rizomas densamente ramificados, agrupados, de ca. $1 \mathrm{~mm}$ de diámetro; culmos erectos o ascendentes, 0.5-1 mm de diámetro, teretes, lisos; catáfilos ausentes o inconspicuos. Hojas laminares 1-2 basales y 1-2 caulinares por cada culmo, 5-20 cm de largo; vainas de 1-5 cm de largo, con márgenes membranáceos, terminando en aurículas redondeadas, $1 \mathrm{~mm}$ de largo; láminas de ca. $1 \mathrm{~mm}$ de diámetro, rectas o a veces ascendentes, redondas a elípticas en sección transversal, la base ligeramente comprimida, septadas tranversalmente. Inflorescencia hasta cuatro veces ramificada y $15 \times 10 \mathrm{~cm}$, hasta 50 cabezuelas de flores, arregladas en una antela, cada cabezuela con 2-10 flores, las últimas cabezuelas ca. $0.3 \mathrm{~mm}$ de diámetro; brácteas inferiores de la inflorescencia usualmente menos de 1/3 del largo de la inflorescencia, parecidas a pequeñas hojas caulinares, brácteas distales semejantes a escamas, membranáceas, brácteas florales membranáceas, de ca. $1.5 \mathrm{~mm}$ de largo. Tépalos casi iguales, lanceolados, agudos pero no acuminados, de color verde a pajizo, los externos 2.2-2.8 $\mathrm{mm}$ de largo, cóncavos, los internos de 2.3-2.5 mm de largo, aplanados. Estambres tres, ca. $1.5 \mathrm{~mm}$ de largo; anteras oblongas ca. $0.5 \mathrm{~mm}$ de largo. Ovario con el estilo 0.1-0.2 mm de largo; estigmas 0.8-1 mm de largo. Cápsula estrechamente ovoide, aguda y cortamente apiculada, trígona, ca. $3 \times 1 \mathrm{~mm}$ y conspicuamente más larga que los tépalos, de color castaño pálido, unilocular. Semillas elipsoidales, ca. $0.4 \times 0.2 \mathrm{~mm}$, reticuladas, de color amarillento-marrón, apéndices ausentes. $2 \mathrm{n}=$ desconocido. 
Distribución general. Juncus debilis se distribuye al este de Estados Unidos de América (de Connecticut a Florida) y hacia el oeste (hasta Texas, Tennessee y Missouri) y de manera disyunta en México y Honduras.

Hábitat y fenología. Juncus debilis crece en bosques montanos húmedos con Magnolia, Ardisia, Podocarpus, Quercus y leguminosas. Se encuentra entre 1600 y 2000 metros sobre el nivel del mar. Esta especie ha sido colectada en flor en enero, febrero y octubre.

Nombres vernáculos y usos. Desconocidos.

Afinidades. Juncus debilis es miembro del subgénero Juncus sección Ozophyllum que en México incluye nueve especies (ver J. acuminatus y J. chiapasensis).

Especímenes examinados. CHIAPAS: Jitotol, $1600 \mathrm{~m}, 12 . \mathrm{II} .1965$, D. E. Breedlove 8894 (F); $12 \mathrm{~km} \mathrm{~N}$ of Jitotol, $2000 \mathrm{~m}, 28 . I X .1971$, D. E. Breedlove 19963 (DS, DUKE, ENCB, MEXU, MICH, MO); Jitotol, $12 \mathrm{~km}, \mathrm{~N}$ of Jitotol, 2000 m, 28.X.1971, D. E. Breedlove \& R. F. Thorne 21486 (MO); E side of Pueblo Nuevo Solistahuacán, 1700 m, 26.X.1971, D. E. Breedlove 21530 p.p. (CHAPA, DS, DUKE, ENCB, F, LL, NY; el pliego del mismo número depositado en MO está identificada como J. microcephalus); $5 \mathrm{~km}$ E of Jitotol, 1600 m, 9.I.1981, D. E. Breedlove \& B. T. Keller 49363 (MO, NY); $9 \mathrm{~km} \mathrm{~S}$ of Pueblo Nuevo Solistahuacán, 1600 m, 24.I.1965, P. H. Raven \& D. E. Breedlove 19938 (DS, US).

10. Juncus dichotomus Elliot, Sketch Bot. S. Carol. 1: 406. 1817.

$\equiv$ Juncus tenuis var. dichotomus (Elliot) Wood, Classbook of Botany 726. 1861.

Lectotipo (designado por Kirschner, 2002): ESTADOS UNIDOS DE AMÉRICA. South Carolina \& Georgia, S. Elliot s.n. (CHARL!).

= Juncus tenuis var. unicornis E. Mey., Linnaea 3: 371. 1828.

Sintipos: BRASIL, A. Chamisso s.n. (LE); MÉXICO, T. Haenke s.n. (PR).

= Juncus cognatus Kunth, Enum. Pl. 3: 349. 1841.

Sintipos: URUGUAY. Montevideo, Montevideo, 1821-1822, F. Sellow s.n. (MO; Bdestruido); BRASIL. Santa Catarina, sin localidad exacta, Ch. Gaudichaud s.n. (P4); MÉXICO. Sin localidad exacta, T. Haenke s.n. (herbario desconocido), Jalapa, C. J. W. Schiede 960 (MO).

= Juncus albicans Fernald, Proc. Amer. Acad. Arts 45(17): 415. 1910. 
Tipo: MÉXICO. Chihuahua, Chihuahua, 15.V.1908, 1300 m, E. Palmer 161 (holo-: GH, n.v.; iso-: $\mathrm{F}$ !, $\mathrm{MO}$ !, NY!).

Hierbas perennes, cespitosas, 10-90 cm de alto. Rizomas densamente ramificados; culmos longitudinalmente estriados; aurículas de ca. $0.5 \mathrm{~mm}$ de largo, más anchas que largas, redondeadas y cartilaginosas. Hojas laminares teretes o acanaladas, cuando acanaladas, con la parte central en corte transversal más gruesa que los márgenes, la cara adaxial con o sin banda central de células hialinas ocupando menos de 1/3 de su ancho. Inflorescencia compuesta de varias cimas unilaterales con flores insertas en parte regularmente y equidistantes; brácteas inferiores de la inflorescencia variando, cortas o más largas que la inflorescencia pero usualmente conspicuamente más largas que las brácteas superiores. Tépalos rectos o ligeramente recurvados, subiguales, (3-)3.3-4.5(-5.5) $\mathrm{mm}$ de largo, los internos ligeramente más pequeños. Estambres seis, insertos, filamentos 0.6-1.2 $\mathrm{mm}$ de largo, anteras 0.4-0.8(-1) mm de largo. Ovario con el estilo de ca. $0.2 \mathrm{~mm}$ de largo; estigmas 1-2 $\mathrm{mm}$ de largo. Cápsula corta o más larga que los tépalos en la madurez, pared gruesa, valvas recurvadas a lo largo de la costura y la cápsula entonces en la parte inferior con tres crestas o ligeramente 3-aquillada. Semillas elipsoidales a lunadas, 0.3-0.4 $\mathrm{mm}$ de largo, $0.2 \mathrm{~mm}$ de ancho, reticuladas, de color castaño, apéndices indistintos. $2 \mathrm{n}=$ desconocido.

Distribución general. Juncus dichotomus se distribuye en el este de Estados Unidos de América desde Massachussetts hasta Oklahoma y Texas en el suroeste. En el Neotrópico se conoce de las tierras altas de México y por otro lado en Sur América, en el sureste de Brasil, Bolivia, Uruguay y Argentina y también en las Antillas (Jamaica). Esta especie es una planta introducida en Nueva Zelanda y Australia. Su rango actual de distribución en el Nuevo Mundo es difícil de definir (Kirschner, 2002c). En México crece en Baja California, Chiapas, Durango, Hidalgo, Jalisco, Estado de México, Michoacán, Oaxaca, Puebla, San Luis Potosí, Tamaulipas y Veracruz. McVaugh (1993) la registra para Aguascalientes, Chihuahua, Guanajuato, Sinaloa, Sonora y Zacatecas.

Hábitat y fenología. Juncus dichotomus crece en lugares húmedos en arroyos, ciénagas, represas y caminos. En México ha sido colectada entre 1900-2700 metros sobre el nivel del mar en bosques de Pinus, Quercus y Arbutus, en bosques de Quercus y Magnolia; bosques de pino-encino, bosques de Liquidambar y Quercus, bosques perturbados de Pinus, en bosques montanos perturbados, en áreas de culti- 
vo (milpa) y en pleno sol. La especie ha sido colectada en flor entre enero y julio y en fruto entre abril y octubre.

Nombres vernáculos y usos. Desconocidos.

Afinidades. Juncus dichotomus forma parte del subgénero Agathryon sección Steirochloa junto con J. dudleyi, J. imbricatus y J. tenuis. Es una especie muy variable.

Especímenes examinados. BAJA CALIFORNIA: 14 km SE of La Misión, 350 m, 14.III.1979, R. Moran 26775 (SD). CHIAPAS: San Cristóbal de las Casas, 2100 m, 3.VIII.1964, D. E. Breedlove 6767 (F, US); Zinacantán-Chamula boundary, road to Zinacantán Center, 2400 m, 20.I.1965, D. E. Breedlove \& P. H. Raven 8140 A (US); Tenejapa, Pahal Ton, 2300 m, 1.X.1965, D. E. Breedlove 12362 (US); 22 km from San Cristobal de las Casa on the road to Tenejapa, then right $3 \mathrm{~km}$ on the road to Matzam, 2400 m, 29.IX.1984, M. J. Huft et al. 2191 (MO); San Cristóbal de las Casas, 16-20 km E of Chilil, 2380 m, 10.XI.1976, D. E. Breedlove 41310 (MO, NY); Tumbala, 12001700 m, 20.X.1895, E. W. Nelson 3334 (US); Paraje Matsab, 2750 m, A. Shilom Ton 946 (DS, LL, MICH, NY); Pueblo Nuevo Solistahuacán, 2000 m, 15.VIII.1967, A. Shilom Ton 2915 (NY, US). CHIHUAHUA: Majalca, 24.VI.1936, H. LeSueur 1122 (MO, PH, US); Cascada de Basaseachic, 1900 m, 23.VII.1986, P. S. Martin s.n. (ARIZ); near Casas Grandes, 15.VII.1899, 2500 m, C. H. T. Townsend \& C. M. Barber 452 (MO, US); southwestern Chihuahua, VIII-XI.1885, E. Palmer 2 (US). DURANGO: Santiago Papasquiaro, Sierra Madre Occidental, $22 \mathrm{~km}$ (air) WNW of Santiago Papasquiaro, 2700 m, 9.VII.1983, R. Corral Diaz \& R. D. Worthington 10953 (NY); Tobar, 2831.V.1906, E. Palmer 253 (F, GH, MO, NY, UC, US); Sierra Jardin, northern Coahuila, 1.IX.1966, D. Flyr 1195 (MO); sin localidad, P. Ibarra García 320 (US). HIDALGO: Ferreria de Apulco, 2150 m, 25.I.1984, K. Taylor \& M. Nee 223 (F, NY). JALISCO: $14 \mathrm{~km}$ al NO de Bolaños, brecha Los Álamos, F. J. Santana M. 1740 (MEXU). ESTADO DE MÉXICO: E slope of Cerro de La Cruz, Sierra de Alcaparrosa, 6 km N of Tepotzotlán, 2300 m, 12.X.1980, R. Galván 707 (GH, US); Desierto de los Leones, 9.VII.1938, L. A. Kenoyer A571 (F); Valle de México near San Augustin, VIII.1855, W. Schaffner 530 (MO). MICHOACÁN: Morelia, Cerros San Miguel, 2200 m, XII.1910, G. Arsène s.n. (NY); S. Miguel, XI.1904, G. Arsène 33 (F). OAXACA: El Molino, $1 \mathrm{~km} \mathrm{~S}$ of Calpulalpan on Ixtlán-Calpulpan road, 2100 m, 3.X.1983, A. García M. 1172 (MO); 3 km de la desv. San Juan Mixtepec-Santo Domingo Yosoñama, 2400 m, 24.VII.1987, J. Sánchez B. 1 (MO). PUEBLA: Huauchinango, 10.VII.1944, A. J. Sharp 441252 (MEXU). SAN LUIS POTOSÍ: Alvarez, Sierra de Alvarez, 2200-2400 
m, 30-31.VII.1934, F. W. Pennell 17886 (GH; los pliegos de este número en NY, PH, US están identificados como Juncus dudleyi); San Luis Potosí, C. W. Schaffner 214 (CAS, CM, F, GOET, NY, US, Z); San Luis Potosí, 1876, C. W. Schaffner 555 (PH). SINALOA: Rosario, 14.IV.1910, J. N. Rose et al. 14601 (US). SONORA: Sierra de los Ajos, 2300 m, 10.X.1992, R. S. Felger 92-898 (ARIZ); Sahuaribo Waterfall, Arroyo Curohui, 1400-1500 m, 20-21.VIII.1992, E. S. Martin s.n. (ARIZ); Cerro Saguarivo, E of San Bernardo, Pacific slope, 1500-1700 m, 7-8.VIII.1935, F. W. Pennell 19623 (PH, US); El Guayabo, crossing of Río Cuchujaqui, $2.6 \mathrm{~km}$ NE of Sabinito Sur, 14 km (air) ESE of Alamos, 350 m, 14.IV.1994, T. R. van Devender 94-295 (ARIZ). TAMAULIPAS: $5 \mathrm{~km}$ N of Miquihuana, 15.VII.1949, Stanford et al. 2475 (GH, MO, NY, US). VERACRUZ: $3 \mathrm{~km} \mathrm{SW}$ of Huayacocotla along road to Palo Bendito, 2150-2250 m, 22.VII.1982, M. Nee \& G. Diggs 25203 (F, NY); 22 km from Palma Sola, 800 m, 16.IV.1969, L. I. Nevling \& A. Gómez-Pompa 1010 (FJ).

11. Juncus dubius Engelm., Trans. Acad. Sci. St. Louis 2: 459. 1868.

Tipo: ESTADOS UNIDOS DE AMÉRICA. California, Mariposa, Clark's Meadow near Big Tree Grove, H. N. Bolander 6032 (G. Engelmann, Herb. Junc. Bor.-Amer. Norm. 52); syn-: MO, NY, PR.

Hierbas perennes, 30-75 cm de alto, rizomatosas, formando macollas sueltas. Rizomas corta o largamente trepadores, 2-3 mm de diámetro, de color marrón claro, no hinchados. Tallo usualmente densamente papiloso-ruguloso, rara vez más o menos liso. Catáfilos 1-2, de color rosado a pajizo, ápice agudo; hojas basales 1-2, 20-30 cm de largo. Hojas caulinares 1-2, 20-30 cm de largo, teretes, perfectamente septadas, septos visibles externamente y prominentes al desecar, rugulosas o rara vez lisas, unitubulares, ápice acuminado; vainas anchamente bordeadas, sus aurículas de 1-4.9 mm de largo, membranáceas, ápice redondeado. Inflorescencia difusa, compuesta, con 25-66 cabezuelas, usualmente de 7-15 cm de largo, con una rama principal erecta a erecta-patente y otras ramas frecuentemente \pm patentes; cabezuelas semiglobosas a obovoides, con 6-10 flores, 5-10 mm en diámetro; brácteas inferiores herbáceas, de color pajizo, lanceoladas a lineares, 1.2-3.2 cm de largo, más cortas que la inflorescencia, erectas; brácteas de color pajizo, lanceoladas, 4-6 mm de largo. Tépalos subiguales, lanceolados, de color pajizo a marrón, acuminados, los externos carinados, con nervio medio prominente, (2-)2.5-3.4 mm de largo, de color pajizo-marrón a castaño, acuminados, con márgenes anchos y membranáceos, los internos con frecuencia ligeramente más largos, aplanados, ápice subagudo a mucronado, (2-)2.6-3.6 mm de largo, distalmente con márgenes membranáceos anchos. 
Estambres seis, no exsertos; anteras $0.6-1 \mathrm{~mm}$ de largo, ca. 1.5 veces más largas o tan largas como el filamento; filamento de $0.5-0.7 \mathrm{~mm}$ de largo. Ovario con estilo de 0.5-0.6 mm de largo; estigmas de 0.6-1.1 mm de largo. Cápsula unilocular, estrechándose en una punta subulada, base estrechamente ovoide, trígona, (2.4-)3-3.9 $\mathrm{mm}$ de largo, de color castaño-marrón, \pm excediendo el perianto. Semillas elipsoideovoides, apiculadas, $0.3-0.5 \times 0.2-0.3 \mathrm{~mm}$, de color marrón claro, claramente reticuladas; apéndices ausentes. 2n $=40$ (Harriman y Redmond, 1976).

Distribución general. Oeste de los Estados Unidos de América (California y Oregón) y noroeste de México (Baja California).

Hábitat y fenología. Juncus dubius crece en bosques de coníferas a 610-2650 metros sobre el nivel del mar. Florece y fructifica en septiembre.

Nombres vernáculos y usos. Desconocidos.

Afinidades. Juncus dubius pertenece al subgénero Juncus sección Ozophyllum que incluye otras nueve especies en México (ver J. acuminatus). Se parece más a Juncus ebracteatus, pero esta última siempre tiene los tallos lisos (vs. generalmente densamente papiloso-rugulosos) y flores sésiles (vs. pediceladas).

Especímenes examinados. BAJA CALIFORNIA: Mun. Ensenada, Parque Nacional Sierra San Pedro Mártir, along Observatory Road, 2430 m, 1.IX.1985, R.F. Thorne et al. 61418 (MEXU); Sierra San Pedro Mártir, above Yerba Buena, 2650 m, 16.VIII.1967, R. Moran \& R. F. Thorne 14217 (UC); Sierra San Pedro Mártir, La Sanca creek, 5 miles NW of La Grulla, 2000 m, 17.IX.1930, I. L. Wiggins \& D. Damaree 4858 (GH, UC); Canyon del Diablo, Cerro la Encantada, 1700 m, 16.VI.1954, K. L. Chambers 619-A (UC); 760 m, 13.VI.1954, K. L. Chambers 646 (UC); 610 m, 13.VI.1954, K. L. Chambers 541 (UC); Upper Arroyo Copal, 2000 m, 25.VIII.1968, R. Moran 15471 (UC); Sierra San Pedro Mártir, Arroyo Copal, 16.VII.1988, S. Boyd \& T. Ross 2537 (F).

12. Juncus dudleyi Wiegand, Bull. Torrey Bot. Club. 27: 524. 1900.

$\equiv$ Juncus tenuis subsp. dudleyi (Wiegand) P. Fourn., Quatre Fl. France 147. 1935 इJuncus tenuis var. dudleyi (Wiegand) F. J. Herm., J. Arnold Arbor. 15: 56. 1944. Tipo: ESTADOS UNIDOS DE AMÉRICA. Nueva York, Truxton, K. M. Wiegand s.n. (holo-: $\mathrm{CU}$ ). 
Hierbas perennes, cespitosas, hasta $70 \mathrm{~cm}$ de alto. Rizomas densamente ramificados; culmos usualmente lisos, a veces algo estriados longitudinalmente. Hojas laminares teretes o acanaladas, cuando acanaladas, el canal central en sección transversal más grueso que los márgenes, la cara adaxial con una banda estrecha de células hialinas ocupando menos de $1 / 3$ de su grosor. Aurículas ca. $0.5 \mathrm{~mm}$ de largo, más anchas que largas, redondeadas, cartilaginosas. Inflorescencia compuesta de varias cimas unilaterales con pocas o muchas flores, agrupadas en una o más cabezuelas, densas; brácteas inferiores de la inflorescencia usualmente filiformes, flexuosas, conspicuamente más largas que las distales. Tépalos subiguales, lanceolados, acuminados, aplanados o ligeramente recurvados, 4-5 $\mathrm{mm}$ de largo, los internos ligeramente más cortos. Estambres seis, insertos; filamentos 0.8-1.2 $\mathrm{mm}$ de largo, anteras 0.6-1 mm de largo. Ovario con estilo ca. $0.2 \mathrm{~mm}$ de largo; estigmas 1.6-2.1 mm de largo. Cápsula con la pared delgada, por lo general claramente más corta que los tépalos en la madruez, valvas no recurvadas a lo largo de la costura y la cápsula por lo tanto no 3-quillada. Semillas 0.4-0.65 × 0.2-0.25 mm, alveoladoreticuladas, apéndices indistintos. $2 \mathrm{n}=42,80$ (Harriman y Redmond, 1976; Love y Love, 1981).

Distribución general. Juncus dudleyi se distribuye en Canadá y Estados Unidos de América y en las tierras altas de Centro América. Probablemente fue introducida en los Andes de Colombia, Venezuela, Ecuador y Perú. También lo fue en algunos países de Europa (Austria, Inglaterra y Eslovaquia). En México crece en Chiapas, Chihuahua, Distrito Federal, Durango, Hidalgo, Jalisco, Estado de México, Michoacán, Oaxaca, San Luis Potosí, Sonora, Tlaxcala y Veracruz.

Hábitat y fenología. Juncus dudleyi prospera en lugares húmedos a lo largo de arroyos, lagos, sitios inundables, caminos en prados y herbazales, en bosque de pino-encino, sobre suelos rocosos y delgados o arenosos y en márgenes de campos de cultivo. En México se encuentra entre 1500 y 3000 metros sobre el nivel del mar. Florece y fructifica entre abril y septiembre.

Nombres vernáculos y usos. Los Tarahumara de Chihuahua la conocen como Vahisori y es consumida por el ganado (R. A. Bye 3942).

Afinidades. Juncus dudleyi forma parte de Juncus subgénero Agathryon sección Steirochloa junto con Juncus dichotomus, J. imbricatus y J. tenuis. Es una especie muy variable que se parece más a J. dichotomus. 
Especímenes examinados. CHIAPAS: San Cristóbal, 2-4 km from Highway 190 on road to San Lucas Zapotal, 2400 m, D. E. Breedlove 37281 (DS). CHIHUAHUA: Urique, Sawirare, Napuchi region NE of Samachique, 2400 m, 2.VI.1973, R. A. Bye, Jr. 3942 (ECON); Sierra Charuco, Rancho Byerly, 1500-1800 m, 17-25. IV.1948, H. S. Gentry 8022 (ARIZ, NY, UC, US). DISTRITO FEDERAL: Lomas, 5.II.1937, E. Lyonnet 1563 (MEXU, US). DURANGO: Suchil, Mesa del Burro, 6 km SW of Piedra Herrada, 2650 m, 16.IX.1982, S. González \& R. Fernández 2128 (NY). HIDALGO: Nopalillo, Epazoyucan, 2700 m, Medina 850B (ENCB); Río Teponapa, near Zacualtipan, 2000 m, 2.VII.1947, H. E. Moore, Jr. $3234 a$ (GH). JALISCO: Bolaños-Guadalajara road, 21.IX.1897, J. N. Rose 3037 (GH, US); Rancho El Mortero, Mezquitic, 2450 m, J. Rzedowski 17707 (ENCB). ESTADO DE MÉXICO: $26 \mathrm{~km} \mathrm{~W}$ of Toluca, $2500 \mathrm{~m}$, H. H. Iltis \& Cochrane 205 (WIS); San José del Vichio, Cahuach, Nicolás Romero, 2600 m, 12.IX.1982, A. Ventura A. 4091 (GH); Tultenango, 13.VII.1901, J. N. Rose \& R. Hay 5427 (GH, US); Cumbre de Acambay, 3000 m, 9.VIII.1953, E. Matuda 28899 (US). MICHOACÁN: E of Jiquilpan, 21.VIII.1953, W. E. \& M. S. Manning 53122d (GH). OAXACA: Río Mayo region, N end of Mesa Campanero, Barranca el Salto, 2120 m, 3.VII.1994, M. E. Fishbein 1734 (ARIZ); municipio de Alamos, upper Río Cuchujaqui, Santa Barbara Arroyo, near Cueva Pintada, 1000 m, 15.V.1990, P. S. Martin s.n. (ARIZ); Totontepec, 1700-2100 m, 15-20.VII.1894, E. W. Nelson 749 (US); $30 \mathrm{~km} \mathrm{SW}$ of Oaxaca, 2300-2900 m, 10-20.IX.1894, E. W. Nelson $1406 b$ (US). SAN LUIS POTOSÍ: Sierra de Alvarez, Alvarez, 2200-2400 m, 30-31.VII.1934, F. W. Pennell 17886 (NY, PH, US; el pliego de este número en GH está identificado como Juncus dichotomus). TLAXCALA: San Salvador Tzompantepec, 2500 m, 3.XI.1981, H. Vibrans 671 (ENCB, MEXU). VERACRUZ: Huayacocotla, Palo Bendito, 2000 m, 20.XII.1970, R. Hernández M. \& Y. Vázquez de Hernández 951 (F); Dos Puentes, Huatusco, 1150 m, 21.II.1972, A. Ventura 4948 (ENCB).

13. Juncus ebracteatus E. Mey., Syn. Junc. 28. 1822.

Tipo: MÉXICO. Guerrero, Acapulco, 1791, T. Haenke s.n. (holo-: PR, n.v.). Figura 4 C, D.

= Juncus trinervis Liebm. a[alpha] elatus Liebm., Mexic. Juncac. 41. 1850.

Tipo: MÉXICO. Puebla, Cerro León, 2135 m, VII.1841, F. M. Liebmann 855 (holo-: $\mathrm{C}$ !; iso-: $\mathrm{C}$ !, fragmento, $\mathrm{MO}$ !).

= Juncus trinervis Liebm. b[betha] minor Liebm., Mexic. Juncac. 41. 1850.

Tipo: MÉXICO. Oaxaca, Hacienda de Castresana, E Oaxaca, 2285 m, VI.1842, Liebmann s.n. (holo-: C!; iso-: C!, K!, P!). 
Hierbas perennes, (5-)15-30(-65) cm de alto. Rizomas estoloníferos, 1-2.5 mm de diámetro, desnudos o con pocas escamas membranáceas, de color castaño pálido, hasta $5 \mathrm{~mm}$ de largo; culmos usualmente surgiendo en los nodos, 1-5 $\mathrm{cm}$ de largo, solitarios a veces unos pocos agrupados, erectos o ligeramente curvados, 0.7-2 mm de diámetro, lisos o longitudinalmente arrugados, no estriados, los internodos basales a veces alargados, separando las hojas de la roseta de los rizomas; catáfilos 0-2 por cada culmo, hasta $6.5 \mathrm{~cm}$ de largo, membranáceos o herbáceos, obtusos, mucronados o con un lámina rudimentaria de hasta $1.5 \mathrm{~mm}$ de largo. Hojas laminares 2-4(-7) por cada culmo, insertas debajo de la mitad de los culmos, a veces todas basales, 4-20 cm de largo; vainas de 1.5-9 cm de largo, márgenes membranáceos, terminando en dos aurículas redondeadas, $0.5-1.5 \mathrm{~mm}$ de largo; láminas lineares, 0.5-3 $\mathrm{mm}$ de diámetro, teretes, ahuecadas, noduladas por septos, 1-15 $\mathrm{mm}$ aparte. Inflorescencia terminal, una antela decompuesta, (1-)2-8(-11) flores por cabezuela, cada cabezuela semi-globosa a globosa en la madurez, 7-12(-14) mm de diámetro; brácteas inferiores de la inflorescencia hasta $6 \mathrm{~cm}$ de largo, pareciéndose a las hojas basales, vainas y láminas septadas transversalmente o reducidas a una vaina con lámina acicular, brácteas distales más cortas, brácteas florales lanceoladas, hasta $3.5 \mathrm{~mm}$ de largo, de color castaño pálido a castaño; pedicelos a veces hasta $2 \mathrm{~mm}$ de largo y visibles en las cabezuelas. Flores (5-)20(-30), conspicuas con los estilos y rostros sobresalientes. Tépalos casi iguales, 2.5-5 mm de largo, lanceolados, agudos, de color castaño, más pálidos hacia la base, a veces de color pajizo o castaño casi negruzco a lo largo, los externos cóncavos o usualmente con forma de $\mathrm{V}$ en sección transversal, los internos a veces ligeramente más cortos que los externos, aplanados, frecuentemente con tres nervios conspicuos. Estambres seis, 1.5-2.3 mm de largo; filamentos aplanados, ensanchados en la base; anteras lineares, 1-1.8 mm de largo, 1.5 veces más largas que los filamentos, de color amarillo pálido o casi blancas en la antesis. Ovario con estilo de 1-3 $\mathrm{mm}$ de largo; estigmas 1-3 $\mathrm{mm}$ de largo, conspicuamente sobresaliendo de la flor. Cápsula obovoide a obclavada, la base trilobada, trígona en el medio, 3-4 × 1-1.3 mm, coronada con un largo y conspicuo rostro 1-2 $\mathrm{mm}$ de largo, sobresaliendo la flor, de color pajizo a castaño, unilocular. Semillas ovoides, apiculadas, 0.4-0.5 $\times$ 0.2-0.3 mm, rugosas, de color castaño, apéndices ausentes. $2 \mathrm{n}=$ desconocido.

Distribución general. Juncus ebracteatus se distribuye en las tierras altas de México y Guatemala, y en Sur América en los Andes desde Perú hasta Bolivia. En México crece en los estados de Aguascalientes, Chihuahua, Distrito Federal, Durango, Guanajuato, Guerrero, Hidalgo, Jalisco, México, Michoacán, Morelos, Oaxaca, 
Puebla, Querétaro, San Luis Potosí y Veracruz. McVaugh (1993) también la menciona para Chiapas.

Hábitat y fenología. Juncus ebracteatus se encuentra en elevaciones entre 1800-3200 metros por encima del nivel del mar, en terrenos mal drenados a la orilla de presas, canales, arroyos, lagos y lagunas localizados en zonas con pastizales o en sitios abiertos de diferentes tipos de bosques. Puede crecer de manera simpátrica con J. nodosus. Juncus ebracteatus florece y fructifica entre mayo a noviembre.

Nombres vernáculos y usos. Desconocidos.

Afinidades. Juncus ebracteatus es miembro del subgénero Juncus sección Ozophyllum que en México incluye ocho especies (ver J. acuminatus). La especie es fácilmente reconocible por sus rizomas largos, rastreros y estoloníferos, las flores con estilos largos y las cápsulas maduras con rostros que sobrepasan a los tépalos. También presenta anteras amarillas pálidas o blancas, más largas que los filamentos. Buchenau $(1890,1906)$ no consideró apropiado el nombre de J. ebracteatus por considerarlo engañoso.

Especímenes examinados. CHIAPAS: Amatenango del Valle, $1800 \mathrm{~m}$, 27.VII.1966, D. E. Breedlove 14626 (NY); Finca Carmen just below Mahosik', Tenejapa, 9.VIII.1966, D. E. Breedlove 14930 (NY, US); N end of San Cristóbal de Las Casas valley towards Chamula, $2200 \mathrm{~m}$, 3.IX.1974, D. E. Breedlove 37113 (MO, NY); $4 \mathrm{~km}$ NE of La Trinitaria along road to Monte Bello, $1550 \mathrm{~m}$, 17.XI.1984, G. Davidse et al. 29932 (MO); Amatenango del Valle, 1800 m, 5.IX.1966, A. Shilom Ton 1087 (NY). CHIHUAHUA: Majarachie, 8.IX.1939, I. Knobloch 5850 (US); 4 km S of Cd. Guerrero, 27.VIII.1971, L. McGill \& D. Keil 8345 (NY); 34 km N of Madera, 27.IX.1939, C. H. Muller 3521 (GH, UC); South-western Chihuahua, VIII-XI.1855, E. Palmer 247 (NY). DISTRITO FEDERAL; Valle de México, 2225 m, 21.VI.1897, C. G. Pringle 6652 (BR, CM, F, G, GH, GOET, K, M, MEXU, MO, NY, P, PH, S, UC, US, WU); Mexico City, 1899, J. N. Rose \& W. Hough 4942 (US). DURANGO: Durango, IV-XI.1896, E. Palmer 391 (F, GH, MO, NY, UC, US); Sierra Madre Occidental, El Salto, Aserraderos, 2530-2540 m, 28.VIII.1934, F. W. Pennell 18367 (GH, NY, PH, US); GUANAJUATO: 25 km al NNE de León, 8.VIII.1987, R. Galván \& J. D. Galván 2825 (MEXU). HIDALGO: Zacualtipan-Tianguistengo road km 5, 2100 m, 4.VII.1947, H. E. Moore, Jr. 3331 (GH, UC); Río Tula, Ixmiquilpan, 1750 m, 15.VII.1947, H. E. Moore, Jr. 3364 (GH); Rancho Nuevo 16 km ENE of Apam, 
$2700 \mathrm{~m}, R$. C. West K3 (WIS). JALISCO: Guadalajara, VII-X.1886, E. Palmer 241 (GH, MO, NY mixed with J. nodosus, P, PH, UC, US, W). ESTADO DE MÉXICO: $60 \mathrm{~km}$ NW of Toluca, 14.VIII.1947, F. A. Barkley et al. 2820 (F, US); Temascaltepec, Tequesquipan, 2480 m, 17.VIII.1932, G. B. Hinton 1332 (F, GH, LL, MO, NY, S, US); Temascaltepec, Cerro Muñeca, 2300 m, 19.VIII.1932, G. B. Hinton 1386 p.p. (F, GH, MO, NY, US); Criaderos, 3000 m, 3.IX.1950, E. Matuda 19391 (F, NY); Jilotepec, 2200 m, 21.IX.1952, E. Matuda 26919 (NY); near Tultenango, 13.VII.1901, J. N. Rose \& R. Hay 5426 (GH); near Halpam, 15.VI.1901, J. N. Rose \& R. Hay 5480 (GH); Nicolás Romero, San José del Vidrio, 2600 m, 12.IX.1982, A. Ventura A. 4095 (GH, MO); Pentecoste, 2200 m, 17.VIII.1982, A. Ventura A. 4109 (GH). MICHOACÁN: Morelia, Loma Sta. Maria, G. Arsène 6687 (P); Morelia, 18.VIII.1938, L. A. Kenoyer $A 570$ (ARIZ, F); $1 \mathrm{~km} \mathrm{~S}$ of Puentecillas, $5 \mathrm{~km} \mathrm{~N}$ of Ario de Rosales, 2200 m, 25.VII.1960, H. H. Iltis et al. 415a (UC); Mex. 15, $1 \mathrm{~km}$ E of Puerto de Gato, 29.VII.1965, R. Kral 25189 (MO); E of Jiquilpan, 21.VIII.1953, W. E. \& M. S. Manning 53122 (GH). MORELOS: Huitzilac, Lago Quila, 3050 m, 26.X.1987, I. Bonilla 347 (MO); Huitzilac, Lago Acomantla, 2810 m, 13.VIII.1988, I. Bonilla 487 (MO). OAXACA: Marquesado near Oaxaca, 1550 m, 11.VI.1896, C. Conzatti 215 (GH); Mixteca Alta, Teposcolula, $1 \mathrm{~km}$ E of San Isidro Lagunas, 2290 m, 11.X.1981, A. Garcia Mendoza 736 (MO); 7 miles north of city of Oaxaca, 30.VII.1947, L. A. Kenoyer 1623 (GH); 7 miles north of city of Oaxaca, 30.VII.1947, L. A. Kenoyer 1673 (GH); La Parada, 2300-2600 m, 19.VIII.1894, E. W. Nelson 994 (US); 31 km SW of Oxacaca, 2300-2900 m, 10-20.IX.1894, E. W. Nelson 1402 (F, US). PUEBLA: Acatzingo, Cepeaca, 1900 m, VII.1907, G. Arsène 1918 (NY). QUERÉTARO: Represa a $3 \mathrm{~km}$ al norte de Amealco rumbo a Quéretaro, $2525 \mathrm{~m}$, 28.IX.1999, A. Novelo $R$. \& L. Ramos V. 3809 (MO). SAN LUIS POTOSÍ: Sierra de San Miguelito S of San Luis Potosí, 1900-2000 m, 28.VII.1934, E. W. Pennell 17713 (GH, NY, PH, US); San Luis Potosí, 1877, I. G. Schaffner 218 (F, GOET, NY, US), I. G. Schaffner 551 (GH). VERACRUZ: Perote, Cruz Blanca, 2300 m, 21.IX.1938, E. K. Balls 5502 (US); Orizaba, 1855, F. Müller 1853, 1954, 1955 (NY); Acultzingo on Puebla border, 2300 m, 28.VII.1971, L. I. Nevling \& Gómez Pompa 2096 (F).

\section{Juncus effusus L., Sp. Pl. 1: 326. 1753.}

Lectotipo (designado por K. A. Lye en S. Edwards, D. Sebsebe \& I. Hedberg, 1997): EUROPA. [Smith:] Mr. W[oodward]; (LINN 449.6!). Figura 2 B.

Hierbas perennes, cespitosas, $50-100 \mathrm{~cm}$ de alto. Rizomas rastreros, 2-5 mm de diámetro, cubiertos por escamas de color oscuro o castaño, internodos muy cor- 
tos y los culmos surgiendo en filas densamente apiladas; culmos erectos, teretes, 2-6 mm de diámetro, externamente estriados por 40-60 trazas longitudinales de esclerénquima subepidérmico corriendo paralelas a los haces vasculares; médula continua, aerénquima con células asteriformes; catáfilos 3-5 por cada culmo, hasta $30 \mathrm{~cm}$ de largo, con láminas aciculares, rudimentarias de hasta $5 \mathrm{~mm}$ de largo, en general densamente envainadoras, de color castaño en la base y castaño claro o pajizo hacia el ápice. Hojas laminares ausentes. Inflorescencias pseudolaterales, con muchas flores, laxamente ramificadas, hasta $10 \times 20 \mathrm{~cm}$, o usualmente pequeñas y a veces aglomeradas, capituliformes, $1.5 \times 1.5 \mathrm{~cm}$, a veces subdivididas, cimas compuestas, consistiendo en varias cimas aglomeradas, las últimas drepanios unilaterales; brácteas inferiores de la inflorescencia surgiendo progresivamente de los culmos, 10-45 cm de largo, usualmente constituyendo $1 / 5$ o más de la altura total de la planta, ligeramente unidas a los culmos, vainas estrechas, brácteas parecidas a escamas o membranáceas. Flor abrazada por dos bractéolas, 0.7-2 $\mathrm{mm}$ de largo. Tépalos desiguales, lanceolados, $2-5 \mathrm{~mm}$ de largo, de color pajizo a castaño, los externos cóncavos, ligeramente más largos, los internos planos. Estambres tres, rara vez seis, 1-2 mm de largo; anteras lineares u oblongas, 0.3-1 mm de largo, más cortas que o iguales a los filamentos. Ovario con estilo muy corto; estigmas $0.6-1 \mathrm{~mm}$ de largo. Cápsula elipsoidal a obovoide, obtusa, trígona a trilobada, 1.5-5 × 1-2.5 mm, de color pajizo a castaño, triseptada. Semillas ovoides, asimétricas, cortamente apiculadas, 0.4-0.6 $\times 0.2-0.3 \mathrm{~mm}$, rugosas, de color amarillo o castaño, apéndices ausentes. $2 \mathrm{n}$ $=42$ (Harriman, 1979).

Distribución general. Juncus effusus es una especie cosmopolita, más frecuente en las regiones templadas del hemisferio norte, pero también en altas elevaciones de los trópicos y en las regiones templadas del hemisferio sur. Weimarck (1946) reportó la presencia de $J$. effusus en el Neotrópico desde las tierras altas de México y Centro América hasta Costa Rica, y en los Andes desde Colombia y Venezuela hasta Perú y Bolivia, el sureste de Brasil y Argentina y en las Antillas en la Española (Haití y República Dominicana) y Guadalupe. En México crece en los estados de Aguascalientes, Baja California, Chiapas, Chihuahua, Distrito Federal, Durango, Guanajuato, Hidalgo, Jalisco, Michoacán, Morelos, Oaxaca, Puebla, Querétaro, San Luis Potosí, Tabasco y Veracruz. McVaugh (1993) también la menciona para Sinaloa y el Estado de México.

Hábitat y fenología. Juncus effusus crece a largo de caminos en pastizales, acequias, canales y otros lugares perturbados por el hombre; también en laderas hú- 
medas, charcos a pleno sol, orillas de cuerpos de agua cerca de carreteras asociados a Equisetum, zonas inundadas en bosques de encino, encino-pino, arroyos y bosques de pinos y ciénagas con Sphagnum. En México se presenta entre 1700-2950 metros sobre el nivel del mar y puede crecer simpátricamente con J. ensifolius. Juncus effusus florece y fructifica a lo largo de todo el año.

Nombres vernáculos y usos. En Guatemala (Cobán) y Costa Rica (Dota) los culmos son usados para tejer tapetes (Standley, 1937; Standley y Steyermark, 1952).

Afinidades. Juncus effusus pertenece al subgénero Agathyron sección Juncotypus junto con $J$. aemulans, $J$. balticus y $J$. textilis. Esta especie se parece más a $J$. aemulans y $J$. textilis. En México y Centro América $J$. effusus comúnmente tiene inflorescencias laxas con muchas flores pequeñas de color pajizo con tépalos cortos de hasta $2 \mathrm{~mm}$ de largo. Tales caracteres concuerdan bastante bien con los de $J$. effusus subsp. solutus (Fernald \& Wiegand) Hämet-Ahti, presente en Norte América (Hämet-Ahti, 1980). Sin embargo, se diferencia porque la primera tiene los tépalos suaves mientras que son duros en J. effusus subsp. solutus.

Especímenes examinados. AGUASCALIENTES: Río Pabellón 11.5 km from San José de Gracia, 12.VI.1979, M. González G. 127 (MEXU). BAJA CALIFORNIA: Sierra San Pedro Mártir, head of Arroyo Copal, 16.VII.1988, S. Boyd \& T. Ross 2543 (F, MO); Sierra San Pedro Mártir, Arroyo Copal, 2000 m, 25.VIII.1968, R. Moran 15506 (SD, US); Arroyo Jatay, from Hwy 1 crossing upstream ca. 15 miles, inland from Bajamr near site of Jatay, 75-100 m, 27.VII.2001, A. C. Sander y M. Elvin 24515 (MO). CHIAPAS: Yal Ichin, Chamula, 2100 m, 26.VIII.1964, D. E. Breedlove 7140 (F, US); Tenejapa, Shohleh, 2400 m, 2.X.1965, D. E. Breedlove 12739 (US); Tenejapa, Sibakte'el, 1800 m, 6.VIII.1966, D. E. Breedlove 14806 (NY); Hghw. 195 between Ixtapa and Pichucalco, 9 km SE of Jitotol, 1700 m, 17.II.1979, T. B. Croat 47733 (MO); San Cristóbal de las Casas, 2200 m, 12.IV.1966, R. M. Laughlin 643 (US); carr. de la desviación de Villahermosa-San Cristóbal de las Casas a $1.8 \mathrm{~km}$, después del pueblo Soyalo a $2.5 \mathrm{~km}$ al norte de Telestaquin 14.VI.1981, M. A. Magaña \& S. Zamudio 288 (MO); Santa Cruz en San Felipe, 15.XI.1986, A. Mendez Ton \& M. Concepción Mtz. de López 9757, 9873 (MO); Tenejapa, Paraje Balum K'anal, 2500 m, 13.IV.1966, A. Shilom Ton 828 (F, NY); Tenejapa, Paraje Matsab, 2700 m, 12.IV.1966, A. Shilom Ton 915 (GH, NY). CHIHUAHUA: Majalca, 24.VI.1936, H. LeSueur 1115 (US); Majalca, 24.VI.1936, H. LeSueur 1121 (PH); Río Chico, 22.VI.1937, H. LeSueur 1285 (F, GH, UC, US). DISTRITO FEDERAL: Tlal- 
pan, 22.VI.1897, C. G. Pringle 7518 (GH, US). GUANAJUATO: Amealco-Acámbaro road km 100, 2000 m, 23.III.1980, E. Argüelles 1341 (MEXU). HIDALGO: Tenango de Doria, road to Santa María, 1300 m, 16.IV.1980, J. Gimate L. 586 (GH, NY); El Protrero, Metepec-Tenango de Doria road, 2100 m, 1.V.1973, J. Gimate L. 979 (GH, NY); $3 \mathrm{~km}$ al NE de Agua Blanca, sobre el camino a San Pedrito, 23.II.1964, L. Gonzalez Q. 392 (GH); 5 km E of Tenango de Doria, 1700-1800 m, 26.III.1980, R. Hernández Magaña \& R. Hernández V. 4162 (MO); Zoquizoquipan, $5 \mathrm{~km} \mathrm{~N}$ of Zacualtipan, 2200 m, 21.XII.1981, R. Hernández M. 6930 (MO); ZacualtipanTianguistengo road, km 5, 2100 m, 4.VII.1947, H. E. Moore Jr. 3328 (GH, US); borde suroeste de la presa, lagunetas y planos inundados que la rodean, aprox. $500 \mathrm{~m}$ al sur de Umécuaro, 2240 m, 26.VIII.1999, A. Novelo \& L. Ramos 3685 (MO); lagunetas y zonas pantanosas aledañas a la cortina de la presa que se encuentra el poblado Umécuaro, aprox. $40 \mathrm{~km}$ al sur de Morelia, 26.VIII.1999, A. Novelo \& L. Ramos 3706 (MO); lago Zirahuén a $6 \mathrm{~km}$ SO de Pátzcuaro, 2095 m, 8.VIII.2000, A. Novelo \& L. Ramos 4001 (MO). JALISCO: Sierra de Manantlán, H. H. Iltis et al. 2395 (WIS). ESTADO DE MÉXICO: Temascaltepec, Guaybal, 2.XII.1933, G. B. Hinton 3379 (NY); Temascaltepec, Comunidad, 2480 m, 14.III.1933, G. B. Hinton 3487 (NY, US); Valle de Allende, 5.X.1952, E. Matuda 26430 (NY); Cerro de Corona, Zacualpan, 2000 m, 2-3.V.1954, E. Matuda 30721 (US); Cerro de Acatitlán, 2000 m, 28-29.III.1954, E. Matuda 30766 (US); Jilotepec, 2450 m, 27.VI.1954, E. Matuda 30958 (US); Estancia Vieja, $10 \mathrm{~km} \mathrm{~S}$ of Temascaltepec, 17.IV.1973, S. Moreno G. 130 (GH, NY); $1.5 \mathrm{~km}$ al NE de San Pablo Ixayoc, $2480 \mathrm{~m}$, Rivas \& Campos 396 (GH); Tultenango, 13.VII.1901, J. N. Rose \& R. Hay 5425 (GH, US); 2 km SE of Tepotzotlán, 2550 m, 8.X.1972, J. Rzedowski 29490 (NY); Vicente Guerrero, San Pedro Villa Nicolás Romero, 2200 m, 23.VIII.1978, A. Ventura A. 3268 (GH, NY); canales aledaños a la ENEP plantel, Cuautitlán, 2250 m, 10.I.1982, A. Velásquez P. s.n. (MO); MICHOACÁN: Barroloso, Coalcoman, 2400 m, 21.X.1939, G. B. Hinton 15363 (GH, NY, UC, US); Río del Salto-La Polvilla 29 km E of Morelia, 2200-2450 m, 9-18.XI.1961, R. M. King \& T. R. Soderstrom 5121 (NY, TEX, UC, US). MORELOS: Valle de México, Cuernavaca, 1800 m, 5.IV.1952, E. Matuda 26095 (NY). OAXACA: Juxtlahuaca, a la orilla del pueblo de Coicoyán, a $200 \mathrm{~m}$ del camino a Tilapa, $1950 \mathrm{~m}, 31 . I I I .1986$, A. de Ávila B. 42 (MO); Zempoatepetl near Ayutla, 19-27.II.1937, W. H. Camp 2749 (NY); Teotitlan, San Bernardino, 11.XII.1907, C. Conzatti 2129 (F); S. Comaltepec, 2000 m, 16.V.1986, S. Hernández López \& G. J. Martin 62a (MO); Vista Hermosa, Comaltepec, Tuxtepec-Oaxaca road, Sierra Juárez km 130, 1700 m, 26.V.1966, G. Martínez Calderón 860 (NY); Tlalpancingo, 1800-2400 m, 7.XII.1894, E. W. Nelson 2063 (F, US). PUEBLA: Apulco, W. Boege 1361 (MEXU). QUERÉTARO: represa 
a $3 \mathrm{~km}$ al norte de Amealco rumbo a Querétaro, $2525 \mathrm{~m}$, 28.IX.1999, A. Novelo $R$. \& L. Ramos V. 3810 (MO). SINALOA: $2 \mathrm{~km} \mathrm{SW}$ of Zaragoza, 25.IV.1958, R. W. Dickerman 1036 (GH); Ocurahui, Sierra Surotato, 1800-2100 m, 1-10.IX.1941, H. S. Gentry 6301 (ARIZ, GH, MO, NY); TABASCO: Villahermosa-San Cristóbal de las Casas $1.8 \mathrm{~km}$ after Pueblo Soyalo, $2.5 \mathrm{~km} \mathrm{~N}$ of Telestaquin, 19.II.1982, M. A. Maga$\tilde{n} a \&$ S. Zamudio 288 (NY). VERACRUZ: Ixhuatlancillo nr. Orizaba, M. Bourgeau 2592 (P); Viborillas, 2200, 26.IV.1971, R. Hernández \& R. Cedillo T. 1212 (MO); Sta. Rita, Sierra Chiconquiaco, 1500 m, A. Gómez Pompa 1809 (GH); Puente Acabaloya, ca. $1 \mathrm{~km}$ SE of Xico Viejo and $5 \mathrm{~km} \mathrm{NW}$ of Xico along trail between the two, 1600 m, 31.III.1983, M. Nee \& K. Taylor 26319 (F, NY, XAL); Nr. Viborillas, Huayacocotla, 2170 m, 26.IV.1983, M. Nee \& K. Taylor 26768 (F, NY, XAL); camino de Apulco a Hueyacocotla, $2000 \mathrm{~m}$, F. Moreno 592 (GH-2); Huayacocotla-Zontecomatlan road $1 \mathrm{~km}$ NE of Agua de La Calabaza, $10 \mathrm{kms}$ (air) NNE of Huayacocotla, $1900 \mathrm{~m}$, 27.IV.1983, M. Nee \& K. Taylor 26897 (F, NY, XAL); Xoampolco, 1700 m, 2.I.1970, F. Ventura A. 305 (GH); El Carrizal, 2270 m, 9.XI.1971, F. Ventura A. 2270 (GH).

15. Juncus ensifolius Wikstr., Kongl. Vetensk. Acad. Handl. 2: 274. 1823. Tipo: ESTADOS UNIDOS DE AMÉRICA. Alaska, 'Unalaska', W. G. Tilesius s.n. (holo-: S, n.v.).

EJuncus iridifolius Willd. ex Kunth, Enum. Pl. 3: 337. 1841, nom. inval.

Hierbas perennes, 30-80 $\mathrm{cm}$ de alto. Rizomas rastreros y ascendentes, 3-5 $\mathrm{mm}$ de diámetro, internodos 1-4 cm de largo; escamas membranosas, de color marrón, hasta $1 \mathrm{~cm}$ de largo, hasta $1 \mathrm{~cm}$ distantes entre sí; culmos erectos, $1.5-6 \mathrm{~mm}$ de ancho, frecuentemente curvados, lateralmente comprimidos con márgenes filosos y estrechamente alados, lisos o longitudinalmente estriados. Hojas laminares 2-6 basales y 2-5 caulinares, las basales hasta $40 \mathrm{~cm}$ de largo, las distales más cortas; vainas ocupando la mitad o más de la longitud de la lámina, fuertemente carinadas, con márgenes papirosos y membranosos que gradualmente desaparecen o terminan en aurículas inconspicuas; láminas lateralmente comprimidas, 3-8 $\mathrm{mm}$ de ancho, con márgenes filosos o estrechamente alados, a veces con particiones transversales parciales pero nunca con septos completos. Inflorescencia una antela compuesta, hasta $20 \times 8 \mathrm{~cm}$ pero usualmente más pequeña y a veces solo $4 \times 2 \mathrm{~cm}$; cabezuelas de flores (2-)5-50, globosas a semi-globosas, 6-12 mm de diámetro; brácteas inferiores de la inflorescencia ensiformes, brácteas distales más cortas, membranosas, brácteas florales tan largas como las flores. Flores de color pajizo o castaño. Tépalos iguales o los externos ligeramente más largos que los internos, 2.5-3.5 mm de largo, 
linear-lanceolados, agudos, los externos cóncavos o ligeramente carinados, los internos aplanados. Estambres seis, 1-1.5 mm de largo; filamentos filiformes, anchos en la base; anteras 0.4-0.7 mm de largo, más cortas que los filamentos. Ovario con el estilo 0.3-0.4 mm de largo; estigmas ca. $1 \mathrm{~mm}$ de largo. Cápsula elipsoidal, rostrada, trígona, 3-4 mm (incluyendo el rostro) $\times$ 0.7-0.8 mm, ligeramente más larga que los tépalos, de color pajizo a ligeramente castaño brillante, unilocular. Semillas elipsoidales, apiculadas, ca. $0.5-0.3 \mathrm{~mm}$, reticuladas, de color castaño. $2 \mathrm{n}=40$ (Harriman y Redmond, 1976).

Distribución general. Juncus ensifolius se distribuye en Norte América desde Alaska hasta California y hacia el este hasta Texas, hacia el sur hasta México. También se encuentra en las islas Kuriles (Rusia) y Japón e introducida en la costa este de Estados Unidos de América, Europa, Nueva Zelanda y Hawái (Kirschner, 2002b). En México se registra de los estados de Baja California, Chihuahua, Distrito Federal, Durango, Guerrero, México, Puebla, San Luis Potosí, Sonora y Veracruz.

Hábitat y fenología. Juncus ensifolius crece en lugares húmedos entre 1850 y 3500 metros sobre el nivel del mar. La especie florece y fructifica entre julio y agosto.

Nombres vernáculos y usos. Desconocidos.

Afinidades. Juncus ensifolius es una de tres especies mexicanas del subgénero Juncus sección Iridifolii, una sección probablemente polifilética con 10 especies distribuidas principalmente en el oeste de Norte América y el este de Asia (Kirschner, 2002b). Juncus ensifolius ha sido dividida en varias entidades como especies u otras categorías infraespecíficas. En la Flora Intermontana (Cronquist et al., 1977) se reconoce una especie y tres variedades: Juncus ensifolius var. ensifolius, J. ensifolius var. montanus y J. ensifolius var. brunnescens. Las tres variedades se sobrelapan en sus rangos geográficos y su variación morfológica, y en su conjunto parecen reflejar la situación de todo el complejo. El material del centro y sur de México concuerda tanto con J. ensifolius var. ensifolius (e.g. Rzedowski 26793; Galván 688, 699) como con J. ensifolius var. montanus (e.g. Parry \& Palmer W), mientras que algunos ejemplares del norte de México (Chihuahua, LeSueur 1125, NY) coinciden con J. ensifolius var. brunnescens.

Especímenes examinados. BAJA CALIFORNIA: Sierra San Pedro Mártir, 2500 m, 16.VIII.1967, R. Moran \& R. F. Thorne 14164 (ARIZ, UC). CHIHUAHUA: 
2 miles N of Basaseachic Falls, 2100 m, 26.VI.1991, R. Spellenberg s.n. (ARIZ); Cascada de Basaseachic, 1900 m, 24.VI.1987, T. R. Van Devender 87-171 (ARIZ); Majalca, 24.VI.1936, LeSueur 1125 (MO, NY, UC). DURANGO: Santiago Papasquiaro, $3.5 \mathrm{~km}$ E of La Soledad, $11 \mathrm{~km} \mathrm{NW}$ of Santiago Papasquiaro, 1900-2100 m, 7.VII.1983, R. Corral Diaz \& R. D. Worthington 10862 (ARIZ). ESTADO DE MÉXICO: 8 km S of Río Frío, Arroyo Aculco, Ixtapaluca, 3200 m, 17.IX.1980, $R$. Galván 688 (AAU); NW slope of Popocatépetl near Paso de Cortés, 3500 m, J. Rzedowski 26793 (AAU); PUEBLA: E slope of Ixtaccihuatl above San Juan Tlale and San Juan Tetla, H. Ern 313 (ENCB). SAN LUIS POTOSÍ: San Luis Potosí, Schaffner 220 (BREM, GOET, M); Morales, 1855, Schaffner 549 (K, MEXU). SONORA: Sierra de los Ajos, 2300 m, 10.X.1992, R. S. Felger 92-895 (ARIZ); Sierra de los Ajos, 2300 m, 10.X.1992, R. S. Felger 92-901 (ARIZ); arroyo del Púlpito near Colonia Oaxaca, 30.VII.1938, S. S. White 720 (ARIZ).

16. Juncus imbricatus Laharpe, Essai Mongr. Jonc. 61. 1825.

Sintipos: ARGENTINA. Buenos-Ayres, P. Commerson s.n. (P, n.v.); CHILE. Concepción: sin localidad precisa, M. Lesson s.n. (K!). Figura 3 C, D, 6.

= Juncus capillaceus Lam. var. chilensis Buchenau, Abh. Naturwiss. Vereine Bremen 6: 377. 1879.

Sintipos: CHILE. Sin localidad precisa, A. Chamisso s.n. (W, n.v.); CHILE. Concepción: sin localidad precisa, $K$. H. Mertens s.n. (BR, n.v.).

= Juncus pringlei Fernald, Proc. Amer. Acad. Arts 45(17): 416. 1910.

Tipo: MÉXICO. Oaxaca, Cuesta de San Juan del Estado, 2125 m, 21.VIII.1894, C. G. Pringle 5818 (holo-: GH!; iso-: MEXU!).

Hierbas perennes, cespitosas, $15-45 \mathrm{~cm}$ de alto. Rizomas rastreros, 2-3 $\mathrm{mm}$ de diámetro, cubiertos con una capa filamentosa de color castaño correspondiente a restos de trazas de esclerénquima formados por la aberturas de los catáfilos y la base de las hojas; internodos muy cortos y los culmos surgiendo en densas filas; culmos erectos, canaliculados, 0.5-1.5(-1.8) mm de diámetro; catáfilos 3-4 por cada culmo, hasta $5 \mathrm{~cm}$ de largo, de color castaño o los superiores a veces de color amarillo-castaño o verde pálido, con láminas rudimentarias de $5 \mathrm{~mm}$ de largo. Hojas todas basales, 1-2 por cada culmo, 10-35 cm de largo; vainas de 1.5-6 cm de largo con márgenes membranosos terminando en dos aurículas de 0.3-0.5 mm de largo; láminas filiformes, 0.6-1 $\mathrm{mm}$ de diámetro, canaliculadas y obtusamente-anguladas, con una hendidura adaxial en la base. Inflorescencia terminal, compuesta, 1-30 flores, en (1-)2-4 grupos, cimas unilaterales (drepanios); brácteas inferiores de la inflorescencia recordando a 
las hojas basales, herbáceas, hasta $8 \mathrm{~cm}$ de largo y excediendo la inflorescencia, o más cortas que la inflorescencia, brácteas distales progresivamente más cortas, las últimas membranáceas, hasta $3 \mathrm{~mm}$ de largo. Flor abrazada por dos bractéolas, 1.5-2 $\mathrm{mm}$ de largo. Tépalos desiguales, lanceolados, agudo, costilla media de color verde, tornándose castaño, márgenes de color castaño, membranáceos en la madurez del fruto, los externos 3.5-5 mm de largo, los internos de 3-4 mm de largo. Estambres seis, 1.7-2.1 mm de largo; anteras lineares, $0.8-1 \mathrm{~mm}$ de largo. Ovario con estilo de 0.1-0.2 mm de largo; estigmas de 0.4-0.8 $\mathrm{mm}$ de largo. Cápsula elipsoidal, apicalmente obtusa a truncada, trígona con los lados algo cóncavos, 3.5-5 × 1.8-2.5 mm, de color castaño, brillante en la madurez, paredes gruesas no mostrando la impresión de su interior. Semillas anchamente ovoides, asimétricas, ligeramente apiculadas, 0.4$0.6 \times 0.2-0.3 \mathrm{~mm}$, rugosas, de color castaño, apéndices ausentes. $2 \mathrm{n}=$ desconocido.

Distribución general. Juncus imbricatus se distribuye principalmente en Sur América en los Andes, desde Colombia hasta Uruguay, Argentina y Chile. Tam-



Fig. 6. Mapa de distribución de los especímenes examinados de Juncus imbricatus $(\bullet), J$. longistylis ( $\mathbf{\Lambda}$ ) y J. macrophyllus (ロ). 
bién se encuentra presente en México, Sur África, Australia y Europa (Portugal), probablemente introducida (Kirschner, 2002c). En México crece en los estados de Hidalgo, México, Oaxaca, Tlaxcala y Veracruz.

Hábitat y fenología. Juncus imbricatus es una maleza en los márgenes de los caminos y campos abandonados y crece entre 2200-2700 metros sobre el nivel del mar. Florece y fructifica en septiembre.

Nombres vernáculos y usos. Desconocidos.

Afinidades. Juncus imbricatus forma parte del subgénero Agathryon sección Steirochloa junto con $J$. dichotomus, $J$. dudleyi y $J$. tenuis. A diferencia de estas especies tiene los rizomas rastreros horizontalmente cubiertos de restos de las bases de las hojas y catáfilos y los internodos cortos con tallos en densas filas, mientras que en las demás especies los rizomas están densamente ramificados, las ramas son cortas o ascendentes, usualmente no rastreras ni cubiertas de restos de las bases de las hojas y catáfilos y los internodos son de longitud variable, y los tallos por lo común se disponen en densas macollas.

Especímenes examinados. HIDALGO: Laguna Hueyapan, Hacienda de San Juan Hueyapan a $14 \mathrm{~km}$ de Tulancingo, 2300 m, 10.VII.2005, M. L. Carmono 311 (MO); $1 \mathrm{~km} \mathrm{~W}$ of Nopalillo, Epazoyucan, 2700 m, 15.III.1981, R. Galván 750 (MO); Cerro de Santa Ana, Tepeapulco, 2700 m, 25.IX.1975, A. Ventura A. 310 (ARIZ, MO); Ranchería Los Sides, Tepeapulco, 2450 m, 3.VII.1976, A. Ventura A. 1720 (MO). ESTADO DE MÉXICO: Texcoco, Baños de Netzahualcóyotl, 2500 m, 2.VIII.1976, S. D. Koch 76129 (CHAPA, ENCB, MEXU); Pentecostés, Texcoco, 2200 m, 15.XII.1982, E. Ventura V. 398 (NY, SD). TLAXCALA: Barranca el Campanario, Hacienda Tecomaluca, Tlaxco, $2600 \mathrm{~m}$, Aguilar 8-E-13 (ENCB). VERACRUZ: Llano Grande near El Puerto, 2300 m, 13.IX.1944, A. J. Sharp 44806 (GH, MEXU).

17. Juncus interior Wiegand, Bull. Torrey Bot. Club 27: 516. 1900.

Tipo: ESTADOS UNIDOS DE AMÉRICA. Illinois. Richview, G. Vasey s.n. (holo-: GH). $=$ Juncus arizonicus Wiegand, Bull. Torrey Bot. Club 27: 517. $1900 \equiv$ Juncus interior var. arizonicus (Wiegand) F. J. Herm., J. Wash. Acad. Sci. 30: 217. 1940.

Tipo: ESTADOS UNIDOS DE AMÉRICA. Nuevo Mexico, Copper Mines, G. Thurber 238 (holo-: GH). 
Hierbas perennes, cespitosas, 20-60 cm de alto. Rizomas cortos, densamente ramificados; culmos erectos, teretes, lisos o longitudinalmente estriados, catáfilos 1-3 por culmo. Hojas laminares 1-2(-3) por culmo, 5-15 cm de largo, todas basales, erectas; vainas de color verde pálido o rojizo, terminando en dos aurículas, 0.20.4(-0.6) $\mathrm{mm}$ de largo, escariosas, de color blanquecino o rojizo; láminas planas y canaliculadas en sección transversal, 0.5-1.1 mm de ancho. Inflorescencia con apariencia de antela o de cimas unilaterales, 1.5-7 cm de largo, con (5-)10-30(50) flores, terminal en el culmo, ocupando menos de 1/4 del tamaño total de la planta, compuesta, cimosa, formada por varias cimas unilaterales (drepanios); brácteas inferiores de la inflorescencia semejantes a las hojas basales, herbáceas, 1-10 cm de largo, más cortas que la inflorescencia, las distales progresivamente más cortas, las últimas membranosas, hasta $5 \mathrm{~mm}$ de largo; bractéolas dos por cada flor, anchamente ovadas, membranáceas, $1.2-1.7 \mathrm{~mm}$ de largo. Tépalos subiguales o los externos un poco más largos, 3-3.8(-4.4) $\mathrm{mm}$ de largo, lanceolados, agudos a acuminados, inicialmente con una banda verde a lo largo de la línea central, cambiando a color pajizo, márgenes membranáceos distintivos. Estambres seis, 0.9-1.5 mm de largo; filamentos 0.5-0.9 mm de largo, anteras 0.4-0.6 mm de largo. Ovario con estilo 0.1$0.2 \mathrm{~mm}$ de largo; estigmas ca. 1.5-2 mm de largo. Cápsula unilocular, anchamente elipsoidal a subglobosa, obtusa, (3.3-)3.8-4.7 $\mathrm{mm}$ de largo, igual a o un poco más larga que los tépalos cuando madura, de color pálido o más oscuro. Semillas elipsoidales, frecuentemente curvadas, 0.4-0.6 mm de largo, muy poco apendiculadas. $2 \mathrm{n}$ $=80$ (Harriman y Redmond, 1976).

Distribución general. Juncus interior crece en el sur de Canadá, oeste y centro de los Estados Unidos de América y norte de México (Coahuila y Durango).

Habitat y fenología. Juncus interior crece en sitios secos y vegetación secundaria a lo largo de caminos, muchas veces en lugares elevados. Florece y fructifica en julio y agosto.

Nombres vernáculos y usos. Desconocidos.

Afinidades. Pertenece a Juncus subgénero Agathryon sección Steirochloa con 35 especies con las flores en cimas terminales y cada flor abrazada por dos bractéolas. Son perennes con las hojas lineares angostas pero claramente bifaciales. En México el grupo tiene cinco especies (J. imbricatus, J. tenuis, J. dudleyi, J. dichotomus y $J$. interior). 
Especímenes examinados. COAHUILA: Sierra del Carmen, $17 \mathrm{~km}$ by road from Hda. Rancho El Jardín, 1750 m, 28.VII.1973, M. C. Johnston 11875 (MO). DURANGO: By Mex 40, 2.3 mi north-east of El Soldado, 25.VIII.1965, R. Kral 25729 (MO).

18. Juncus liebmannii J. F. Macbr., Field Mus. Nat. Hist., Bot. Ser. 11(1): 9. 1931.

Hierbas perennes, hasta $65 \mathrm{~cm}$ de alto. Rizomas rastreros, 0.5-7 mm de diámetro, escamas ausentes o pocas, membranáceas, internodos de $0.5-1 \mathrm{~cm}$ de largo; culmos erectos, en general ligeramente flexuosos, 1-2.5 mm de diámetro; catáfilos 0-3 por cada culmo, $1.5-7 \mathrm{~cm}$ de largo, rojizos cuando jóvenes, de color castaño pálido con márgenes membranáceos distintivos con el tiempo, láminas rudimentarias hasta $2 \mathrm{~mm}$ de largo. Hojas laminares 1-4 basales y 1-2 caulinares por cada culmo, 10-30 cm de largo; vainas de 3-12 cm de largo, márgenes membranáceos terminando en dos aurículas, 0.3-1.3 mm de largo, redondeadas a agudas, escariosas; láminas 1-2.5 $\mathrm{mm}$ de diámetro, elípticas a redondas en sección transversal, lateralmente comprimidas, ahuecadas, noduladas por septos, $5-15 \mathrm{~mm}$ aparte, pero a veces inconspicuas. Inflorescencia terminal, racimo compuesto, últimas ramas con tres o muchas flores juntas; brácteas inferiores de la inflorescencia hasta $12 \mathrm{~cm}$ de largo, semejantes a las hojas caulinares, a veces membranáceas y cortas, hasta $2 \mathrm{~cm}$ de largo, brácteas distales más cortas, las últimas escariosas y hasta $4 \mathrm{~mm}$ de largo, brácteas florales hasta $3 \mathrm{~mm}$ de largo. Tépalos subiguales, lanceolados, de color castaño, a veces con la costilla media verde y los márgenes castaños en la base, los externos 2.3-3 mm de largo, agudo-acuminados con un mucrón subulado, carinados o con forma de $\mathrm{V}$ en sección transversal, al menos cuando jóvenes, los internos 2-6 mm de largo, aplanados, agudos con un mucrón subulado. Estambres seis, 1.1-1.8 mm de largo, verticilo interno a veces ligeramente más corto que el exterior; filamentos $0.8-1 \mathrm{~mm}$ de largo, aplanados o filiformes, ligeramente ensanchados en la base; anteras oblongas, 0.4$0.8 \mathrm{~mm}$ de largo, 1-2 veces más largas que los filamentos. Ovario con estilo 0.2-0.3 $\mathrm{mm}$ de largo; estigmas 0.8-1 mm de largo. Cápsula elipsoidal a elíptica, apiculada, trígona, tornándose 3-quillada antes de la dehiscencia, 2-3 × (0.9-)1-1.6 mm, a veces más larga que los tépalos, en la madurez de color castaño oscuro, unilocular. Semillas elipsoidales, apiculadas, 0.4-0.5 $\times 0.2 \mathrm{~mm}$, con un patrón conspicuamente reticulado, de color amarillo-castaño, apéndices ausentes. $2 \mathrm{n}=$ desconocido.

Distribución general. Juncus liebmannii se distribuye desde México y Centro América hasta Sur América, en los Andes de Colombia y Ecuador. Existen tres va- 
riedades pero solo dos en el país. En México se encuentra en Chiapas, Chihuahua, Distrito Federal, Durango, Hidalgo, Jalisco, Estado de México, Michoacán, Morelos, Oaxaca, Puebla, San Luis Potosí, Sinaloa, Sonora, Veracruz y Zacatecas.

Clave para las variedades de Juncus liebmannii en México

1. Inflorescencias con 1-2(-4) glomérulos J. liebmanii var. liebmannii

1. Inflorescencias con 10-30 cabezuelas J. liebmanii var. polycephalus

\subsection{Juncus liebmannii J. F. Macbr. var. liebmannii}

$\equiv$ Juncus brevifolius Liebm., Mexic. Juncac. 40. 1850, nom illeg., non Rostkov, 1801. = Juncus brevifolius var. mexicanus Buchenau, Bot. Jahrb. Syst. 12: 355. 1890.

Tipo: MÉXICO. Puebla, Chinantla, 2150 m, V.1841, F. M. Liebmann s.n. (holo-: C!; iso-; foto del holo-: BH!, G!, GH!, K!, MO!, P!).

Hierbas perennes, (15-)20-50(-65) cm de alto. Rizomas 1.5-3 mm de diámetro; catáfilos 0-3 por cada culmo, $1.5-7 \mathrm{~cm}$ de largo. Hojas basales 1-4 y 1-2 caulinares por cada culmo, 10-30 cm de largo; vainas de 3-12 cm de largo, terminando en dos aurículas, 0.3-1.3 mm de largo, escariosas; láminas 1-2.5 $\mathrm{mm}$ de diámetro, elípticas a redondas en sección transversal, lateralmente comprimidas, ahuecadas, noduladas por la presencia de septos, éstos distantes entre sí 5-15 mm, pero a veces inconspicuos. Inflorescencia 1-7 × 1-3 cm, con 1-2(-4) cabezuelas; cabezuelas 8-10(-20) mm de ancho. Tépalos casi iguales, lanceolados, los externos 2.3-3 mm de largo, los internos 2-2.5 mm de largo, aplanados. Estambres seis; anteras más cortas que los filamentos. Cápsula elipsoidal, 2-3 $\times(0.9-) 1-1.6 \mathrm{~mm}$, a veces más larga que los tépalos. $2 \mathrm{n}=$ desconocido.

Distribución general. Juncus liebmannii var. liebmannii se distribuye en México, Guatemala y Panamá. En México se encuentra en Chiapas, Chihuahua, Distrito Federal, Durango, Hidalgo, Estado de México, Michoacán, Morelos, Puebla, Oaxaca, San Luis Potosí y Veracruz. McVaugh (1993) también la menciona para Jalisco y Zacatecas.

Hábitat y fenología. Juncus liebmannii var. liebmannii crece en pantanos y ciénagas a lo largo de arroyos, a veces en bosques de Pinus hartwegii, en elevaciones entre 2100-3200 metros por arriba del nivel del mar. Florece desde agosto hasta noviembre y fructifica en noviembre. 
Nombres vernáculos y usos. Desconocidos.

Afinidades. Juncus liebmannii var. liebmannii es miembro del subgénero Juncus sección Ozophyllum, con 84 especies y ocho en México (ver J. acuminatus $y$ J. chiapasensis). Las hojas laminares de J. liebmannii son lateralmente comprimidas así que superficialmente son similares a las de J. ensifolius (subgénero Juncus sección Iridifolii). La lámina de J. liebmannii es sin embargo claramente unitubular y septada en sección transversal, ocupando la sección completa del tubo.

Especímenes examinados. CHIAPAS: Tenejapa, Ach’lum, 2775 m, 23.VIII.1966, D. E. Breedlove 15252 (DS, F, GH, MEXU, MO, US); Tenejapa, NE of Matsab, 2800 m, 25.VIII.1966, D. E. Breedlove 15276 (F, MO); Tenejapa, Paraje Matsab, 2600 m, 25.V.1966, A. Shilom Ton 974 (NY). CHIHUAHUA: Majalca, 24.VI.1936, H. LeSueur 1100 (GH, UC, US); Majalca, 24.VI.1936, H. LeSueur 1126 (GH); Sierra Madre, 2900 m, 3.X.1887, C. G. Pringle 1388 (GH, NY, PH, US); sin localidad precisa, VIII-XI.1885, E. Palmer $63 b$ (GH, US). DISTRITO FEDERAL: San Miguel, VI.1936, E. Lyonnet 1288 (US); Desierto de los Leones, 1938, E. Lyonnet 2149 (US); 4o. Dinamo de Contreras, 3000 m, 8.VIII.1965, J. Rzedowski 20403 (MO). DURANGO: 7 km E of El Salto, 100 km SW of Durango, 13.VIII.1957, U. T. Waterfall 13695 (US). HIDALGO: Real del Monte-El Chico road above Pueblo Nuevo, below Parque Nacional El Chico, 3000 m, 6.VII.1948, H. E. Moore, Jr. \& C. E. Wood. Jr. 3708 (A); Canales Station, 1850 m, 31.VII.1904, C. G. Pringle 10011 (CAS, ENCB, F, GH, IJ, SD, UC, US, WIS). ESTADO DE MÉXICO: Temascaltepec, Comunidad, 2460 m, 8.IX.1932, G. B. Hinton 1564 (GH, NY, US); Nevado de Toluca, X.1903, I. N. Rose \& I. H. Painter 7930 p.p. (NY, el pliego de este número en US es J. balticus subsp. ater), 15.X.1903, J. N. Rose \& J. H. Painter 7931 (US); Valle de Mexico, 2400 m, VIII.1855, W. Schaffner 532 (MO). MICHOACÁN: 4 km al E de San José de la Cumbre, carretera Morelia-Mil Cumbres, sobre el camino a Mil Cumbres, 23.II.1986, J. Rzedowski 40449 (MO). MORELOS: Lagunas Zempoala, 17.IX.1938, E. Lyonnet 2483 (US). SAN LUIS POTOSÍ: 18002400 m, 1878, C. C. Parry \& E. Palmer 894 1/2 (MO). VERACRUZ: Cruz Blanca, Perote, 2300 m, 21.IX.1938, E. K. Balls et al. 5501 (K, UC, US); Actopan, Cofre de Perote, 14.IX.1938, E. K. Balls 5451 (K, UC, US).

18.2. Juncus liebmannii var. polycephalus Balslev, Ann. Missouri Bot. Gard. 75: 381. 1988.

Tipo: MÉXICO. Chiapas, Southern city limits of Teopisca, $1800 \mathrm{~m}$, D. E. Breedlove 15065 (holo-: DS-609015!; iso-: MICH!, NY!). Figura 7 A, B. 
Hierbas perennes. Rizomas rastreros, 0.5-7 mm de diámetro; catáfilos 0-1 por cada culmo. Hojas basales 1-3, hojas caulinares 1-2, 10-30 cm de largo, vainas con los márgenes terminados en dos aurículas redondeadas a agudas, 1-3.2 mm, membranáceas; láminas teretes, $1.5-31 \mathrm{~cm}, \times 0.5-2.2 \mathrm{~mm}$. Inflorescencias 4-9 $\times$ 1.5-3 cm, 10-30 flores, cabezuela 5-6 mm de diámetro. Tépalos lanceolados, los externos 2.8-6.2 mm, agudos a acuminados con un mucrón subulado, los internos 2.4-6 mm, agudos a acuminados con mucrón subulado. Estambres seis; anteras 1-2 veces más largas que los filamentos. Cápsula elíptica, 2.3-3.7 mm, incluida a ligeramente exserta, rostrada. Semillas elipsoidales, 0.4-0.5 mm, sin apéndice. $2 \mathrm{n}$ $=$ desconocido.

Distribución general. Juncus liebmannii var. polycephalus crece en México y Guatemala. En México se distribuye en Chiapas, Chihuahua, Durango, Jalisco, Sinaloa, Sonora y Zacatecas.

Hábitat y fenología. Juncus liebmannii var. polycephalus crece en márgenes de ríos, lagos, pantanos, humedales y praderas húmedas entre 1400-2700 metros sobre el nivel del mar. Esta variedad florece en marzo y agosto y fructifica en marzo, agosto y noviembre.

Nombres vernáculos y usos. Desconocidos.

Afinidades. Juncus liebmannii var. polycephalus posee las típicas inflorescencias de la sección Ozophyllum; las flores se disponen en racimos de cabezuelas que luego se arreglan en antelas, y así la inflorescencia parece una cima donde las ramas proximales alcanzan las distales.

Especímenes examinados. CHIAPAS: San Cristóbal de las Casas 16-20 km E of Chalil, road to Chanal, 2380 m, 10.XI.1976, D. E. Breedlove s.n. (NY). CHIHUAHUA: Montana al este de Concheño, 1.VII.1936, H. LeSueur s.n. (GH). DURANGO: Sierra Madre Occidental, $20 \mathrm{~km}$ air WNW of Santiago Papasquiaro, 2400 m, 25.VIII.1983, R. Corral Díaz \& R. D. Worthington 11387 (NY, TEX, UTEP); El Salto, Aserraderos, 2350-2540 m, 28.VIII.1934, F. W. Pennell 18373 (PH, US); Metates N of Cueva, 2650-2700 m, 29-30.VIII.1934, E. W. Pennell 18390 (PH, US); Sierra Madre, Santa Teresa, Territorio de Tepic, 12.VIII.1897, J. N. Rose 2216 (GH, NY, US). JALISCO: Bolaños, S. N. Rose 2982 (GH, NY, US). SINALOA: Ocurahui, Sierra Suratato, 1500-1800 m, 17-24.III.1945, H. S. Gentry 6298 (ARIZ, GH, MO, 
Balslev y Duno de Stefano: Las Juncaceae en México

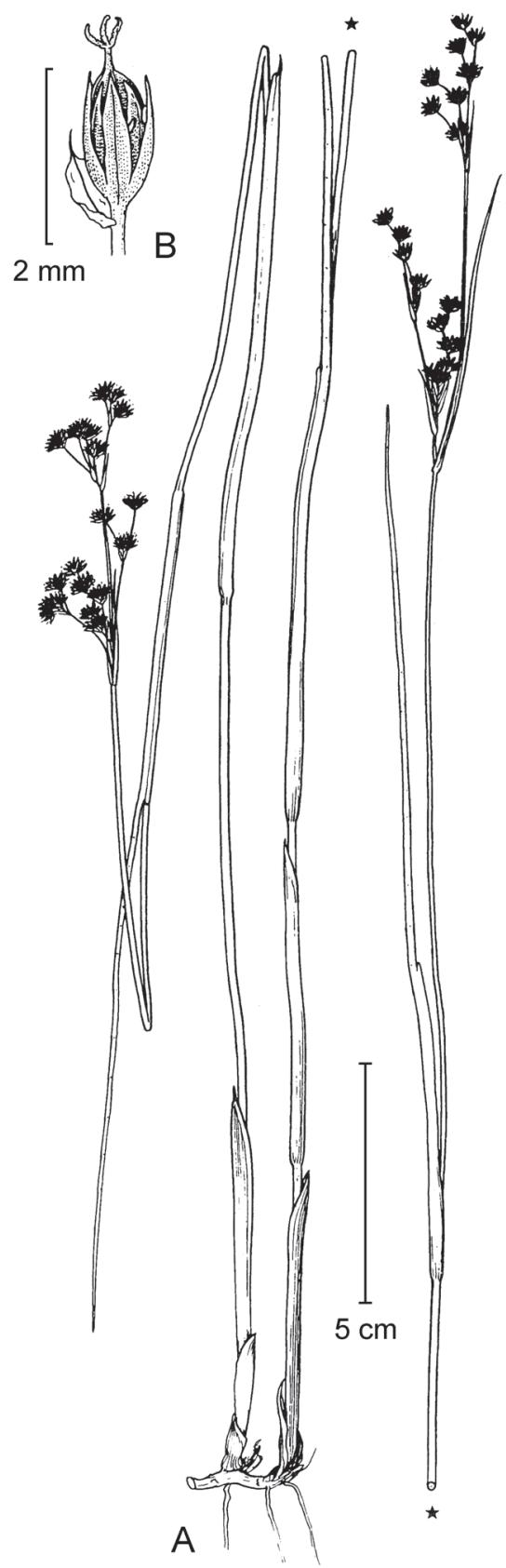

Fig. 7. Juncus liebmannii var. polycephalus. A. hábito; B. flor con una cápsula casi madura (Breedlove 15065, DS). Originalmente publicado en Balslev, 1988. 
NY, WIS). SONORA: Río Mayo Region, Chiribo, Sierra Sahuaribo, $17 \mathrm{~km}$ SE of San Bernardo, 1400 m, 22-24.VIII.1993, P. S. Martin s.n. (ARIZ). ZACATECAS: Sierra Madre, 18.VIII.1897, J. N. Rose 2374 (GH, US).

19. Juncus longistylis Torr. en W. H. Emory, Rep. U.S. \& Mex. Bound. Bot. 223. 1858. Sintipos: ESTADOS UNIDOS DE AMÉRICA. Nuevo Mexico, near the copper mines, VI.1850, J. M. Bigelow s.n. (herbario desconocido), C. Wright 1924 p. p. (MO). Figura 6.

Hierbas perennes, laxamente cespitosas, 20-70 cm de alto. Rizomas 1-2 mm de grosor, ramificados en partes y formando macollas más o menos densas, algunos rizomas formando vástagos o guías laterales que dan origen a nuevas plantas, distantes hasta $10 \mathrm{~cm}$ de la planta madre; culmos erectos, teretes, $1-2 \mathrm{~mm}$ de diámetro, lisos; catáfilos ausentes o inconspicuos. Hojas laminares basales y caulinares; las basales 2-3 por cada culmo, vainas de 2-6 $\mathrm{cm}$ de largo con los márgenes terminados en aurículas redondeadas, 0.5-1 mm de largo; láminas 5-20 × 0.1-0.3 cm, planas, usualmente con un nervio abaxial y 2-3 adaxiales claramente visibles, aparte de eso sin diferenciación o con algo de células hialinas en la superficie adaxial; hojas caulinares esparcidas a lo largo del culmo, similares a las basales pero las superiores progresivamente más cortas. Inflorescencia una antela decompuesta, 1-3 $\times 1-7 \mathrm{~cm}$, ramas principales hasta $5 \mathrm{~cm}$ de largo y $0.5 \mathrm{~mm}$ de diámetro, las ramas distales más cortas, las cortas de ca. $0.3 \mathrm{~mm}$ de diámetro, con 1-7 cabezuelas por culmo, cada cabezuela 8-16 mm de diámetro; brácteas inferiores de la inflorescencia usualmente más cortas que las inflorescencias, con una vaina membranácea y una lámina acicular, brácteas distales más cortas, brácteas florales lanceoladas, membranáceas, más cortas que las flores, bractéolas ausentes. Flores (3-)5-10(-30), de color verde claro, pajizo o castaño. Tépalos iguales, 4.5-6 mm de largo, los externos cóncavos, lanceolados, acuminados con márgenes anchamente membranáceos bordeando una línea central de color verde o castaño, los internos aplanados, mucronados. Estambres seis, 2-2.2 mm de largo; filamentos lineares, algo aplanados; anteras lineares, 1-1.4 mm de largo, usualmente tan largas o más largas que los filamentos, amarillas, delicadas, encerradas en las flores; filamentos $0.6-1 \mathrm{~mm}$ de largo. Ovario con estilo 1-1.5 mm de largo; estigmas 1-1.5 mm de largo. Cápsula más corta que los tépalos, obovada, emarginada, usualmente con estilo persistente, estilo 3-lobado en sección transversal, 3.5-4 × 1.8-2 mm, de color dorado-castaño con la superficie brillante, trilocular o unilocular con la placenta profundamente introrsa, dehiscente lateralmente en la parte distal y al principio permaneciendo unida al estilo. Semillas es- 
trechamente elipsoidales, apiculadas, 0.5-0.6 $\times 0.2 \mathrm{~mm}$, débilmente reticuladas, de color castaño, apéndices ausentes o apenas conspicuos. $2 n=40$ (Love y Love, 1981).

Distribución general. Juncus longistylis crece en la costa oeste de Norte América desde la Columbia Británica hasta Ontario en Canadá, y desde Washington hasta Nebraska y hacia el sur hasta California, Arizona y Nuevo México en los Estados Unidos de América y México. En México se encuentra en Baja California y Chihuahua.

Hábitat y fenología. Juncus longistylis crece en elevaciones entre 400-2800 metros sobre el nivel del mar en prados y ciénagas en suelos húmedos y arenosos, a veces con rizomas flotantes en el agua. La especie ha sido colectada en flor en junio y octubre.

Nombres vernáculos y usos. Desconocidos.

Afinidades. Juncus longistylis pertenece al subgénero Juncus sección Graminifolii, una sección con 22 especies, de las cuales solo cuatro se encuentran en México: J. longistylis, J. marginatus, J. macrophyllus y J. repens. Se parece más a J. macrophyllus con seis estambres (las otras dos con solo tres), anteras más largas que los filamentos (iguales o más cortas en las otras dos). El protólogo original de este taxon hace referencia a dos especímenes tipo, J. M. Bigelow s.n. y Wright 1924, sin indicar el herbario de resguardo. Considerando su amplia distribución en el oeste de Norte América requiere una pronta lectotipificación que no es posible en este momento.

Especímenes examinados. BAJA CALIFORNIA: Las Juntas, 3.VII.1884, $C$. R. Orcutt 1169 (GH, NY). CHIHUAHUA: Río Negro, 29.VIII.1937, H. LeSueur 1292 (F, GH), 1293 (GH; el pliego de este número en F es de Juncus acuminatus); Sierra Madre, 2900 m, 7-23.X.1887, C. G. Pringle 1387 (F, GH, NY, PH, US).

20. Juncus macrophyllus Coville, Univ. Calif. Publ. Bot. 1: 65. 1902. Tipo: ESTADOS UNIDOS DE AMÉRICA. California, Mill Ck Canyon, San Bernardino Mtns, 400 ft, S. B. Parish \& W. F. Parris 1091 (holo-: MO). Figura 6. $\equiv$ Juncus canaliculatus Engelm., Bot. Gaz. 7: 6. 1882, nom illeg., non Juncus canaliculatus Liebm. (1850).

Hierbas perennes, densamente cespitosas, $20-90 \mathrm{~cm}$ de alto. Rizomas cortos; estolones ausentes; culmos más o menos teretes, lisos, erectos; catáfilos 0-2 por 
culmo, 5-10 cm de largo, laxos, de color gris-castaño pálido, frecuentemente con matices rosados, márgenes anchos y membranáceos, escariosos, auriculados; láminas reducidas a simples escamas. Hojas basales 2-5, de color castaño claro, hasta 45 cm de largo, 1-3 mm de ancho, planas. Hojas caulinares, 1-3, 8-15 cm de largo, $2 \mathrm{~mm}$ de ancho, márgenes papiloso-serrulados; vainas con los márgenes estrechos y escariosos; aurículas oblongas, obtusas a truncadas, 1.2-2.5 mm de largo, escariosas; brácteas inferiores más o menos de color castaño pálido a verdoso, hasta $4 \mathrm{~cm}$ de largo, con el ápice filiforme, mucho más cortas que la inflorescencia. Inflorescencia más o menos laxa, usualmente $7-20 \mathrm{~cm}$ de largo, con apariencia de una panícula, con 5-25 cabezuelas obcónicas, pedúnculo usualmente ramificado, de varias longitudes; brácteas de los capítulos escariosas, $4 \mathrm{~mm}$ de largo. Flores 2-5(-7), pálidas. Tépalos más o menos iguales o los internos ligeramente más largos, lanceolados, 4.2-5.5 mm de largo, los externos agudos, subagudos a subobtusos, mucronados, banda central lisa, con venación conspicua, verde pálida, tornándose de color castaño claro o más o menos pajizo, márgenes muy anchos, escariosos. Estambres seis; filamentos 0.5$0.9 \mathrm{~mm}$ de largo; anteras 1.7-2.6 mm de largo. Ovario con estilo 0.8-1.5 mm de largo; estigmas 3-3.5 mm de largo. Cápsula trilocular, estrechamente obovoide, 3.4-4.5 $\mathrm{mm}$ de largo, con un mucrón de 0.4-0.7 mm de largo, truncada en el ápice, de color castaño claro, más corta o más o menos igual de largo que el perianto. Semillas más o menos ovoides, ca. $0.4-0.6 \times 0.2-0.3 \mathrm{~mm}$, distinta y regularmente reticuladas, apéndices ausentes. $2 \mathrm{n}=$ desconocido.

Distribución general. Juncus macrophyllus se distribuye en el suroeste de Estados Unidos de América (Arizona, California y Nevada) y México (Baja California). Esta especie florece entre mayo y septiembre y fructifica entre agosto y octubre.

Hábitat y fenología. Juncus macrophyllus crece en lugares húmedos arenosos o con grava a lo largo de arroyos y áreas pantanosas entre 150 y 2500 metros sobre el nivel del mar.

Nombres vernáculos y usos. Desconocidos.

Afinidades. Juncus macrophyllus pertenece al subgénero Juncus sección Graminifolii, que incluye 22 especies, con solo cuatro en México: J. longistylis, J. macrophyllus, J. marginatus y J. repens. Para discusión ver J. longystilis. El protólogo original hace referencia a una colección de S. B. Parish \& W. F. Parris sin nú- 
mero ni datos del herbario donde fue depositada. En el herbario del Jardín Botánico de Missouri (MO) hay una colección de ambos botánicos con el número 1091. Sin embargo, Kirschner (2002b) hace referencia al número 1095. Este es otro taxon que requiere de una pronta lectotipificación.

Especímenes examinados. BAJA CALIFORNIA: Sierra San Pedro Mártir, Cerro la Encantada, 2300 m, 19.VIII.1967, R. Moran 14362 (SD); N slope Cerro Blanco, 875 m, 15.VI.1969, R. Moran 16146 (SD); Cañada Ancha, Sierra Blanca, 675 m, 15.V.1976, R. Moran 23186 (SD); Sierra San Pedro Mártir, 1725 m, 31.V.1976, R. Moran 23345 (SD); Sierra San Pedro Mártir, La Sanca creek, 5 miles northwests of La Grulla, 17.IX.1930, I. L. Wiggins \& D. Demaree 4857 (GH, NY, US); Sierra Juárez, Cañada el Rincón, 1440 m, 4.VII.1976, R. Moran 23618 (ARIZ, SD); Sierra San Pedro Mártir, 4 kms E of Socorro, 1650 m, 20.VI.1977, R. Moran et al. 24253 (SD); Sierra San Pedro Mártir, Rancho San José (Meling), 625 m, 3.IX.1978, R. Moran 26228 (SD); Sierra Juárez, Laguna Hanson, 1610 m, 17.VIII.1980, R. Moran 29195 (SD); 5 miles S of Laguna Hanson, 1550 m, 18.IX.1983, R. F. Thorne 57150 (SD); Cañada de Ciprés, 4.3 miles from El Sauzal N along Hwy 3, 160-375 m, 30.V.1987, R. F. Thorne et al. 62675 (F); Valle Redondo, 30.V.1932, F. R. Fosberg 8385 (MO); Rancho San José, east of San Telmo, 14.IX.19930, I. L. Wiggings \& D. Demaree 4840 (US).

\section{Juncus marginatus Rostk., De Junco 38, t. 2, f. 3. 1801.}

Lectotipo (designado por Balslev, 1996): ESTADOS UNIDOS DE AMÉRICA. Pennsylvania, sin localidad precisa, Muehlenberg s.n. (B-Willd!; iso-: B-Willd.). Figura $8 \mathrm{~A}, \mathrm{~B}$.

= Juncus canaliculatus Liebm., Mexic. Juncac. 43. 1850.

Lectotipo (designado por Balslev, 1996): MÉXICO. Veracruz, S. Antonio Huatusco, Agosto 1841, F. M. Liebmann 726 (C!; iso-: C, fragmento, W).

Hierbas perennes, cespitosas, 40-100 cm de alto. Rizomas cortos, densamente ramificados, 2-4 mm de diámetro; culmos a veces bulbosos en la base, erectos, ligeramente comprimidos, 0.5-3 mm de diámetro, lisos; catáfilos ausentes. Hojas laminares basales y caulinares presentes; las basales 2-5 por cada culmo, vainas de hasta $9 \mathrm{~cm}$ de largo, con márgenes terminando en dos aurículas redondeadas, $0.5-1(-3) \mathrm{mm}$ de largo; láminas 10-30 × 0.1-0.5 cm, planas, usualmente con un nervio abaxial y dos nervios adaxiales claramente visibles, por otro lado sin diferenciación macroscópica; hojas caulinares espaciadas a lo largo del culmo, similares a las basales pero las superiores progresivamente más cortas. Inflorescencia una antela compuesta, 4-15× 
2-10 cm, ramas principales hasta $10 \mathrm{~cm}$ de largo y $1 \mathrm{~mm}$ de diámetro, ramas distales más cortas, las últimas de ca. $0.3 \mathrm{~mm}$ de diámetro, cabezuelas (5-)10-40(-60) por culmo, 5-7 mm de diámetro; brácteas inferiores de la inflorescencia semejantes a hojas caulinares, tan largas o más cortas que la inflorescencia, brácteas distales más cortas, brácteas florales lanceoladas, agudas, membranáceas, tan largas o más cortas que las flores, bractéolas ausentes. Flores 3-5(-10), de color pajizo a castaño oscuro. Tépalos desiguales, los externos 2-2.8(-3) $\mathrm{mm}$ de largo, lanceolados, obtusos a agudos, aristados, cóncavos, membranáceos hacia los márgenes, los internos de 2.4-3 mm de largo, apicalmente obtusos a agudos, con márgenes membranáceos, planos e inflexos y formando una pequeña capucha cuando jóvenes. Estambres tres, 1.2-2.2(-3) mm de largo; filamentos lineares, algo aplanados; anteras oblongas, 0.4-1(-1.5) $\mathrm{mm}$ de largo, por lo común conspicuamente más cortas que los filamentos pero ocasionalmente del mismo tamaño, de color castaño oscuro, robustas en apariencia, frecuentemente sobresaliendo entre los tépalos después de la antesis. Ovario con estilo ca. $0.1 \mathrm{~mm}$ de largo; estigmas 0.5-1 mm de largo. Cápsula tan larga como los tépalos, anchamente elipsoidal, apiculada, redonda en sección transversal, 2-2.5 × 1.8-2 mm, de color castaño oscuro, con la superficie brillante, triseptada, dehiscente apicalmente, los lóbulos tornándose inflexos. Semillas estrecha y oblicuamente elipsoidales, apiculadas, 0.5-0.6 $\times$ 0.15-0.2 $\mathrm{mm}$, con costillas longitudinales y transversales, de color amarillo-castaño, apéndices ausentes. 2n $=40$ (Harriman y Redmond, 1976; Harriman, 1979).

Distribución general. Juncus marginatus está ampliamente distribuida en Norte América, en la costa este desde Nueva Escocia en Canadá hasta Florida en los Estados Unidos de América y hacia el oeste hasta Arizona, hacia el sur se extiende a través de México hasta Honduras, y en Sur América, en Venezuela (pocas colecciones) y es común en el sureste de Brasil, Uruguay, Paraguay y Argentina. También se encuentra en las Antillas (Bermudas y Cuba). En México crece en Chiapas, Chihuahua, Durango, Guanajuato, Jalisco, Estado de México, Michoacán, Nayarit, Oaxaca, Sonora y Veracruz. McVaugh (1993) también la mencionan para San Luis Potosí y Tamaulipas.

Hábitat y fenología. Juncus marginatus prospera en bajas elevaciones en áreas de clima templado pero en Centro América y Sur América (Venezuela) ha sido colectada entre 800-2000 metros por encima del nivel del mar. Se desarrrolla en lugares húmedos a lo largo de acequias y arroyos, así como laderas de montaña con Pinus y Quercus. Puede crecer de manera simpátrica con J. microcephalus y J. tenuis. Juncus marginatus florece en junio y julio y fructifica entre agosto y diciembre. 

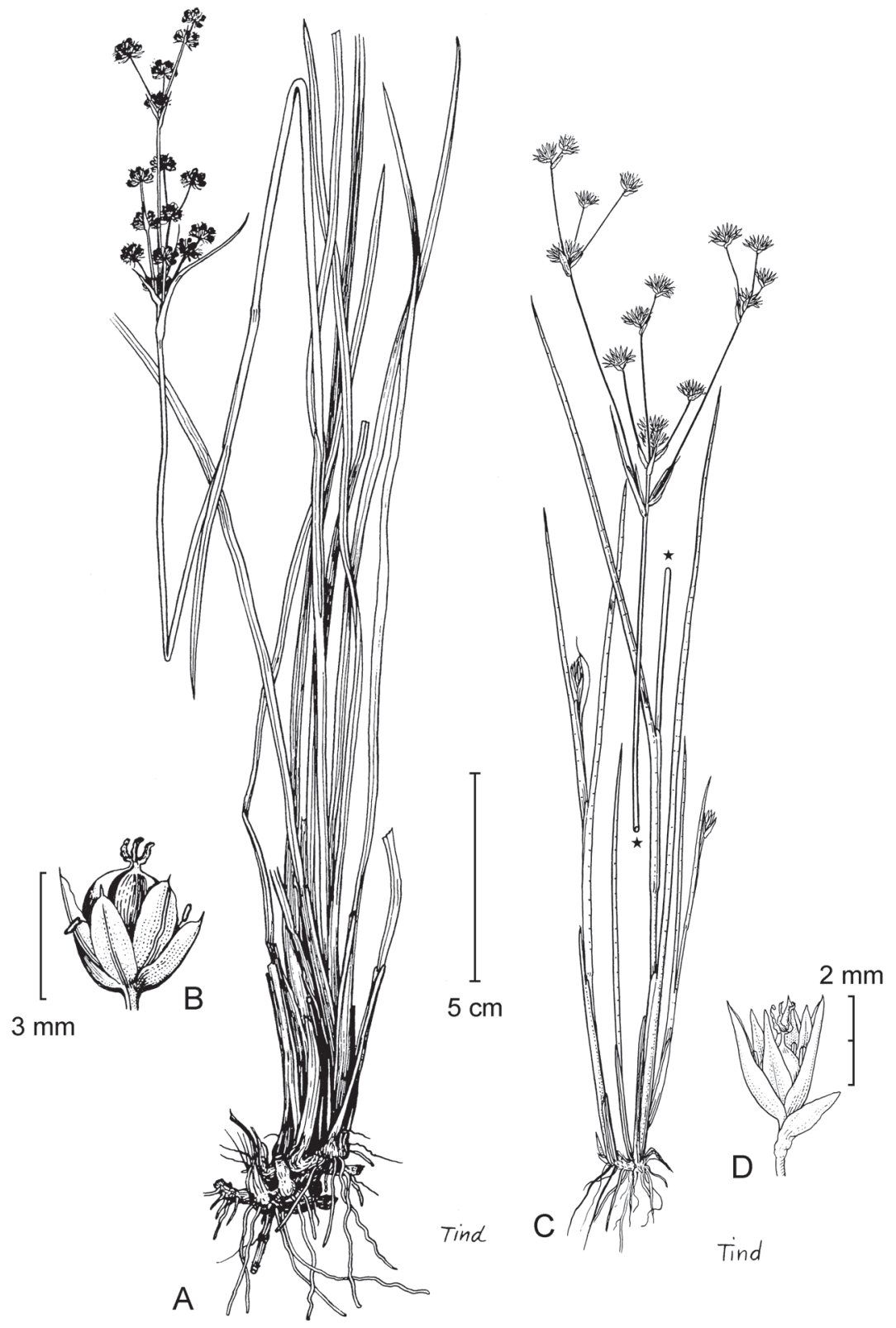

Fig. 8. Juncus marginatus y J. microcephalus. A. hábito y B. flor con una cápsula casi madura de J. marginatus (Holm-Nielsen 4697, AAU, originalmente publicado en Balslev, 1996). C. hábito y D. flor con una cápsula casi madura de J. microcephalus (Harling et al. 10408, AAU, originalmente publicado en Balslev, 1979). 
Nombres vernáculos y usos. En Chihuahua, el pueblo Tarahumara la conoce como sakalhma o sakalhname y las raíces son utilizadas todo el año para la captura de peces en los riachuelos por su efecto narcotizante (Bye 3159). En Oaxaca se conoce como tule (Maya 1566).

Afinidades. Juncus marginatus pertenece al subgénero Juncus sección Graminifolii, una sección con 22 especies, con cuatro en México: J. longistylis, J. macrophyllus, J. marginatus y J. repens (ver J. longistylis). Engelmann (1866) dividió a $J$. marginatus en tres variedades tomando como base el número de cabezuelas y el de flores en cada una. Coville (1893) añadió caracteres de las semillas y también dividió la especie en tres variedades, las que sin embargo fueron circunscritas de una manera distinta. Small (1903) elevó las variedades propuestas por Coville a rango de especies, pero en las floras de Norte América más recientes (e.g. Britton y Brown, 1913; Gleason, 1968; Gleason y Cronquist, 1991) solo se reconocen dos especies: $J$. marginatus y $J$. biflorus; la primera con dos variedades: J. marginatus var. marginatus y J. marginatus var. setosus. Juncus biflorus tiene de muchas a 2-3 cabezuelas mientras que $J$. marginatus tiene pocas a 5-12 cabezuelas por inflorescencia. También J. marginatus presenta tépalos obtusos o agudos, una cápsula de color castaño, mientras que $J$. marginatus var. setosus se puede reconocer por la cápsula brillante y los tépalos internos aristados. Sin embargo, el material mexicano no se ajusta fácilmente a esta delimitación.

Especímenes examinados. CHIAPAS: limits of Teopisca, 1800 m, 19.VIII.1966, D. E. Breedlove 15069 (NY); $12 \mathrm{~km} \mathrm{~N}$ of Jitotol along side road to an oil well, 2000 m, 28.X.1971, D. E. Breedlove \& R. F. Thorne 21445 p.p. (NY; el pliego de este número en MO es Juncus microcephalus); Las Margaritas-Campo Alegre road, 6-10 km NNE of La Soledad, La Independencia, 1600 m, 30.IX.1981, D. E. Breedlove 53197 (MO, NY); along Highway 195, between Ixtapa and Pichalco, ca. 5 miles SE of Jitotol, $1700 \mathrm{~m}$, T. B. Croat 47735 (MO); $5 \mathrm{~km}$ N of Jitotol, near Colonia El Laurel, 1600 m, 13.XI.1984, G. Davidse et al. 29635 (MO). CHIHUAHUA: ciénega de Norogachic, 2366 m, VIII.1972, R. A. Bye Jr. 3159 (ECON); Sierra Madre Occidental, Estación Chico, al sur de Cumbre, 2100-2250 m, 19.XI.1934. F. W. Pennell 19025 (GH). DURANGO: Los Corralitos, 2100 m, 27.XI.1970, O. H. Soule 2206 (MO). JALISCO: Sierra de Nayarit, Huichol, s.f., M. L. Diguet s.n. (NY, US); Río Blanco, VI-X.1886, E. Palmer 13 (GH, MO, NY, PH, US). ESTADO DE MÉXICO: Nanchititla, 1800 m, 4-12.XII.1954, E. Matuda 31951 (MEXU, US). OAXACA: Ayutla, 19-27.II.1937, W. H. Camp 2748 (NY); Cueva Redonda (near Mitla), 11.II.1966, W. 
R. Ernst 2679 (US); al E de Benito Juárez por el camino a la División, ca. 37 km en línea recta al NNE de San Pedro Tapanatepec, 1100 m, 24.IV.1985, S. Maya J. 1566 (MO). SAN LUIS POTOSÍ: San Luis Potosí, 1877, J. G. Schaffner 219 (GOET, NY); Morales, 1876, J. G. Schaffner 550 (GH, MEXU, PH). SONORA: Sierra Madre Occidental, Canyon de Tejas, Sierra Charuco, 1200-1400 m, 24.IV.1948, H. S. Gentry 8131 (ARIZ, US). 17.2 miles SSE of Magdalena, Cerro Cinta de Plata (= Sierra Babiso), 8-9.IV.1977, T. R. van Devender et al. s.n. (ARIZ). Arroyo el Huirotal (= A. el Guaje), Rancho Uvalama, E slope Sierra de Álamos, $7 \mathrm{~km}$ SW of Álamos, $600 \mathrm{~m}$, 6.VII.1992, T. R. van Devender 92-767 (ARIZ); Río de Bavispe, Arroyo de la Gallera, 27.VII.1940, S. S. White 3063 (GH); Arroyo de los Llanos, 29.VI.1853, A. Schott s.n. (F, mezclado con J. saximontanus). VERACRUZ: Coatzacoalcos, along hwy. Mex. 180, $2 \mathrm{~km} \mathrm{~W}$ of Veracruz-Tabasco state border, $17 \mathrm{~km} \mathrm{~N}$ of Las Choapas, 10 m, 2.I.1986, M. Nee 32446 (MO, NY); Jalapa, 1200 m, 17.IV.1899, C. G. Pringle 8123 (BR, CM, F, GH, GOET, MEXU, MO, NY, PH, S, US, Z); Coatzacoalcos, Isthmus of Tehuantepec, 8.III.1895, C. L. Smith 1121 (F, GH, MO, NY, UC, US); Dos Ríos, Pinoltepec, 800 m, 17.VI.1971, F. Ventura A. 3715 (ARIZ, MO).

\section{Juncus microcephalus Kunth, Nov. Gen. Sp. 1: 237. 1816.}

$\equiv$ Juncus microcephalus var. typicus Buchenau, Abh. Naturwiss. Vereine Bremen 6: 408. 1879.

Tipo: COLOMBIA. Quindio, sin localidad precisa, A. von Humboldt \& A. Bonpland s.n. (holo-. P!; iso-: B!, GH!). Figura 8 C, D.

Hierbas perennes, cespitosas, $20-100 \mathrm{~cm}$ de alto. Rizomas densamente ramificados, 1-4 mm de diámetro, con pocas escamas membranáceas, delgadas; culmos erectos, 0.5-4 mm de diámetro, teretes, lisos o estriados; catáfilos 0-2 por cada culmo, hasta $15 \mathrm{~cm}$ de largo, verdes o con matices rojizos, con márgenes distintivamente membranáceos. Hojas laminares basales 1-3 y las caulinares 1-2 por cada culmo, (5-)10-50 cm de largo; vainas de (1.5-)5-15 cm de largo, con márgenes membranáceos terminando en dos aurículas redondeadas, $0.5-5 \mathrm{~mm}$ de largo; láminas 0.7-4 $\mathrm{mm}$ de diámetro, redondas a elípticas en sección transversal, conspicuamente septadas, a veces con una hendidura conspicua adaxial en la base. Inflorescencia una antela compuesta, (3-)5-20(-30) × (1.5-)3-10(-15) cm, cabezuelas (3-)7-50(-100), cónicas a globosas, 5-10 mm de diámetro, última cabezuela con ramas de menos de $0.4 \mathrm{~mm}$ de diámetro; brácteas inferiores de la inflorescencia hasta $5(-12) \mathrm{cm}$ de largo, mucho más cortas que la inflorescencia, con forma de escamas con láminas reducidas $\mathrm{u}$ ocasionalmente semejantes a pequeñas hojas basales con láminas bien desarrolladas, 
brácteas distales más cortas, brácteas florales acuminadas, ca. $3 \mathrm{~mm}$ de largo, membranáceas, usualmente del mismo color que los tépalos. Flores (3-)10-35, de color pajizo a castaño. Tépalos desiguales 1-3.5(-5) mm de largo, lanceolados, agudos, los externos cóncavos y membranáceos hacia los márgenes, los internos planos con márgenes membranáceos distintivos. Estambres seis o tres, 1-2 $\mathrm{mm}$ de largo; filamentos planos, lineares; anteras oblongas a lineares, 0.3-0.7 mm de largo, o cerca de la mitad del largo de los filamentos. Cápsula elipsoidal a obovoide, redonda en sección transversal y trilobada en la base, obtusa a claramente aguda o cortamente mucronada, 2-3.5 $\times 1-1.5 \mathrm{~mm}$, de color pajizo, castaño o casi negro, unilocular. Semillas elipsoidales, apiculadas, $0.4-0.5 \times$ ca. $0.2 \mathrm{~mm}$, reticuladas, de color amarillo-castaño con la cubierta seminal hialina, apéndices ausentes. $2 \mathrm{n}=$ desconocido.

Distribución general. Juncus microcephalus se distribuye a través de las tierras altas de todo el Neotrópico desde el centro de México hasta Bolivia y el sureste de Brasil. Introducida en Australia y posiblemente en otros países incluyendo Alemania y Nueva Zelanda (Kirschner, 2002b). En México se encuentra en Aguascalientes, Chiapas, Distrito Federal, Durango, Guerrero, Hidalgo, Jalisco, Estado de México, Michoacán, Morelos, Oaxaca, Puebla, Querétaro, San Luis Potosí, Tlaxcala y Veracruz. McVaugh (1993) la menciona para Nayarit, Guanajuato y Zacatecas.

Hábitat y fenología. Juncus microcephalus crece en sitios pantanosos, acequias, zanjas, orillas de canales, estanques, arroyos, fondos de cañadas y en bosque de encino y encino-pino entre 1450 y 2600 metros sobre el nivel del mar. Esta especie florece y fructifica irregularmente a lo largo del año pero la floración más comúnmente ocurre entre julio y septiembre.

Nombres vernáculos y usos. Desconocidos.

Afinidades. Juncus microcephalus es miembro del subgénero Juncus sección Ozophyllum que en México incluye ocho elementos (ver J. acuminatus). Es una especie muy variable, más parecida a J. pallescens (Sur América) pero se diferencia porque la primera tiene las ramas de la inflorescencia más delgadas y semillas estrechamente elipsoidales; puede también ser confundida con J. acuminatus que tiene seis estambres (no tres).

Especímenes examinados. AGUASCALIENTES: San José de Gracia, La Congoja, $2500 \mathrm{~m}$, J. Rzedowski \& R. McVaugh 849 (AAU). CHIAPAS: $12 \mathrm{~km} \mathrm{~N}$ 
of Jitotol, 2000 m, 28.X.1971, D. E. Breedlove \& R. E. Thorne 21445 (MO; el pliego de este número en NY es de Juncus marginatus); Pueblo Nuevo Solistahuacán, 1700 m, 26.X.1971, B. E. Breedlove \& R. F. Thorne 21530 p.p. (MO; otros pliegos del mismo número depositados en CHAPA, DS, DUKE, ENCB, F, LL, NY están identificadas como J. debilis); $3.5 \mathrm{~km}$ SE of Pueblo Nuevo Solistahuacán, $1500 \mathrm{~m}$, 25.VII.1965, E. Lathrop 5962 (US). DISTRITO FEDERAL: Barrancas de Mixcoac, 10.IX.1938, E. Lyonnet 2378 (US). DURANGO: El Salto, Aserraderos, 2530-2540 m, 28.VIII.1934, F. W. Pennell 18375 (PH); 4 miles east of El Salto, 57 miles SW of Durango, 13.VIII.1957, U. T. Waterfall \& C. S. Wallis 13696 (US). GUANAJUATO: Guanajuato road, 15.VIII.1947, L. A. Kenoyer 2104 p.p. (GH, mezclado con J. tenuis y $J$. marginatus); $24 \mathrm{~km}$ al NNW de Juventino Rosas, 22.IX.1987, S. Zamudio R. 5728 (MO). GUERRERO: Taxco, 21.VII.1937, R. Q. Abbott 271 (GH). HIDALGO: Tulancingo, 2100 m, 4.XI.1980, R. Hernández 5269 (MEXU, MO). JALISCO: Río Grande de Santiago near Atequiza, 20.V.1890, C. G. Pringle 3131 (BR, CM, F, GH, GOET, K, M, MEXU, MO, NY, PH, S, UC, US, Z); Guadalajara, 1500 m, 10.X.1903, C. G. Pringle 11721 (C, F, GH, MO, US). ESTADO DE MÉXICO: $1 \mathrm{~km}$ al E de ENEP Cuautitlán, 2250 m, 25.IV.1981, R. Galván 768 (MO); $0.5 \mathrm{~km} \mathrm{~W}$ of ENEP, Cuautitlán, 2250 m, 6.VI.1982, R. Galván 1179 (NY, SD); Jilotepec, 2200 m, 21.IX.1952, E. Matuda 26919a (NY); Cañada de Nanchititla, 1600 m, 25-26.V.1954, E. Matuda 30817 (US); México-Querétaro road $2 \mathrm{~km} \mathrm{~W}$ of Cuautitlán, $2250 \mathrm{~m}$, 1.V.1973, J. Rzedowski 30474 (ARIZ, MO). MICHOACÁN: Puerto de Los Tepetates, $22 \mathrm{~km} \mathrm{~W}$ of Ciudad Hidalgo on Highway 15, 2280 m, 10.X.1985, B. Bartholomew et al. 2856 (GH, NY). MORELOS: Cuernavaca, 2000 m, VII-IX.1896, C. G. Pringle 6509 (BR, CAS, CM, F, GH, GOET, K, M, MEXU, MO, NY, PH, S, UC, US, Z). NAYARIT: Near La Labor, ca. 15 miles southeast of Tepic, 25.IX.1960, $R$. McVaugh 19429 (MO); Arroyo Santa Rosa al S de Santa Teresa, 2070 m, P. Tenorio \& G. Flores F. 16421 (MO). OAXACA: Ixtlán, 4 km E of Ixtlán de Juárez, road to Capulapan, 2200 m, 20.IX.1980, G. I. Martin 194 (MO). PUEBLA: Nr. Tepoxuchil, 10.VII.1910, G. Nicolás s.n. (GH, US). QUERÉTARO: Amealco road, 2400-2500 m, E. Argüelles 477 (MEXU); Represa a $3 \mathrm{~km}$ al norte de Amealco rumbo a Querétaro, 2525 m, 28.IX.1999, A. Novelo \& L. Ramos 3817 (MO). SAN LUIS POTOSÍ: San Luis Potosí, J. W. Schaffner s.n. (M); 1877, J. W. Schaffner 552 (GH). TLAXCALA: San Juan Quetzalcuapan, 2500 m, H. Vibrans 842 (ENCB, MEXU). VERACRUZ: Zacuapan, J. Linden 266 (K).

23. Juncus nodosus L., Sp. P1. 2 ed. 1: 466. 1762.

Tipo: CANADÁ. Sin localidad precisa, P. Kalm s.n. (holo-: LINN-449.17). 
$\equiv$ Juncus nodosus var. vulgaris Torr. Fl. New York 2: 326. 1843, nom. inval.

$\equiv$ Juncus nodosus var. genuinus Engelm., Trans. Acad. Sci. St. Louis 2: 436. 1866, nom. inval.

= Juncus nodosus var. meridianus F. J. Herm, J. Arnold Arbor. 25: 58. 1944.

Tipo: MÉXICO. Chihuahua, Chihuahua, 1300 m, 5-10.VI.1908, E. Palmer 360 (holo-: $\mathrm{US}$; iso-: $\mathrm{F}, \mathrm{GH}, \mathrm{K}, \mathrm{NY}, \mathrm{S}$ ).

Hierbas perennes, 10-40 cm de alto. Rizomas horizontales, estoloníferos, largamente rastreros, $0.5-1 \mathrm{~mm}$ de diámetro, frecuentemente con bulbos engrosados en la base de los culmos, internodos hasta $7 \mathrm{~cm}$ de largo, escamas ausentes o pocas; culmos erectos, 0.5-1.5 mm de diámetro, lisos; catáfilos 0-2 por cada culmo, hasta $4 \mathrm{~cm}$ de largo, inconspicuos. Hojas laminares (1-)2-4(-6), espaciadas a lo largo del culmo o a veces agrupadas en la base, (2-)10-25 cm de largo; vainas de 1.5-5 cm de largo, con márgenes membranáceos terminando en dos aurículas redondeadas, (0.5-)1-2 mm de largo; láminas 0.5-1 mm de diámetro, teretes, ahuecadas, con septos usualmente inconspicuos, 1-5 $\mathrm{mm}$ separados entre sí, con una hendidura a lo largo de la cara adaxial. Inflorescencia una antela compuesta, hasta $8 \times 4 \mathrm{~cm}$, cabezuelas (1-)3-5(-7), globosas, 8-12 $\mathrm{mm}$ de diámetro, ramas principales hasta $6 \mathrm{~cm}$ de largo y $1 \mathrm{~mm}$ de diámetro; brácteas inferiores de la inflorescencia (1.5-)5-15 cm de largo, semejantes a hojas caulinares con vainas de $0.5-1 \mathrm{~cm}$ de largo, brácteas distales más cortas. Flores (5-)15-25(-30) por cabezuela, de color verde pálido a pajizo o a veces una ligera pigmentación roja. Tépalos iguales, 2.8-4.5 $\mathrm{mm}$ de largo, linear-lanceolados, subulados, los externos cóncavos, los internos planos. Estambres tres, 1.2-1.6 mm de largo; filamentos planos; anteras oblongas a lineares, 0.5-0.7 mm de largo, usualmente tan largas o más cortas que los filamentos, antes de la antesis a veces ligeramente más largas como los filamentos. Ovario con estilo de 0.1-0.2 mm de largo; estigmas 0.5$0.9 \mathrm{~mm}$ de largo. Cápsula estrechamente ovoide, gradualmente atenuada hacia arriba, rostro de $0.5 \mathrm{~mm}$ de largo, trígona, 3-4.7 $\mathrm{mm}$ (incluyendo el rostro) $\times$ 0.7-1.3 mm, conspicuamente más larga que los tépalos cuando madura, de color castaño pálido a castaño oscuro, unilocular. Semillas elipsoidales, apiculadas, 0.4-0.5 $\times$ 0.2-0.25 $\mathrm{mm}$, reticuladas, de color amarillo-castaño, apéndices ausentes. $2 \mathrm{n}=40$ (Harriman y Redmond, 1976; Love y Love, 1981).

Distribución general. Juncus nodosus es una especie de regiones típicamente templadas de Norte América distribuida a lo largo de la costa este de Canadá (Terranova y Labrador) y los Estados Unidos de América, extendiéndose hacia el oeste sin alcanzar la costa. En México crece en los estados de Chihuahua, Coahuila, 
Durango, Guanajuato, México, Michoacán, Nuevo León, Puebla, San Luis Potosí y Tamaulipas.

Hábitat y fenología. En México, J. nodosus se observa en lugares húmedos cerca del agua, en bosque de pino a elevaciones entre 500-2100 metros sobre el nivel del mar. Esta especie ha sido colectada en flor en abril y julio y en fruto entre junio y agosto.

Nombres vernáculos y usos. Desconocidos.

Afinidades. Juncus nodosus es miembro del subgénero Juncus sección Ozophyllum que en México incluye ocho elementos (ver J. acuminatus) y está cercanamente relacionada con $J$. torreyi y $J$. texanus. Un carácter común a estas tres especies, originalmente consideradas variedades de $J$. nodosus, es su rizoma estolonífero con largos internodos y bulbos en la base de los culmos. Esta característica no ha sido observada en ningún otro representante del género. Juncus texanus se distribuye en las tierras bajas de Texas (Estados Unidos de América) y se diferencia de $J$. nodosus por ser de un tamaño mayor, tener las anteras más largas que los filamentos $\mathrm{y}$ un largo rostro que hace a la cápsula subulada y estrecha. Juncus torreyi se conoce de la mayor parte de Canadá y los Estados Unidos de América y es aún más grande que $J$. texanus. Se puede distinguir por sus largas cabezuelas con 40-50 flores.

Especímenes examinados. CHIHUAHUA: El Cima, 29.VI.1936, H. LeSueur 1112 (GH, MO, UC); Chihuahua, 1300 m, 8-27.IV.1908, E. Palmer 52 (MO); Río Florido, Cd. Jimenez, $1400 \mathrm{~m}, 28$. VII.1939, S. S. White 2089 (GH); $5 \mathrm{~km} \mathrm{~W}$ of Camargo, 1200 m, 2-5.VIII.1939, S. S. White 2268 (ARIZ, GH). COAHUILA: Chihuahua border, Sierra Almagre, Rancho El Almagre, 11.IX.1940, I. M. Johnston \& C. H. Muller 1203 (GH); Buenos Aires, Mts. E of Saltillo, 17.VIII.1948, L. A. Kenoyer \& Crum 2761 (GH); Saltillo, VI.1898, E. Palmer 264 (F, GH, MO, NY, UC, US); municipio Gral. Cepeda, Presa El Tulillo, $9 \mathrm{~km}$ towards Hipólito from Saltillo-Torreón road, 1.VI.1983, J. Á. Villareal \& M. A. Carranza 2116 (ARIZ). DURANGO: Santiago Papasquiaro, $3.5 \mathrm{~km}$ E of La Soledad, 1900-2100 m, 7.VII.1983, R. Corral Diaz \& R. D. Worthington 10867 (NY, TEX, UTEP); Durango, 3.XI.1896, E. Palmer 98 (F, GH, MO, NY, UC). GUANAJUATO: Irapuato, L. A. Kenoyer 1864 p.p. (GH, mezclado con J. acuminatus). MICHOACÁN: Morelia, Loma Sta. María, 1980 m, G. Arsène 2519 (MEXU). NUEVO LEÓN: Villa de Santiago, 750 m, 21.VI.1940, W. C. Leavenworth 158 (F, GH, MO); Huasteca del Río Santa Catarina, 16.VIII.1944, F. A. Barkley $14597 A$ (MO); Sierra Madre Oriental, Río Santa Catarina, Monterrey, 500- 
600 m, 17.VI.1934, F. W. Pennell 16801 (GH, NY, PH, US). PUEBLA: Puebla, 2190 m, G. Arsène 227 (MEXU). SAN LUIS POTOSÍ: Estación de Catorce, 1900-2100 m, 24-25.VII.1934, F. W. Pennell 17586 (GH, NY, PH, US); Río Verde N of town along road to Las Tablas, 900 m, 24.VI.1982, W. Wayt Thomas 2776 (NY); Charcas, VI-VIII.1934, C. L. Whiting 630 (WIS), C. L. Whiting 634 (NY), C. L. Whiting 639 (F). TAMAULIPAS: $5 \mathrm{~km}$ N of Miquihuana, 15.VII.1949, L. R. Stanford et al. 2479 (GH, MO, NY, US).

24. Juncus patens E. Meyer, Syn Luzl. 28. 1823.

Tipo: ESTADOS UNIDOS DE AMÉRICA. California, Monterrey ("Regosmontanae"), Haenke s.n. (PR).

Hierbas cespitosas, 30-90 cm de alto. Rizomas rastreros, 2-5 mm de diámetro, cubiertos con escamas de color castaño oscuro, internodos muy cortos y los culmos saliendo en densas filas agrupadas; culmos verdes o glaucos, erectos, teretes, 1.5-2.5 $\mathrm{mm}$ de diámetro, externamente estriados por trazas subepidérmicas longitudinales dispuestas paralelamente a los haces vasculares, médula continua, aerénquima con células asteriformes; catáfilos 3-5 por cada culmo, hasta $12 \mathrm{~cm}$ de largo, con láminas rudimentarias, aciculares, hasta $3 \mathrm{~mm}$ de largo, usualmente envainadas, de color castaño oscuro en la base, de color castaño claro o pajizo hacia arriba. Hojas laminares ausentes. Inflorescencia pseudo-lateral, con muchas flores, laxamente ramificada, hasta $3 \times 9 \mathrm{~cm}$, o éstas a veces agrupadas, la cima compuesta, consistiendo de varias cimas, las últimas siendo drepanios laterales; brácteas inferiores de la inflorescencia pareciendo continuaciones del culmo, 5-20 cm de largo, usualmente formando $1 / 5$ o más del total de la planta, ligeramente unidas a los culmos, vainas estrechas, brácteas superiores membranáceas. Flor abrazada por dos bractéolas, 0.7$1 \mathrm{~mm}$ de largo. Tépalos desiguales, lanceolados, 2.5-3 $\mathrm{mm}$ de largo, extendidos en la madurez del fruto, de color pajizo a rojizo, los externos cóncavos, ligeramente más largos que los internos. Estambres seis, 1-2 mm de largo; anteras lineares a oblongas, iguales o más largas que los filamentos. Cápsula elipsoidal, igual o más larga que los pétalos, obtusa, 2-3 $\times 1-1.5 \mathrm{~mm}$, de color pajizo a castaño, triseptada. Semillas ovoides, asimétricas, cortamente apiculadas, 0.4-0.5 $\times 0.2-0.3 \mathrm{~mm}$, rugosas, de color amarillo a castaño, apéndices ausentes. $2 \mathrm{n}=$ desconocido.

Distribución general. Juncus patens se distribuye en el oeste de Estados Unidos de América desde Oregon hasta California, en México en Baja California y de manera disyunta en el estado de Puebla. 
Hábitat y fenología. Juncus patens crece a orillas de los bosques de coníferas, a veces a lo largo de bancos de grava, en pantanos salinos o en cerros rocosos secos. Juncus patens florece de mayo a julio y está en fruto desde mayo hasta septiembre.

Nombres vernáculos y usos. Desconocidos.

Afinidades. Juncus patens forma parte del subgénero Agathryon sección Juncotypus junto con $J$. aemulans, J. balticus, J. effusus y $J$. textilis (ver J. aemulans para más discusión).

Especímenes examinados. BAJA CALIFORNIA: $9 \mathrm{~km}$ SSE of Eréndira, 30 m, 15.VI.1976, R. Moran 23553 (SD); 2 km ENE of Rancho Estela, 400 m, 31.VII.1977, R. Moran 24379 (SD); 2 km NW of Cerro Solo, 100 m, 6.IV.1979, $R$. Moran 27180 (SD, UC); Arroyo Jatay, $1.5 \mathrm{~km}$ from mouth, $40 \mathrm{~m}, 11 . V I .1980, R$. Moran 28768 (ARIZ); Arroyo Hediondo 6 km ESE of Eréndira, 170 m, 22.VII.1979, $R$. Moran 27896 (SD, US); 1 km E of Rancho la Salina, 100 m, 14.VI.1980, R. Moran 28839 (SD); Canyon N of the road about $3.5 \mathrm{~km}$ inland at the $\mathrm{N}$ end of Guatay Grade, $41 \mathrm{~km}$ north of Ensenada, 11.IX.1929, I. L. Wiggins \& Gillespie 3983 (F, GH, MO, NY, SD, US). PUEBLA: Santa Barbara, VII.1909, G. Nicolás s.n. (P).

25. Juncus repens Michx., Fl. Bor.-Amer. 1: 191. 1803.

Lectotipo (designado por Balslev, 1996): ESTADOS UNIDOS DE AMÉRICA. Carolina y Georgia, A. Michaux s.n. (P!; iso-: MO!, P!, W!). Figura 9.

$\equiv$ Cephaloxys flabellata Desv., J. Bot. (Desvaux) 1: 324. 1809, nom illeg.

Hierbas perennes heteromórficas; la forma cespitosa, $5-15 \mathrm{~cm}$ de alto con uno o varios culmos cortos y erectos con 1-4(-8) flores por cabezuela; la forma postrada con tallos rastreros, enraizados y produciendo rosetas de hojas de $5-10 \mathrm{~cm}$ de largo cada una, una tercera forma flotante con rosetas de hojas espaciadas a lo largo del tallo. Rizomas ausentes en las plantas postradas, escasamente desarrollados, densamente ramificados, de $0.5-1.5 \mathrm{~mm}$ de diámetro en las plantas cespitosas; culmos aplanados, 0.8-2 mm de diámetro, lisos, más cortos que las rosetas de hojas, tallos rastreros y flotantes, $1.5-2.5 \mathrm{~mm}$ de diámetro, hasta $50 \mathrm{~cm}$ de largo, internodos de 5-10 cm de largo. Hojas laminares en macollas de rosetas, 2-15 $\times 0.1-0.4 \mathrm{~cm}$, planas; vainas de $0.5-1.5 \mathrm{~cm}$ de largo, no claramente separadas de la lámina, márgenes membranáceos, terminando en dos aurículas redondeadas, $0.5 \mathrm{~mm}$ de largo. Inflorescencia de 2-8 cabezuelas dispuestas en antelas decompuestas que sobrepasan las 
hojas, cabezuelas de flores cónicas a hemiesféricas, 7-13(-20) mm de diámetro; brácteas inferiores de la inflorescencia semejantes a las hojas basales, las distales más cortas, brácteas florales anchamente lanceoladas, mucronadas, 1-2 mm de largo, bractéolas ausentes. Flores 2-20. Tépalos desiguales, verdes, a veces de color rojizo en la porción apical o a todo lo largo, los externos de 2.8-4.2 $\mathrm{mm}$ de largo, cóncavos, membranáceos hacia los márgenes, los internos notablemente largos, (3.5-)4-5 $\mathrm{mm}$ de largo, planos, subulados, con márgenes distintivamente estrechos, involutos, membranáceos. Estambres tres, 2-3 mm de largo, opuestos a los tépalos externos; filamentos delicadamente filiformes, hialinos; anteras 0.3-1 mm, inicialmente lineares y tan largas como los filamentos, luego de la antesis marchitándose hasta reducirse a un 1/7 de la longitud de los filamentos. Ovario con estilo de ca. $0.2 \mathrm{~mm}$ de largo; estigmas de ca. $0.4 \mathrm{~mm}$ de largo. Cápsula linear a lanceolada, apicalmente truncada o tricarinada, retusa, trígona, 2.5-3.5 $\times$ 0.7-1.1 mm, tan larga o más larga que los tépalos externos pero más corta que los internos, la base con las paredes delgadas y hialinas, el ápice más grueso, de color pajizo o dorado-castaño, trilocular, con columna central, placentación y óvulos ascendentes. Semillas oblicuas, ovoides, apiculadas, ca. $0.3 \times 0.15 \mathrm{~mm}$, finamente rugosas, de color castaño o blancuzco, 100 o más por cápsula, apéndices ausentes. $2 \mathrm{n}=$ desconocido.

Distribución general. Juncus repens se distribuye en el este de Estados Unidos de América desde Delaware hasta Florida y hacia el oeste hasta Arkansas y Texas, y dos poblaciones disyuntas en México (Baja California y Tabasco). También se conoce de las Antillas, en la provincia de Pinar del Río y en la Isla de Pinos (Cuba).

Hábitat y fenología. Juncus repens crece en suelos cenagosos o arenosos en los márgenes de cuerpos de agua y estanques, lagunas, pantanos, ciénagas y frecuentemente en bosques de pino o suelos estériles con pinos. Esta especie ha sido colectada en flor en febrero y en fruto en los meses de mayo y noviembre.

Nombres vernáculos y usos. Desconocidos.

Afinidades. Juncus repens pertenece al subgénero Juncus sección Graminifolii, una sección con 22 especies, con solo cuatro especies en México: J. longistylis, J. macrophyllus, J. microcarpus y J. repens (ver J. macrophyllus). La variación morfológica y anatómica de $J$. repens fue descrita en detalle por Holm (1899). Su crecimiento está correlacionado con la naturaleza de su hábitat. Cuando está sumergida produce largos vástagos con largos internodos y hojas en rosetas en los nodos; 


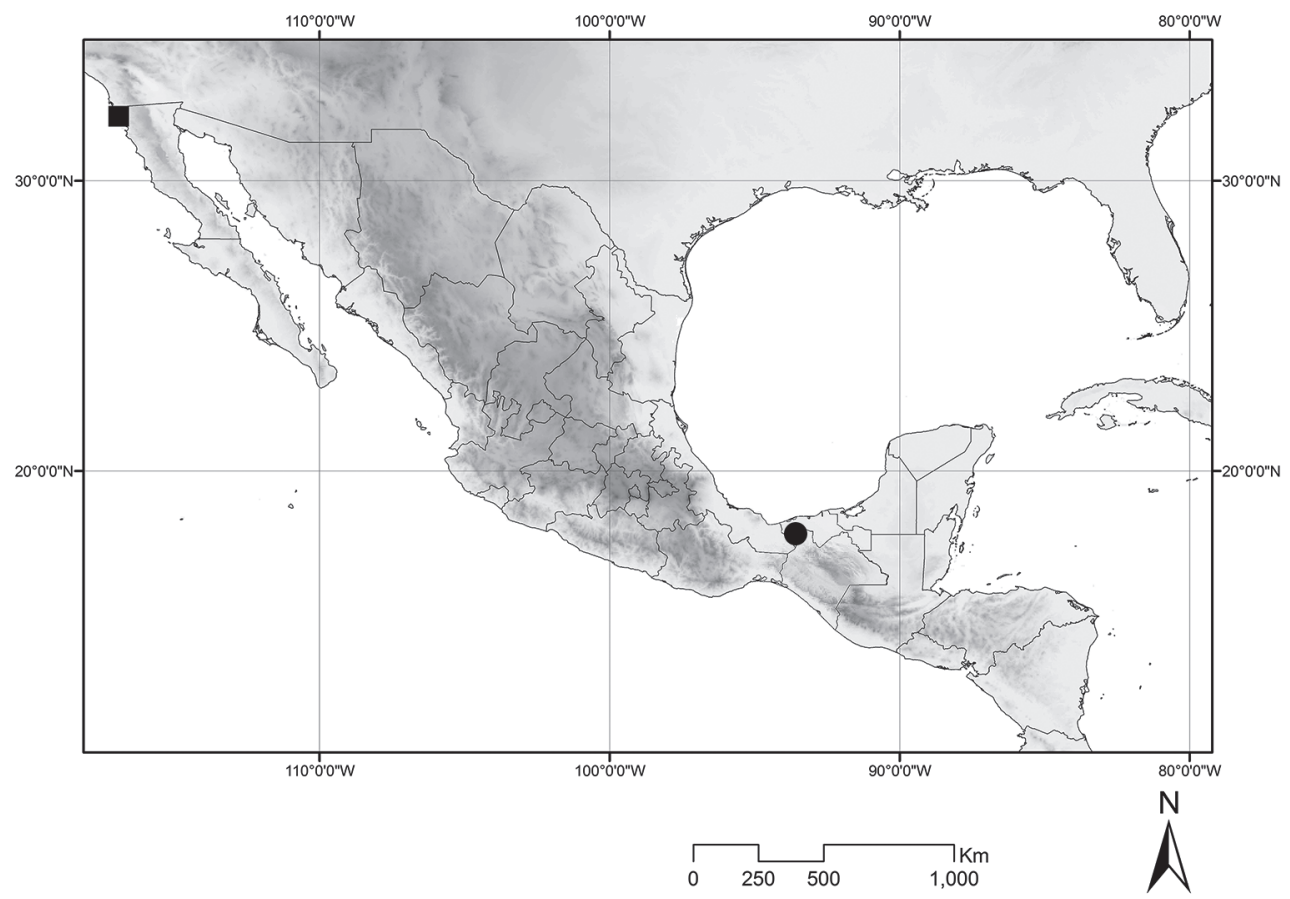

Fig. 9. Mapa de distribución de los especímenes examinados de Juncus repens $(\bullet)$ y J. textilis (घ).

en agua poco profunda los largos vástagos pueden enraizar en los nodos. Cuando la planta crece fuera del agua retiene su hábito macollante. Formas intermedias se encuentran en uno u otro hábitat.

Especímenes examinados. BAJA CALIFORNIA: sin localidad exacta, 1884, C. R. Orcutt s.n. (US). TABASCO: Huimanguillo-Malpaso road km 10, 24.X.1979, T. Cowan et al. 2576 (CAS, CHAPA, ENCB, MEXU, MO, NY, PH, TEX); Huimanguillo-Francisco Rueda road km 41, 16.XI.1979, T. Cowan 2666 (CAS, CHAPA, ENCB, MO), km 35, 30 m, 16.II.1980, A. Lot \& A. Novelo 1123 (NY); Huimanguillo, río Arroyo Hondo, $32.9 \mathrm{~km} \mathrm{~W}$ of take of from Huimanguillo-Francisco Rueda road, 35 m, 27.I.1984, A. Lot \& A. Novelo 1373 (F, MO).

26. Juncus saximontanus A. Nelson, Bull. Torrey Bot. Club 29: 401. 1902. Lectotipo (designado por Balslev, 1996) : ESTADOS UNIDOS DE AMÉRICA. Colorado. E. Hall \& J. P. Harbour 564 (MO). 
Hierbas perennes, 20-40(-55) cm de alto. Rizomas rastreros y ascendentes, ramificados, estolones comúnmente presentes; culmos erectos, 1.5-2.5 $\mathrm{mm}$ de ancho, lateralmente comprimidos. Hojas laminares 2-4(-5), basales y caulinares, las basales hasta $15 \mathrm{~cm}$ de largo, las distales más cortas; vainas ocupando la mitad o más de la longitud de las láminas, fuertemente carinadas, con márgenes papirosos y membranosos que gradualmente desaparecen o terminan en aurículas inconspicuas o hasta $1.2 \mathrm{~mm}$ de largo; láminas lateralmente comprimidas, 1.5-3(-4.5) mm de ancho, con márgenes filosos o estrechamente alados, a veces con particiones transversales parciales pero nunca con septos completos. Inflorescencia una antela compuesta con cabezuelas de 7-20 flores, globosas a semi-globosas, 6-8 mm de diámetro; brácteas inferiores de la inflorescencia ensiformes, brácteas distales más cortas, membranosas, brácteas florales tan largas como las flores. Flores de color pajizo o castaño con línea central verde. Tépalos iguales o los externos ligeramente más largos que los internos, 2.5-3 mm de largo, linear-lanceolados, agudos, los externos cóncavos o ligeramente carinados, los internos aplanados. Estambres seis (raramente 3-5), 1-2 mm de largo; filamentos filiformes, anchos en la base, 0.5-1 mm de largo; anteras de 0.5-1 mm de largo, más cortas que los filamentos. Ovario con el estilo de 0.5-0.7(-1) $\mathrm{mm}$ de largo; estigmas hasta $1.5 \mathrm{~mm}$ de largo. Cápsula oblonga-elipsoidal, subobtusa, 2.4-3.5 mm de largo (incluyendo el rostro), más o menos del largo de los tépalos, de color profundamente castaño, liso. Semillas elipsoidales, apiculadas, ca. 0.4-0.6 $\times 0.2 \mathrm{~mm}$, reticuladas, de color castaño. $2 \mathrm{n}=$ desconocido.

Distribución general. Norte América desde la Columbia Británica y Alberta (Canadá) hasta California, Nuevo México y Texas (Estados Unidos de Norte América) y en México en Baja California, Chihuahua, Coahuila, Durango, Estado de México, Guerrero, Hidalgo, San Luis Potosí, Sonora, Tamaulipas.

Habitat y fenología. Juncus saximontanus crece a lo largo de riachuelos, lagos, y pantanos, generalmente en las montañas hasta 3000 metros sobre el nivel del mar.

Nombre vernáculos y usos. Desconocidos.

Afinidades. Juncus saximontanus pertenece a Juncus subgénero Juncus sección Iridifolii que incluye 10 especies con los culmos y láminas lateralmente comprimidos. En México hay otras dos especies de esta sección: Juncus ensifolius y J. xiphioides.

Especímenes examinados. BAJA CALIFORNIA: Santa Catarina Mts., 17.IX.1884, Orcutt s.n. (GH); Cañon del Diablo, north and west of Picacho del Dia- 
blo, Cerro La Encantada, eastern flank of Sierra San Pedro Mártir, 15.VI.1954, K. L. Chambers 592 (UC); La Sanca creek, Sierra San Pedro Mártir, 17.IX.1930, I. L. Wiggins \& D. Demaree 4856 (UC, US); Río San Rafael al norte de Ejido E. López Zamora, 21.IX.1983, R. F. Thorne 57355 (UC); Sierra San Pedro Mártir, Cerro Venado Blanco, 17.VII.1988, S. Boyd et al. 2604 (F). CHIHUAHUA: Sierra Madre, Colonia Garcia, 5.VII.1899, C. H. T. Townsend \& C. M. Barber 108 (F, GH, NY, UC, US); Sierra Madre, 5.X.1887, C. G. Pringle 1389 (F, GH, NY, US); Majalca, 24.VI.1936. H. LeSueur 1111 (F, GH, UC, US); Majalca, 24.VI.1936, H. LeSueur 1124 (MEXU, PH, US); South-western Chihuahua, VIII-XI.1885, E. Palmer 101 (NY); Mojárachic, 4.X.1938, Knobloch s.n. (US), 5077 (F); COAHUILA: Villa Acuña, Sierra del Carmen, Canyon de Sentenela, Had. Piedra Blanca, 6.VI.1936, F. L. Wynd \& C. H. Mueller 509 (ARIZ, GH, MO, NY, WIS); La Casita, 22.VIII.1948, Keynoyer \& Crum 2980 (GH); Cañon del Indio Felipe, ca. lat. 28 33' close to Chihuahua border, 27-29. IX.1940, R. M. Stewart 145 (GH); Sierra Madre del Carmen, Cañon El Dos, 2250 m, 3.VIII.1974, T. Wendt 454 (MO). DURANGO: Tobar, 28-31.V.1906, E. Palmer 254 (F, GH, MO, NY, UC, US); Durango, IV-XI.1896, E. Palmer 885 (US); Sierra Madre Occidental, El Salto, Aserraderos, Arroyo de Agua, 1.IX.1934, F. W. Pennell 18568 (GH, US). GUERRERO: 4 km S of Guerrero, L. McGill \& D. Keil 8339 (NY). HIDALGO: Sierra de Pachuca, 22.VII.1901, J. N. Rose \& R. Hay 5590 (GH, US). ESTADO DE MÉXICO: $8 \mathrm{~km}$ al sur de Río Frío, Arroyo Aculco, Ixtapaluca, 18.IX.1983, R. Galván 1458 (AAU, MO); Ixtapaluca, 8 km S of Río Frío, 21.VIII.1975, 3250 m, S. D. Koch 75408 (MO), 75348 (F); Mt. Popocatépet1, 26.VII.1938, E. K. Balls et al. 5108 (K, UC, US). SAN LUIS POTOSÍ: $22^{\circ} \mathrm{N}$ lat., $1850-2450 \mathrm{~m}, 1878$, C. C. Parry \& E. Palmer 897 (GH, MO, NY). SONORA: San José Mts., 5 miles south of Naco, 6.VI.1928, C. B. Wolf 2509 (GH); Río Bavispe, Las Tierritas-El Tigre, pine zone, 22.VIII.1940, S. S. White 3469 (ARIZ, GH); Las Tierritas de El Temblor, Sierra de El Tigre, 18-24.VIII.1940, S. S. White 3512 (GH); Fronteras, VI.1837, G. Thurber 342 (F, NY); Valle de Sta. Cruz, A. Schott s.n. (F); Arroyo de los Llanos, 29.VI.1853, A. Schott s.n. (F, mezclado con J. marginatus). TAMAULIPAS: 3 miles north of Miquihuana, 15.VII.1949, Stanford et al. 2476 (GH, MO, NY, US).

27. Juncus tenuis Willd., Sp. P1. 2: 214. 1799.

Lectotipo (designado por Balslev, 1996): ESTADOS UNIDOS DE AMÉRICA. America boreali, colector desconocido (B-Willd.!; iso-: HBG!). Figura 3 E.

Hierbas perennes, cespitosas, $15-70 \mathrm{~cm}$ de alto. Rizomas densamente ramificados, 1.5-2 mm de diámetro; culmos erectos, teretes, lisos o longitudinalmente 
estriados, 0.8-1.5 mm de diámetro; catáfilos 0-3 por culmo, inconspicuos, hasta 5 $\mathrm{cm}$ de largo, márgenes membranáceos; láminas rudimentarias, aciculares, hasta 15 $\mathrm{mm}$ de largo. Hojas laminares todas basales, erectas, de 1/3 del largo o iguales a los culmos; vainas de 1.5-9 cm de largo, con márgenes membranáceos, terminando en dos aurículas, 0.5-1.5 mm de largo, usualmente más largas que anchas, redondeadas, escariosas o cartilaginosas; láminas planas y canaliculadas en sección transversal, 0.5-1.5 mm ancho, cara adaxial con una banda de células hialinas que ocupan 3/4 del ancho total, solo los márgenes con células densamente dispuestas llenas de clorofila. Inflorescencia terminal en el culmo, ocupando menos de 1/4 del tamaño total de la planta, compuesta, cimosa, formada por varias cimas unilaterales (drepanio); brácteas inferiores de la inflorescencia semejantes a las hojas basales, herbáceas, 2-20 $\mathrm{cm}$ de largo, las distales progresivamente más cortas, las últimas membranosas hasta $5 \mathrm{~mm}$ de largo; bractéolas dos por cada flor, 1.5-2 mm de largo. Tépalos subiguales, recurvándose hacia los ápices, lanceolados, agudos a acuminados, márgenes membranáceos distintivos, primero de color verde que se torna de color castaño a pajizo con el tiempo, los externos 3.5-4.5 mm de largo, cóncavos, los internos de 3-4.4 mm de largo, planos. Estambres seis, 1.3-1.8 $\mathrm{mm}$ de largo; anteras lineares a oblongas, 0.4-0.8 mm de largo. Ovario con estilo 0.1-0.2 mm de largo; estigmas ca. $1.5 \mathrm{~mm}$ de largo. Cápsula elipsoidal, aguda a obtusa, apiculada, 2.5-3.5 × 2-2.5 mm, más corta que los tépalos cuando madura, de color castaño pálido en la madurez, triseptada. Semillas elipsoidales, apiculadas, frecuentemente curvadas, $0.4-0.6 \times 0.2-0.3 \mathrm{~mm}$, lisas hasta ligeramente rugosas, de color amarillo-castaño, apéndices ausentes o diminutos. $2 \mathrm{n}=40$, ca. 60, 80, 84 (Harriman y Redmond, 1976; Harriman, 1979; Love y Love, 1981; Druskovic, 1995).

Distribución general. Juncus tenuis es muy común y está ampliamente distribuida en Norte América. Esta especie fue introducida a Europa occidental en el siglo XIX donde ocupa un área vasta y sigue expandiéndose. También lo fue en Japón, las islas Azores y Nueva Zelanda, donde es frecuente (Kirschner, 2002c). En el Neotrópico se conoce de tierras altas. Wiegand (1900) sugiere que la variación morfológica de las poblaciones neotropicales es el resultado de varias introducciones desde las regiones templadas de Norte América. Una solución satisfactoria de la taxonomía de la especie requiere una revisión completa del complejo en Norte América. La especie fue dividida en tres variedades que no son distinguibles por un solo carácter, pero usando más de uno, la mayor parte de los especímenes de herbario pueden ser asignados a una de estas variedades. Juncus tenuis var. tenuis es la más común y se encuentra a lo largo de las regiones templadas de Norte América y ha sido intro- 
ducida en Japón, Nueva Zelanda y Europa donde ha recibido varios nombres, entre ellos el más común J. macer. En el Neotrópico se distribuye en México y Centro América, en las Antillas en Jamaica y Puerto Rico y en Sur América en los Andes de Venezuela y Colombia hasta Ecuador y Argentina.

Hábitat y fenología. Juncus tenuis var. tenuis es una maleza cuya distribución está influenciada por la actividad y movilidad humana, comúnmente crece entre 1000-3000 metros sobre el nivel del mar, a lo largo de caminos y sitios perturbados con suelos húmedos. La dispersión de esta especie es facilitada por la habilidad de la cubierta seminal de hincharse y hacerse pegajosa, gelatinosa y adherirse con facilidad a los animales que pastan. Crece en pastizales, bosques de Pinus, Quercus y Arbutus, cerca de caminos y pequeños arroyos. Juncus tenuis ha sido colectada en flor entre junio y septiembre y en fruto desde mayo hasta diciembre.

Nombres vernáculos y usos. En Chihuahua el pueblo Tarahumara la conoce como Bajisori y dicen que el ganado tiene gran preferencia por esta especie (Bye 4196).

Afinidades. Juncus tenuis forma parte del subgénero Agathryon sección Steirochloa junto con $J$. dichotomus, $J$. dudleyi (ver para más discusión), J. interior y J. imbricatus.

Especímenes examinados. CHIAPAS: San Cristóbal de las Casas, valley towards Chamula, 2200 m, 3.IX.1974, D. E. Breedlove 37122 (NY); Zinacantán near Paraje Nachij, 2400 m, 28.X.1981, D. E. Breedlove \& G. Davidse 53830 (CAS, MO, NY). CHIHUAHUA: Between Bocoyna and Creel, $2200 \mathrm{~m}, 13$. VII.1973, R. A. Bye Jr. 4196 (GH); Río Mayo, Memelichic, 2300 m, 16.VIII.1989, P. D. Jenkins 89-211 (ARE). Basaseachi Falls, 6.VII.1936, H. LeSueur 1117a (GH, UC, US); Río Mayo, El Capitan, 2100 m, 23.VI.1987, P. S. Martin s.n. (ARIZ); Temosachic, Cañon Huahuatan, 17 km SE of Madera, 25.IX.1939, C. H. Muller 3488 (GH, UC). COAHUILA: Sierra del Pino near La Noria, 20-26.VIII. 1940, I. M. Johnston \& C. H. Muller 481 (F, GH); Cañon de Indio Felipe, Sierra Hechiceros close to Chihuahua boundary, 2729.IX.1940, R. M. Stewart 111 (GH); Sierra del Pino near La Noria, 27-28.VIII.1941, R. M. Stewart 1202 (F, GH); DURANGO: Hwy. 40, $72 \mathrm{mi} \mathrm{W}$ of Río Mimbres, ca. 32 $\mathrm{mi}$ W of Durango, $2766 \mathrm{~m}$, C. A. Bennett et al. 771 (MO); 1.5 miles east of El Salto, near Mexico Hwy. 40, 22.VII.1975, 2816 m, D. Le Doux et al. 1933 (MO); 33.7 miles W of Durango Hwy. 40, 2750 m, 21.VII.1975, K. J. Torke et al. 223 (MO); 56 km W of Durango, 11.VIII.1956, U. T. Waterfall 12626 (GH, UC, US). GUERRERO: Puerto 
del Gallo to La Golondrina, 2400 m, 23.V.1987, I. S. Miller \& G. Campos 2910 (MO). HIDALGO: Real del Monte, 13.IX.1910, I. W. Clokey 1856 (UC); Hwy. 85, Tamazunchale-Jacala km 37, near Palomas, 1500 m, 25.VI.1977, T. B. Croat 39306 (MO); Tlanchinol, $1450 \mathrm{~m}$, Puig 4627 (ENCB); El Cirio, $8 \mathrm{~km}$ al este de Tenango de Doria, 1700 m, 21.V.1982, R Hernández Magaña 7327 (MO). ESTADO DE MÉXICO: Temascaltepec-Toluca road km 15, 2800 m, Marcks 1132b (WIS). OAXACA: Sierra Juárez 27 km N of Ixtlán, 2500 m, 16-17.IX.1965, K. Roe \& E. Roe 1942 (DS, F, NY, UC, US, WIS); just W of La Soledad Tectitlán on road to San Juan Quiotepec at point where road curves to south, $1990 \mathrm{~m}, 26 . I$ V.1986, R. E. Gereau \& G. J. Martin 1995 (MO). SONORA: Canyon de Tejas, Sierra Charuco, 1200-1400 m, 24.IV.1948, H. S. Gentry 8121 (US). VERACRUZ: Huayacocotla, 2000 m, 21.XII.1970, R. Hernández M. \& Y. Vásquez de Hernández 1000 (F); Jalacingo, Coapa, 1700 m, F. A. Ventura 17662 (AAU, MEXU).

28. Juncus textilis Buchenau, Abh. Naturwiss. Vereine Bremen 17: 336. 1902. t. 6. Tipo: ESTADOS UNIDOS DE AMÉRICA. California, San Gabriel Cañon, among trees, II.1861, W. H. Brewer 168 (holo-: GH!; iso-: US!). Figura 9.

Hierbas perennes, 100-200 cm de alto. Rizomas rastreros, 2-5 mm de diámetro, internodos muy cortos o más frecuentemente hasta $4 \mathrm{~cm}$ de largo, los culmos insertos todos juntos o espaciados; culmos erectos, 5-7 mm de diámetro, estriados, con numerosas y finas estrías longitudinales; catáfilos 2-4 por cada culmo, los inferiores hasta $1 \mathrm{~cm}$, los superiores hasta $25 \mathrm{~cm}$ de largo; usualmente con láminas rudimentarias, hasta $3 \mathrm{~mm}$ de largo, mucronadas, de color castaño a pajizo. Hojas laminares ausentes. Inflorescencia pseudolateral, usualmente con muchas flores, laxa, hasta $10 \times 7 \mathrm{~cm}$, en forma de cima compuesta, consistiendo de varias cimas juntas, de las cuales las últimas son drepanios unilaterales; brácteas inferiores de la inflorescencia apareciendo como un continuo desde los culmos, 5-20 cm de largo, o usualmente conformando entre $1 / 10$ y $1 / 5$ del total de la altura de la planta, brácteas distales más cortas, membranáceas. Flor abrazada por dos bractéolas, $1.5-2.5 \mathrm{~mm}$ de largo, membranáceas. Tépalos iguales, lanceolados, de color pajizo, los externos de 4-5 mm de largo, cóncavos, agudos, los internos de 3.5-5 mm de largo, planos a cóncavos, acuminados con una arista corta. Estambres seis, 1.5-3 mm de largo; filamentos planos, ensanchados hacia la base; anteras lineares, torcidas, 2-2.5 mm de largo, mucho más largas que los filamentos. Ovario con estilo ca. $1 \mathrm{~mm}$ de largo; estigmas ca. $1 \mathrm{~mm}$ de largo. Cápsula globosa, apiculada, redonda a trígona, 4-6 $\times 2-3 \mathrm{~mm}$, igual o más larga que los tépalos, de color castaño claro a castaño oscuro, brillante, 
triseptada. Semillas oblongo-ovoides, cortamente apiculadas, 0.6-0.8 $\times 0.2-0.5 \mathrm{~mm}$, rugulosas, de color castaño pálido y castaño abajo de la cubierta seminal hialina, apéndices ausentes. $2 \mathrm{n}=$ desconocido.

Distribución general. Juncus textilis está distribuida en un área relativamente pequeña del sur del estado de California (Estados Unidos de América) y apenas alcanzando Baja California en México donde ha sido colectada una sola vez.

Hábitat y fenología. Juncus textilis crece comúnmente en áreas húmedas en rodales densos hasta los 1800 metros sobre el nivel del mar. En Baja California se encuentra solo por debajo de los 50 metros de altitud. En México ha sido colectada en flor en agosto.

Nombres vernáculos y usos. Juncus textilis es utilizada para realizar cesterías hermosas, duraderas y valiosas (Buchenau, 1902).

Afinidades. Juncus textilis forma parte del subgénero Agathryon sección Juncotypus junto con J. aemulans, J. balticus, J. effusus y J. patens. Es una especie distintiva; recuerda de alguna manera a especímenes grandes de $J$. arcticus, y también a $J$. lesueurii del oeste de Estados Unidos de América por sus rizomas robustos, tallos gruesos y grandes flores, pero se diferencia de ellas por sus flores de color pajizo, y tallo con estrías longitudinales conspicuas originándose de trazos de esclerénquima subepidérmicos. En este último carácter recuerda también a $J$. effusus, de la cual sin embargo es notablemente diferente en apariencia.

Especímenes examinados. BAJA CALIFORNIA: Cantamar, 5 m, 4.VIII.1979, R. Moran 27945 (MO, NY, SD).

29. Juncus tiehmii Ertter, Mem. New York Bot. Gard. 39: 60. 1986.

Tipo: ESTADOS UNIDOS DE AMÉRICA. California, Riverside Co., Kenworthy Forest Station on Rt. 74 in Gamer Valley, San Jacinto Mts., 26.VI.1979, ca. 1400 m, B. J. Ertter \& J. L. Strachan 2971 (holo-: NY!; iso-: CAS!, F!, GH!, K!, MICH!, MO!, OSC!, PH!, RSA!, SD!, TEX!, UC!, US!, UTC!, WTU!). Figura 10.

Hierbas $0.8-5(4.3) \mathrm{cm}$ de alto, con matices rosados, tornándose de color pajizo con matices rosados. Hojas hasta 2.2(-2.5) cm de largo; láminas 0.1-0.3 mm de ancho; culmos 0.5-4.8(4) $\mathrm{cm}$ de largo, 0.1-0.2 $\mathrm{mm}$ de grueso, frecuentemente 
tornándose rosadas; brácteas 2-4(-8), ovadas, agudas, usualmente no pigmentadas, a veces de color rojizo-castaño en la base, $0.6-1.5 \mathrm{~mm}$ de largo, rara vez tepaloides y entonces hasta $2 \mathrm{~mm}$ de largo; pedicelos 0.1-0.5 mm de largo. Inflorescencia una cabezuela terminal reducida. Flores 1-4(-7), usualmente dímeras; tépalos 4(-6), (1-)1.9$2.9 \mathrm{~mm}$ de largo, 0.4-0.6 mm ancho, casi iguales, rara vez con diferencia de $0.1 \mathrm{~mm}$, agudos o acuminados, la banda central de color verde pálido con márgenes rojizos y la punta oscura, a veces rojizos oscuros en toda su extensión, 0.1-0.3 $\mathrm{mm}$ ancho, los márgenes no pigmentados, 0.1-0.2 mm ancho. Estambres 2(-3), 0.8-1.2 mm de largo, ca. 1/2 (3/4 en las flores pequeñas) del largo de los tépalos; filamentos 0.5-0.8 $\mathrm{mm}$ de largo; anteras 0.3-0.4 mm de largo, ca. la mitad del largo de los filamentos. Ovario con estilo de hasta $0.3 \mathrm{~mm}$ de largo; estigmas 2(-3), 0.2-0.7 mm de largo, de color blanco, más cortos que los tépalos en la antesis. Cápsula obovoide, elíptica a estrechamente oblonga, 2(-3)-valvada, usualmente aplanada, redondeada a ligeramente retusa, usualmente igualando o excediendo a los tépalos por $0.9 \mathrm{~mm}$, rara vez 0.3 mm más corta, (1.5-)1.9-2.9 mm de largo, 1.1-1.5 mm ancho, usualmente con matices rosados, similar en color a los tépalos. Semillas hasta 7 por fila y de ca. 30 por cada cápsula, oblongas u ovoides, (0.3-)0.35-0.55 mm de largo, frecuentemente apiculadas y umbonuladas, las costillas longitudinales distintivas (ampliación 30 x), líneas transversales muy finas estrechamente espaciadas. $2 n=34$ (Ertter, 1986).

Distribución general. Juncus tiehmii se distribuye en la costa oeste de Estados Unidos de América desde Idaho, Nevada y Oregon hacia el sur hasta California, y en México en Baja California hasta la Sierra San Pedro Mártir.

Hábitat y fenología. Juncus tiehmii crece en arenas graníticas a lo largo de riachuelos, cerca de charcos y áreas deprimidas de los prados y a veces formando alfombras, entre 300 y 3000 metros sobre el nivel del mar. Juncus tiehmii florece entre mayo y septiembre.

Nombres vernáculos y usos. Desconocidos.

Afinidades. Juncus tiehmii y J. bryoides son los únicos miembros mexicanos del subgénero Juncus sección Caespitosi. Juncus tiehmii es virtualmente más grande en todas su partes desde el tamaño general de la planta hasta el fruto.

Especímenes examinados. BAJA CALIFORNIA: Sierra San Pedro Mártir, La Corona de Abajo, 2100 m, 4.VI.1988, S. Boyd et al. 2351 (F); Sierra San Pedro 


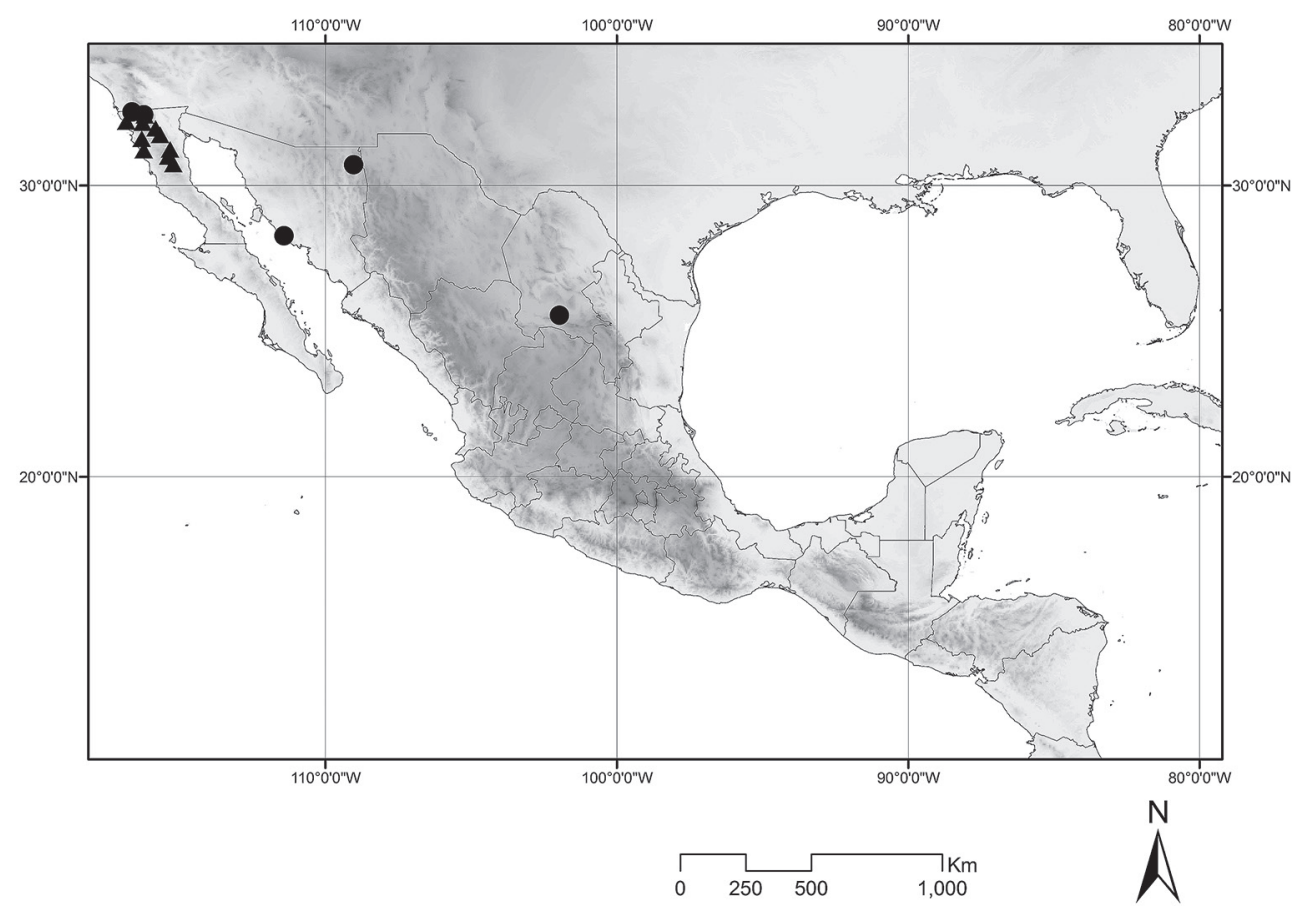

Fig. 10. Mapa de distribución de los especímenes examinados de Juncus tiehmii ( $\mathbf{\Delta})$ y $J$. torreyi $(\bullet)$.

Mártir, La Corona de Abajo, 2100 m, 20.VII.1988, S. Boyd \& T. Ross 2755 (UC); San Pedro Mártir, 2500 m, 17.V.1893, J. S. Brandegee s.n. (F); 22.V.1893, J. S. Brandegee s.n. (F, UC); Sierra San Pedro Mártir, La Encantada, 2200 m, 18.VIII.1967, R. Moran \& R. F. Thorne 14302 (SD, UC); Sierra San Pedro Mártir, La Grulla, 2100 m, 21.VIII.1967, R. Moran \& R. F. Thorne 14452 (SD); N slope of Cerro Blanco, 875 m, 15.VI.1969, R. Moran 16150 (SD, UC); Sierra San Pedro Mártir, Rancho el Potrero, 875 m, 5.VII.1969, R. Moran 16333 (SD); Sierra de Juárez, El Progreso, 1450 m, 24.V.1975, R. Moran 22024 (SD); Sierra San Pedro Mártir, La Víbora, Arroyo la Grulla 4 km SW of La Grulla, 1900 m, 9.VIII.1977, R. Moran 24415 (SD); Sierra San Pedro Mártir, 2 km SE of Yerba Buena, 2450 m, 4.IX.1978, R. Moran 26242 (SD); Sierra de Juárez, Mesa los Alacranes, 1410 m, 27.V.1979, R. Moran 27464 (NY, SD, UC, US); Sierra de Juárez, N of Agua Amarga, $6 \mathrm{~km} \mathrm{~N}$ of Laguna Hanson, 1670 m, 28.V.1979, R. Moran 27521 (SD); Sierra de Juárez, Laguna Hanson, 1620 m, 24.VI.1979, R. Moran 27700 (SD); Sierra Juárez, Arroyo la Zacatosa 1.5 km N of El Torito, 1175 m, 7.VII.1979, R. Moran 27740 (SD); Sierra San Pedro Mártir, La Grulla, 
2050 m, 9.VI.1982, R. Moran 30935 (SD); Laguna Hanson, Constitution National Park, Sierra de Juárez, 1610 m, 28.V.1983, R. E. Thorne et al. 55743 (SD); Sierra San Pedro Mártir, San Felipe Desert to Los Emes, 1400 m, 11.V.1941, I. L. Wiggins 9884 (UC); Baja California sin localidad exacta, 7.VII.1884, C. R. Orcutt 1166 (GH).

30. Juncus torreyi Coville, Bull. Torrey Bot. Club 22: 303. 1895.

三Juncus nodosus var. megacephalus Torr., Fl. New York 2: 326. 1915.

इJuncus megacephalus (Torr.) A.W. Wood, Class-Book Bot. 724. 1861, nom illeg., non M. A. Curtis 1835.

Tipo: ESTADOS UNIDOS DE AMÉRICA. Shores of Lake Ontario, VIII.1834, A.Gray (holo-: NY!). Figura 10.

Hierbas perennes, 30-100 cm de alto. Rizomas horizontales, estoloníferos, largamente rastreros, 1-2 mm de diámetro, frecuentemente con bulbos engrosados en la base de cada culmo, internodos hasta $7 \mathrm{~cm}$ de largo, escamas ausentes o pocas; culmos erectos, surgiendo en solitario a lo largo del rizoma, 1-2 mm de diámetro, lisos; catáfilos 0-2 por cada culmo, hasta $10 \mathrm{~cm}$ de largo, no prominentes. Hojas laminares (1-)2-4(-6) espaciadas a lo largo de los culmos o a veces algo agrupadas en la base, $10-50 \mathrm{~cm}$ de largo; vainas de $5-15 \mathrm{~cm}$ de largo, con márgenes membranáceos, terminados en dos aurículas circulares, 1-4 mm de largo; láminas 1-5 mm de diámetro, teretes, ahuecadas, con septos más o menos prominentes, distantes entre sí $15 \mathrm{~mm}$, adaxialmente con una hendidura a todo lo largo. Inflorescencia una antela decompuesta, hasta $8 \times 4 \mathrm{~cm}$; cabezuelas (1-)3-5(-25), globosas, 10-15 mm diámetro, cabezuelas con ramas frecuentemente cortas y enteras; brácteas inferiores de la inflorescencia (1.5-) 5-15 cm de largo, semejantes a hojas caulinares con vainas de 0.5-1 cm de largo, brácteas distales más cortas. Flores (5-)25-60(-80), de color verde pálido a pajizo a veces con una ligera pigmentación rojiza. Tépalos (3-)3.4$4.6 \mathrm{~mm}$ de largo, rígidos, linear-lanceolados, subulados, los externos cóncavos y ligeramente más largos que los internos, los internos planos. Estambres seis, 1.2-1.6 $\mathrm{mm}$ de largo; filamentos planos; anteras oblongas a lineares, 0.5-0.7 mm de largo, usualmente tan largas o más cortas que los filamentos, antes de la antesis a veces ligeramente más largas que los filamentos. Ovario con estilo 0.1-0.2 mm de largo; estigmas 0.9-1.2 mm de largo. Cápsula estrechamente ovoide, trilobada, adelgazándose gradualmente hacia el ápice, rostro $0.5 \mathrm{~mm}$ largo, $3-5 \mathrm{~mm} \times 0.7-1.3 \mathrm{~mm}$, más larga que los tépalos cuando madura, de color castaño pálido a castaño oscuro, unilocular. Semillas oblongas, apiculadas, 0.4-0.5 $\times 0.2-0.25 \mathrm{~mm}$, reticuladas, de color amarillo-castaño. $2 \mathrm{n}=40$ (Harriman y Redmond, 1976; Love y Love, 1981). 
Distribución general. Juncus torreyi se distribuye ampliamente en los Estados Unidos de América y sur de Canadá pero sin alcanzar la costa este. En México se conoce de Baja California, Coahuila y Sonora.

Hábitat y fenología. Juncus torreyi prospera en prados y tierras boscosas húmedas, a lo largo de arroyos, acequias y aguas poco profundas. Puede ser muy común en algunos sitios. Crece desde el nivel del mar hasta los mil metros de altitud; en Estados Unidos de América hasta los 600 m s.n.m. Esta especie fructifica de mayo hasta noviembre.

Nombres vernáculos y usos. Desconocidos.

Afinidades. Juncus torreyi es miembro del subgénero Juncus sección Ozophyllum que en México incluye ocho especies (para más discusión ver J. acuminatus). Juncus torreyi está estrechamente relacionada con J. nodosus, pero es más grande en todas sus proporciones.

Especímenes examinados. BAJA CALIFORNIA: Sierra de Juárez, Agua Azul, 1 km SE of Rancho la Hechicera, 1070 m, 7.VII.1979, R. Moran 27756 (SDmezclado con J. arcticus var. mexicanus); Tecate, 500 m, 31.X.1981, R. Moran 29859 (SD). COAHUILA: El Carmen Mts., 9.VIII.1936, E. G. Marsh 647 (F, GH), 745 (F, GH); Monclova, 5.V.1939, E. G. Marsh, Jr. 1648 (F, GH); Northern Lower California, 25.VII.1885, C. R. Orcutt 1308 (US). SONORA: "Sonora, Plants of the Mex. Bound. Survey", A. Schott s.n. (F); Colorado of the West, Mexican Boundary, A. Schott s.n. (F); Arroyo de Púlpito, near Colonia Oaxaca, 30.VII.1938, S. S. White 710 (DUKE).

31. Juncus xiphioides E. Mey., Syn. Junc. 50 (1822).

Tipo: ESTADOS UNIDOS DE AMÉRICA. Bolander 07 (holo-MO).

$\equiv$ Juncus xiphioides var. littoralis Engelm., Trans. Acad. Sci. St. Louis 2: 481. 1868. Tipo: MÉXICO. In Nova Hispania prope Real del Monte, T. Haenke (holo-: PR).

Hierbas perennes, (25-)35-55(-110) cm de alto, robustas, laxamente cespitosas. Rizomas usualmente gruesos, hasta $4.5 \mathrm{~mm}$ de diámetro, internodos horizontales cortos; estolones no vistos. Tallos comprimidos, con doble filo, de ca. $3.6 \mathrm{~mm}$ de ancho; catáfilos 1-2, de color purpúreo-marrón, márgenes membranáceos, de ca. $5 \mathrm{~cm}$ de largo. Hojas sub-basales 1-3. Hojas caulinares usualmente 3-6, (6-)12-25(-40) cm de largo, (3-)4-9(-11) $\mathrm{mm}$ de ancho en la porción media; vainas libres, márgenes distintivamente membranáceos; aurículas ausentes; láminas pluritubulares, imperfectamente septadas; márgenes 
agudos, ligeramente papilosos; ápice subulado. Inflorescencia decompuesta, ca. 6-15 cm de largo; ramas primarias 1-4, erectas, rígidas; ramas secundarias cortas, erecto-patentes, muchas cabezuelas aglomeradas o subaglomeradas; cabezuelas globosas, 12-20-flores (o cuando aglomeradas, hasta 70-flores), usualmente $8 \mathrm{~mm}$ en diámetro o más; brácteas inferiores como hojas, de ca. 2-4(-7) cm de largo, más cortas que la inflorescencia. Tépalos subiguales o los externos más largos, estrechamente lanceolados, acuminados, 2.8-3.9 mm de largo, verdosos, de color pajizo marrón a castaño marrón; márgenes distintivamente escariosos. Estambres seis; anteras de 0.5-0.9 mm de largo; filamentos de 0.6-0.7 $\mathrm{mm}$ de largo. Ovario con estilo difícil de distinguir del ápice de la cápsula, hasta $0.5 \mathrm{~mm}$ de largo; estigmas hasta $1 \mathrm{~mm}$ de largo. Cápsula unilocular, oblongo-cilíndrica, 2.8-3.5 mm de largo, acuminada; segmentos de la cápsula de $1 \mathrm{~mm}$ de ancho, más largos que el perianto. Semillas elipsoidales-turbinadas, de color marrón claro, 0.45-0.55 $\times 0.2$ $\mathrm{mm}$, claramente reticuladas, apiculadas; apéndices ausentes. $2 \mathrm{n}=40$ (Snogerup, 1963).

Distribución general. Juncus xiphioides se distribuye en el suroeste de los Estados Unidos de América (Arizona, California, Nevada y Utah) y en el norte de México (Baja California, Chihuahua).

Hábitat y fenología. Juncus xiphioides crece en pantanos salobres, lugares húmedos, acequias, manantiales y lagos, entre 500 y 1600 metros sobre el nivel el mar. Esta especie florece y fructifica entre mayo y octubre.

Nombres vernáculos y usos. Desconocidos.

Afinidades. Juncus xiphioides es miembro del subgénero Juncus sección Iridifolii que incluye diez especies y solo tres de ellas en México (Juncus ensifolius, J. saximontanus y J. xiphioides).

Especímenes examinados. BAJA CALIFORNIA: Rancho San Jacinto, 7.IX.1930, I. L. Wiggins \& D. Demaree 4744 (US); Palm Valley, 30.V.1883, C. R. Orcutt 861 (F, US); Todos Santos Bay, 1882, F. E. Fish s.n. (US); Sierra de la Laguna, 21.X.1893, J. S. Brandegee s.n. (US). CHIHUAHUA: Mun. Bocoyna, E de Gongochic, 2225 m, 24.VIII.1977, R. Bye B. 7948 (MEXU).

Luzula DC., Fl. Franç., $3^{\text {rd }}$ ed., 3: 158. 1805. nom. cons. Tipo: Luzula campestris (L.) DC, typ. cons.

Juncoides Möhing, Primae Lin. Hort. Priv. 1737. 
Luciola Smith, Engl. fl. 2 ed. 177. 1828.

Juncodes Kuntze, Revis. Gen. Pl. 2: 722.1891.

Hierbas perennes, rizomatosas, márgenes de las hojas y brácteas pilosos. Rizomas ausentes; culmos erectos. Hojas alternas, con escamas en estolones y rizomas, escamas foliares en la base de los culmos y con forma de brácteas de la inflorescencia; vainas cerradas, sin aurículas en la unión con la lámina; láminas lineares a estrechamente lanceoladas, planas, cóncavas o con márgenes involutos. Inflorescencia con muchas flores individuales insertadas en forma laxa, panículas muy ramificadas o flores agregadas en densos grupos los cuales a su vez se disponen en panículas, antelas o racimos, o bien flores comprimidas en densas estructuras parecidas a espigas. Flores perfectas, cada flor con dos brácteas subyacentes en la base del pedicelo y abrazadas por 1-2 bractéolas insertas justo debajo de la flor. Tépalos desiguales o casi iguales, lanceolados; márgenes enteros, a veces membranáceos o divididos en lóbulos ciliados. Estambres tres o seis; filamentos filiformes, rara vez lineares y aplanados; anteras oblongas, rara vez lineares. Ovario sésil; estilo corto, filiforme; estigmas tres, filiformes, torcidos, cubiertos con papilas muy pegajosas. Cápsula trígona, a veces basalmente trilobada, unilocular. Semillas tres por cápsula, unidas a la placenta por un largo y delicado funículo, elipsoidales a oblongas, de color castaño a castañorojizo, cubierta seminal blanca, hialina o de color castaño, apéndices ausentes.

El nombre Luzula se origina del verbo en latín lucciola en referencia al brillo de la inflorescencia producido por el indumento que la recubre.

Kirschner (2000a) reconoció tres subgéneros: Luzula, Marlenia Ebinger y Pterodes (Griseb.) Buchenau, el primero con siete secciones. Luzula es un género cosmopolita con cerca de 115 especies (Kirschner, 2000a), la mayoría de las cuales se distribuyen en las regiones templadas del hemisferio norte. En las zonas tropicales Luzula está completamente ausente en tierras bajas pero presente en tierras altas por encima de los 2500 metros sobre el nivel del mar. En América tropical hay ocho especies de Luzula, de las cuales cinco existen en México.

Clave para las especies de Luzula en México

1. Flores insertas individualmente en las inflorescencias y los pedicelos visibles; inflorescencias panículas laxas L. denticulata 
1. Flores en cabezuelas redondas o agrupamientos alargados; las cabezuelas arregladas en antela, panículas laxas, racimos parecidos a espigas ............................. 2

2. Ápice de las hojas obtuso, con punta callosa ……………………………….... 3

3. Inflorescencia una espiga, terminal, erecta, con ligeras interrupciones, las espigas inferiores usualmente tan largas como el pedúnculo, pero no dobladas hacia afuera de las inflorescencias L. caricina

3. Inflorescencia de varias cabezuelas redondas o ligeramente alargadas dispuestas en una antela, las ramas proximales más largas y sobrepasando las distales L. comosa

2. Ápice de las hojas agudo, sin punta callosa 4

4. Estolones presentes; culmos usualmente rectos; brácteas de los agregados de flores membranáceas y no excediendo al grupo L. vulcanica

4. Estolones ausentes; culmos usualmente curvados; brácteas, al menos de las flores de los agregados inferiores herbáceas y excediendo al grupo

L. racemosa

1. Luzula caricina E. Mey., Linnaea 22: 418. 1849.

$\equiv$ Juncoides caricina (E. Mey.) Kuntze, Revis. Gen. Pl. 2: 724. 1891.

Lectotipo (designado por Balslev, 1996): MÉXICO. Oaxaca, $2450 \mathrm{~m}, 1840, H$. G. Galeotti 5758 (lecto-:, W!; iso-: G!, K!, P!, W!).

$\equiv$ Luzula interrupta Desv., J. Bot. (Desvaux) 1: 163, t. 6, f. 4. 1808b. nom rejic. propos. Tipo: America calidiore: sine coll. (holo-: P!).

= Luzula barbata Liebm., Mexic. Juncac. 45. 1850.

Lectotipo (designado por Balslev, 1996): MÉXICO. Puebla, Chinantla, 2150-2450 m, F. M. Liebmann s.n. (holo-: C!; photo of lectotype BH!; iso-: G!, GH!, K!, P!, S!, $\mathrm{W}$ !).

Hierbas perennes, cespitosas, 10-60 $\mathrm{cm}$ de alto. Rizomas erectos o ascendentes, a veces engrosados en la base de los culmos; culmos erectos y usualmente rectos, teretes, frecuentemente sulcados cuando secos, 0.7-2 $\mathrm{mm}$ de diámetro. Hojas basales 3-10 por cada culmo; láminas 5-15 × 0.2-0.4 cm, gradualmente atenuadas en una punta obtusa y callosa; márgenes pilosos, al menos cuando jóvenes. Hojas caulinares 1-3 por cada culmo, semejantes a las hojas basales pero erectas y usualmente más cortas. Inflorescencia un racimo de grupos de flores parecido a una espiga, erecto, $2-5 \times 0.5-1 \mathrm{~cm}$ y usualmente acompañado de un racimo de grupos de flores similar al anterior pero naciendo hasta $8 \mathrm{~cm}$ por debajo del terminal e insertado en un pedúnculo erecto que lo eleva justo por debajo del racimo 
terminal; el raquis usualmente visible entre los grupos de flores; brácteas de la inflorescencia proximal semejantes a pequeñas hojas caulinares, las brácteas distales más cortas y membranáceas con los márgenes enteros o divididos en lobos ciliados. Tépalos lanceolados, acuminados a mucronados, 2-3.5 $\mathrm{mm}$ de largo, de color pajizo o castaño, los externos cóncavos, los internos planos. Estambres seis, 1.2-2 mm de largo; anteras lineares, 0.6-1 mm de largo, iguales o más largas que los filamentos. Ovario con estilo 0.3-0.6 mm de largo; estigmas 1.8-1.9 mm de largo. Cápsula obovoide, aguda a mucronada, trígona a trilobada, 2-3 × 1.2-1.8 $\mathrm{mm}$. Semillas elipsoidales, 1.5-1.8 $\times$ 0.8-1 mm, con una carúncula conspicua, de color castaño por debajo de la cubierta seminal hialina y finamente rugosa. $2 \mathrm{n}=$ desconocido.

Distribución general. Luzula caricina se distribuye desde el norte de México hasta Guatemala. En México se encuentra en los estados de Chiapas, Chihuahua, Distrito Federal, Guerrero, Hidalgo, México, Michoacán, Morelos, Oaxaca, Puebla, Querétaro y Veracruz. McVaugh (1993) también la menciona para Jalisco.

Hábitat y fenología. Luzula caricina prospera en elevaciones entre 2400-3200 metros en planicies y laderas con diversos bosques de altura: pino, pino-encino, pino-oyamel (Abies), encino-Magnolia, así como también en pequeños pastizales asociados a bosque de oyamel (Abies), pastizales y herbazales alpinos. Puede crecer simpátricamente con $L$. denticulata y L. racemosa. En México, L. caricina ha sido colectada en flor y fruto desde mayo hasta noviembre.

Nombres vernáculos y usos. Desconocidos.

Afinidades. Luzula caricina junto con L. comosa forman parte del subgénero Luzula sección Luzula, es la especie más fácilmente reconocible por la siguiente combinación de caracteres: láminas de las hojas con los ápices obtusos y callosos, inflorescencias dispuestas en grupos de flores que parecen espigas erectas, distantes entre sí, así que el raquis es visible, y usualmente los grupos más basales de las flores presentan un pedúnculo muy largo. El pedúnculo de los grupos basales de las flores es erecto y se inserta muy por debajo de la parte distal de la inflorescencia, lo que los eleva y ubica cerca de los grupos terminales, de manera que la inflorescencia no aparenta estar subdividida. Las hojas con los ápices obtusos y callosos también la relacionan con L. campestris, la cual sin embargo se puede distinguir por sus inflorescencias de cabezuelas dispuestas en una antela. 
Especímenes examinados. CHIAPAS: Tenejapa, Colonia San Antonio trail, 2400 m, 12.VII.1965, D. E. Breedlove 10799 (DS, ENCB, LL, MICH, US); Tenejapa, San Cristóbal de las Casas road above Tenejapa Center, 2150 m, 12.VII.1965, D. E. Breedlove 10883 (F); 15 km SE of San Cristóbal de las Casas, near Rancho Nuevo, 2750 m, 20.VIII.1966, D. E. Breedlove 15106 (F); Paraje Matsab, 300 m, 12.V.1966, A. Shilom Ton 948 (GH). CHIHUAHUA: Mt. Mohinora, SW Chihuahua, 1.IX.1898, E. W. Nelson 4878 (GH, US); Sierra Madre, 2700 m, 7.X.1887, C. G. Pringle 1166 (NY). DISTRITO FEDERAL: Desierto de 1os Leones, VII.1938, E. Lyonnet 2144 (CAS, MEXU, US); Desierto de los Leones, 23.IX.1938, E. Lyonnet 2593 (US). GUERRERO: Teotepec, Mina, Gro., 3200 m, 17.VII.1939, G. B. Hinton 14452 (ARIZ, F, MO, NY, US). HIDALGO: Sierra de Pachuca, 21-23. VII.1901, J. N Rose \& R. Hay 5591 (GH, US). JALISCO: Sierra de Manantlán, El Chante-Cuzalapa, $2750 \mathrm{~m}, R$. McVaugh 23130 (ENCB). ESTADO DE MÉXICO: La Venta, 2500 m, 12.VII.1935, G. L. Fisher 35218 (F, MO, NY, US); Ojos de Agua, Nevado de Toluca, 3650 m, 10.VII.1938, E. K. Balls 4979 (UC, US). MICHOÁCAN: SW side of Cerro San Andres $12 \mathrm{~km} \mathrm{~N}$ of Hidalgo, 3100 m, 6.IX.1960, J. H. Beaman 4325 (GH, US); N slope Cerro Tancítaro, 3200 m, 22.VII.1941, W. C. Leavenworth \& H. Hoogstraal 1174a (F). MORELOS: S slope of Serjana de Ajusco, Zempoala-Huitzilac road km $4300 \mathrm{~m}$, H. H. Iltis et al. 248 (WIS). OAXACA: NW side of summit of Mt. Zempoaltepec, 3000-3350 m, 5-13. VII.1894, E. W. Nelson 650 (US); near Cerro San Felipe, 2900-3350 m, VIII.1894, E. W. Nelson 1099 (F, US); Cerro San Felipe, 2900-3350 m, 1894, E. W. Nelson 1072 (US); $30 \mathrm{~km}$ SW of Oaxaca, 2300-2900 m, 10-20.IX.1894, E. W. Nelson 1335 (US); Sierra de San Felipe, 3150 m, 29.VIII.1894, C. G. Pringle 4853 (BR, CM, ENCB, GH, GOET, M, MEXU, MO, NY, PH, UC, US). PUEBLA: S side of Mt. Ixtaccihuatl, 3940 m, 31.VII.1958, J. H. Beaman 1981 (GH, MEXU, US, WIS); Sierra de San Felipe, 3050 m, 28.VIII.1894, C. L. Smith 961 (US). QUERÉTARO: parte alta del Cerro Zamorano, J. Rzedowski 44398 (IEB). VERACRUZ: La Zimiento, Cerro de Perote, 3200 m, 27.V.1958, E. K. Balls 4641 (UC, US); NW side of Mt. Cofre de Perote, 3590 m, 7.VIII.1958, J. H. Beaman 2194 (GH, MEXU, UC); NE slope of Pico de Orizaba, 3200-3300 m, 6.VII.1982, M. Nee \& G. Diggs 24777 (F mezclado L. denticulata, NY); $7 \mathrm{~km}$ from Altotonga towards Perote, 2200 m, 14.VII.1971, L. I. Nevling \& F. Chiang 1723 (F).

2. Luzula comosa E. Mey., Syn. Luzul. 21. 1823.

इJuncoides campestre var. comosum (E. Mey.) Kuntze, Revis. Gen. P1. 2: 724.1891 (como Juncodes). 
三Juncoides comosa (E. Mey.) Sheldon, Minnesota Bot. Stud. 1: 64.1894 (como Juncodes).

三 Luzula campestris var. comosum Fernald \& Wiegand, Rhodora 15: 41.1913.

Tipo: CANADÁ. Columbia Británica, Nootka Sound, T. Haenke s.n. (holo-: PR!).

Hierbas perennes, cespitosas, hasta $35 \mathrm{~cm}$ de alto. Rizomas ascendentes; culmos erectos lisos o sulcados cuando secos, 0.7-1.5 mm de diámetro. Hojas basales varias por cada culmo; vainas hasta $0.5 \mathrm{~cm}$ de largo; láminas lineares, 5-15 × 0.2-0.4 $\mathrm{cm}$, planas, estrechándose gradualmente en una punta obtusa y callosa; márgenes pilosos. Hojas caulinares 1-2 por cada culmo, hasta $2 \mathrm{~cm}$ de largo, similares a las hojas basales pero más cortas y con vainas. Inflorescencia una antela no ramificada de cabezuelas hasta $5 \times 3 \mathrm{~cm}$, ramas no extendidas, cabezuelas redondas o alargadas, $0.8-1.5 \times 0.8 \mathrm{~cm}$; brácteas de las inflorescencias proximales semejantes a pequeñas hojas caulinares, brácteas distales más cortas y escariosas. Flores 6-12 por cabezuela. Tépalos iguales, 3.5-4 mm de largo, lanceolados, acuminados, de color castaño. Estambres seis, ca. $2.2 \mathrm{~mm}$ de largo; anteras lineares, ca. $1.5 \mathrm{~mm}$ de largo, más largas que los filamentos. Ovario 0.4-0.7 mm de largo; estigmas 1.3-2.8 mm de largo. Cápsula obovoide, mucronulada, más corta que los tépalos. Semillas elipsoidales, 1-1.4 mm de largo, cuando inmaduras con una carúncula esponjosa, blanca ocupando cerca de la mitad de la semillas. $2 \mathrm{n}=$ desconocido.

Distribución general. Luzula comosa está ampliamente distribuida en regiones templadas de Norte América, incluyendo Alaska y toda la costa oeste del Pacífico. Kirschner (2002a) considera que esta especie junto con L. subsessilis requiere un estudio detallado en el oeste de Norte América.

Hábitat y fenología. Luzula comosa crece en Norte América entre 50 y 3200 metros sobre el nivel del mar, en México ha sido colectada en una localidad en Baja California cerca de los $2500 \mathrm{~m}$ y en Chihuahua por encima de los 3000 metros. En el oeste de Norte América se encuentra principalmente en lugares húmedos en bosques abiertos, bosques de coníferas y prados. En Norte América L. comosa florece y fructifica entre marzo y agosto. En México ha sido colectada en fruto de junio a octubre.

Nombres vernáculos y usos. Desconocidos.

Afinidades. Luzula comosa es junto con L. caricina miembro del subgénero Luzula sección Luzula (ver L. caricina). 
Especímenes examinados. BAJA CALIFORNIA: Parque Nacional San Pedro Mártir, along stream on Observatory road above forestry camp, $N$ of Vallecitos, 2460 m, 19.VI.1985, R. E. Thornem (SD). CHIHUAHUA: Chuhuichupe, VIII-IX.1936, $H$. LeSueur 1114 (GH, MO, UC); Sierra Mohinora, 3050-3150 m, 16-17.X.1959, D. S. Correll \& H. S. Gentry 23173 (NY).

3. Luzula denticulata Liebm., Mexic. Juncac. 46. 1850.

$\equiv$ Luzula parviflora (Ehrh.) Desv. var. denticulata (Liebm.) Buchenau, Bot. Jahrb. Syst. 7: 171. 1885.

Lectotipo (designado por Hämet-Ahti, 1971): MÉXICO. Veracruz, Mt. Orizaba, Vaquería del Jacal, 3050 m, IX.1841, F. M. Liebmann s.n. (C!; iso-: C!, G!, GH!, K!, P!, S!, UPS!). Figura 11 A-D.

=Luzula laetevirens Liebm., Mexic. Juncac. 46. 1850.

Lectotipo (designado por Hämet-Ahti, 1971): MÉXICO. Veracruz, Mt. Orizaba, 2750-3050 m, IX.1841, F. M. Liebmann s.n. (C!; iso-: C!, P!).

= Luzula latifolia Liebm., Mexic. Juncac. 47. 1850.

Lectotipo (designado por Hämet-Ahti, 1971): MÉXICO. Oaxaca, Cumbre de Ixtepec, 3050 m, IX.1842, F. M. Liebmann s.n. (C!).

Hierbas perennes, 15-90 $\mathrm{cm}$ de alto. Rizomas ascendentes, 1-2 $\mathrm{mm}$ de diámetro, frecuentemente dando origen a estolones ascendentes que terminan en una roseta de hojas; culmos erectos, teretes, 0.8-3 mm diámetro. Hojas basales 3-15 en una roseta; vainas cortas; láminas erectas o doblándose hacia afuera del culmo, lineares a estrechamente lanceoladas, $5-25 \times 0.8-1.2 \mathrm{~cm}$, planas, márgenes pilosos. Hojas caulinares 3-8 por cada culmo, semejantes a las basales pero con una vaina de hasta $7 \mathrm{~cm}$ de largo y la lámina más corta y erecta, las hojas distales progresivamente más cortas. Inflorescencia una panícula extendida de tipo antela, terminal, laxa, muy ramificada, 5-20 × 3-10 cm; segmentos del raquis muy cortos, de menos de 1 $\mathrm{cm}$ de largo; brácteas basales de la inflorescencia lineares, herbáceas, hasta $6 \mathrm{~cm}$ de largo, brácteas distales de la inflorescencia lineares a lanceoladas, membranáceas; márgenes enteros o divididos en lóbulos ciliados. Flores insertadas individualmente en distintos pedicelos. Tépalos iguales o los externos ligeramente más largos, 1.7-2.5 $\mathrm{mm}$ de largo, de color castaño claro a castaño oscuro, los externos cóncavos, los internos planos o ligeramente cóncavos. Estambres seis, 0.8-1.5 mm de largo; anteras oblongas, 0.4-0.8 mm de largo, iguales o más largas que los filamentos. Ovario con estilo 0.1-0.2 $\mathrm{mm}$ de largo; estigmas 0.8-1 mm de largo. Cápsula anchamente elipsoidal a suborbicular, cortamente apiculada, trígona a trilobada, 1.5-1.7 × 1.2-1.7 mm, 

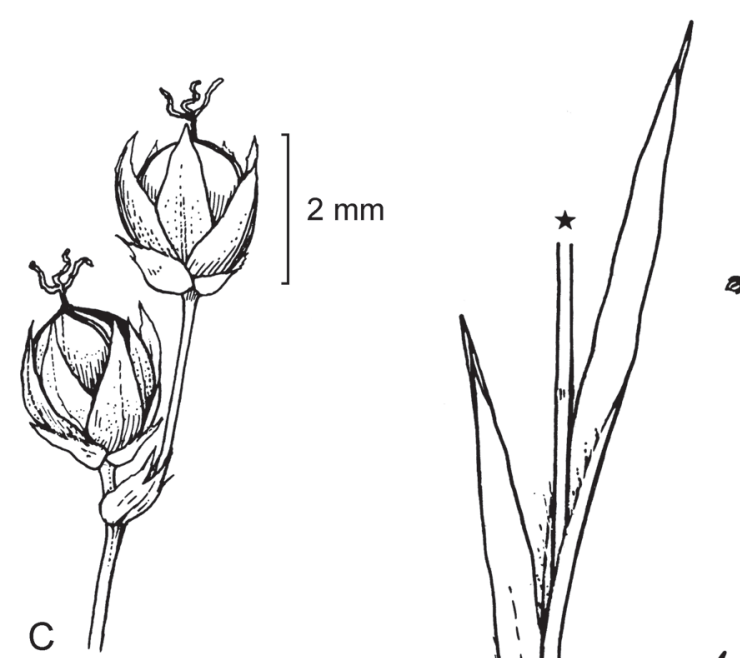
de color verde claro, tornándose de color castaño oscuro y luego castaño brillante cuando madura. Semillas elipsoidales a oblicuamente oblongas, anchamente apiculadas, 1.1-1.3 $\times$ 0.6-0.8 mm, lisas a rugosas, de color castaño abajo de la cubierta seminal hialina y blanca. $2 \mathrm{n}=$ desconocido.

Distribución general. Luzula denticulata se distribuye desde México a través de todo Centro América hasta Panamá. En México crece en los estados de Chiapas, Chihuahua, Distrito Federal, Hidalgo, Jalisco, México, Michoacán, Morelos, Puebla, Querétaro y Veracruz. McVaugh (1993) la menciona también para Guererro y Oaxaca.

Hábitat y fenología. Luzula denticulata crece entre 2000-3900 metros sobre el nivel del mar y es más común por encima de los 3000 metros en bancos húmedos, pantanos y en claros de bosque de pino-encino. La especie ha sido colectada en flor entre abril y diciembre, y en fruto desde julio hasta enero.

Nombres vernáculos y usos. Desconocidos.

Afinidades. Luzula denticulata es el único miembro mexicano del subgénero Luzula sección Diprophyllatae fácilmente reconocible por sus flores insertadas individualmente y no en grupos de cabezuelas o grupos de flores. Todas las ramas primarias de la inflorescencia surgen al final del culmo. Esta especie pertenece al complejo de la especie circumboreal L. parviflora. Buchenau (1906) y Hämeth-Ahti (1971) incluyeron a $L$. denticulata en la sinonimia de L. gigantea, una especie que crece exclusivamente en los Andes de Sur América pero con inflorescencias subdivididas por largos segmentos del raquis. McVaugh (1993) mantiene la tradición de llamarla L. gigantea.

Especímenes examinados. CHIAPAS: NE slope Zontehuitz nr. summit, San Cristóbal de las Casas, 2850 m, 20.IX.1965, D. E. Breedlove 12342 (DS, F, LL, MICH, US); N and W slope of Cerro Mozotal, Huixtla-El Porvenir-Siltepec road, $3000 \mathrm{~m}$, 19.IX.1976, D. E. Breedlove 40268 (MO); Motozintla de Mendoza, N slope of Mozotal near summit, 2900-3000 m, 15.X.1980, D. E. Breedlove \& I. Strother 46286 (MO, NY). CHIHUAHUA: N side Cerro Mohinora ca. $22 \mathrm{~km}$ SW of Guadalupe y Calvo, $2950 \mathrm{~m}$, 20.VIII.1988, G. Nesom \& A. McDonald 6470 (MO). DISTRITO FEDERAL: Desierto de los Leones,VII.1938, E. Lyonnet 2143 (GH, MO, UC, US); Monte Alegre, W slope of Ajusco, Tlalpan, 3400 m, 29.IV.1978, J. Rzedowski 35611 (SD); Los Dinamos, Con- 
treras, 2800 m, 21.X.1979, A. Ventura A. 3580 (GH, US). GUERRERO: Tlacotepec, Mt. Teotepec, 3200 m, J. Rzedowski 18572 (DUKE, ENCB, MEXU, TEX). HIDALGO: El Chico, VII.1928, E. Lyonnet 265 (CAS, ENCB, GH, MEXU, MO, NY, K, US). JALISCO: NE slope Nevado de Colima, 3100-3300 m, 13.IX.1952, R. McVaugh 12900 (US). ESTADO DE MÉXICO: Sierra de las Cruces, 3000 m, 11.IX.1892, C. G. Pringle 4216a (F, GH, NY, UC, US); Mesón Viejo, Temascaltepec, 2930 m, 10.VIII.1932, G. B. Hinton 1307 (F, GH, MO, NY, US); Nevado de Toluca, Ojos de Agua, 3650 m, 10.VII.1938, E. K. Balls 4981 (UC, US); Base of Ixtaccíhuatl, 2900 m, 1.V.1952, E. Matuda 26111 (US); San Rafael, E of Ixtaccihuatl, 2900 m, 16.XI.1952, E. Matuda 27613 (US). MICHOÁCAN: Paricutín Volcano, near summit Cerro Tancítaro, $3650 \mathrm{~m}$, 13.VII.1950, W. A. Eggler 44 (MO, US); Tancitaro, Uruapan, 6.XI.1940, G. B. Hinton 15647 (NY, US); Mt. Tancitaro, 3200-3700 m, 22.VII.1941, W. C Leavenworth \& H. Hoogstraal 1139 (F, GH, MO, NY). MORELOS: Lagunas de Zempoala, 17.IX.1938, E. Lyonnet 2473 (US). OAXACA: Oaxaca-Tuxtepec road, km 130-140 beyond Cerro Pelón, 3500 m, 3.I.1974, M. Carlson 4126 (F); Tlalixtac, 4 kms E of Cumbre along road to Etla, 3050 m, 16.IX.1980, G. J. Martin 173 (MO); NW side of summit of Mt. Zempoaltepec, 3050-3350 m, 5-13.VII.1894, E. W. Nelson 645 (US); 2450-3050 m, 10.VII.1894, E. W. Nelson 688 (US); Sierra San Felipe, 3050-3300 m, IX.1894, C. L. Smith 932 (A, ENCB, F, NY, US). PUEBLA: Tesmalaquilla, Sierra Negra, Mt. Orizaba, 3200 m, 9.V.1938, E. K. Balls et al. 4475 (K, UC, US); E slope Ixtaccihuatl above San Juan Tlale and San Juan Tetla, 3800 m, 7.X.1968, H. Ern 304 (B). QUERÉTARO: parte alta del Cerro Zamorano, J. Rzedowski 44407 (IEB). VERACRUZ: Calcahualco, $12 \mathrm{~km}$ W of Escola, $3.5 \mathrm{~km} \mathrm{~N}$ of Vaqueria, $2700 \mathrm{~m}$, 15.XI.1981, M. Nee 23130 (F); Calcahualco, 4 km SW of Jacal, 3200-3300 m, 6.VII.1982, M. Nee \& G. Diggs 24777 (F, mixed with L. caricina); Pico de Orizaba, 3800 m, H. G. Galeotti 5764 (G, P); Mt. Orizaba, 25-26.VII.1901, J. N. Rose \& R. Hay 5747 (US).

4. Luzula racemosa Desv., J. Bot. (Desvaux) 1: 162, t. 6. f. 3. 1808.

$\equiv$ Juncoides racemosa (Desv.) Kuntze, Revis. Gen. Pl. 2: 734. 1891. 三Luzula racemosa Desv. var. typica Buchenau En: Engler, Pflanzenreich IV, 36 (Heft 25): 75. 1906. Figura 12 A, B.

Lectotipo (designado por Kirschner, 2002a): America calidiore; sin colector, s.n. (lecto-: P n.v.).

$=$ Luzula spicata (L.) DC var. interrupta E. Mey., Linnaea 22: 415. 1849, non Luzula interrupta Desv.

Lectotipo (designado por Kirschner, 2002a): America calidiore; sin colector, s.n. (lecto-: P!). 
Hierbas perennes, cespitosas, 5-45 cm de alto. Rizomas erectos o ascendentes, con estolones; culmos erectos o de manera más frecuente ligeramente curvados, 0.5-2 mm de diámetro. Hojas basales cinco a muchas por cada culmo, en una roseta laxa o escuarrosa; vainas cortas; láminas apicalmente agudas, $5-25 \times 0.1-0.5 \mathrm{~cm}$, planas o a veces gruesas y cóncavas. Hojas caulinares $0-4$ por cada culmo, hasta 15 cm de largo, la vaina ocupando 1/6-1/3 de la longitud, márgenes de la hoja pilosos, especialmente en las hojas jóvenes y caulinares. Inflorescencia un racimo parecido a una espiga con tres a más grupos de flores, erecto o péndulo, 1-6 $\times 0.5-2 \mathrm{~cm}$; brácteas basales de la inflorescencia herbáceas, lineares, usualmente más largas que los grupos de flores y hasta $5 \mathrm{~cm}$ de largo, brácteas distales progresivamente más cortas. Flores en grupos oblongos a ovoides, 0.5-1.5 $\times 0.3-1 \mathrm{~cm}$, sésiles o a veces cortamente pedunculados, compactos o a veces espaciados a lo largo del raquis. Tépalos desiguales, de color castaño oscuro o blanco, membranáceos cuando viejos, los tépalos externos 2.5-4 mm, los internos 2-3.5 mm de largo. Estambres usualmente tres pero también seis, 0.6-1.5 mm de largo; anteras oblongas a lineares, 0.2-0.5 mm de largo, usualmente más cortas que los filamentos. Ovario con estilo 0.1-0.2 mm de largo; estigmas 0.6-0.9 mm de largo. Cápsula anchamente elipsoidal a ovoide, trilobada a trigonal, 1.5-2 × 1-1.5 mm, por lo común conspicuamente más corta que los tépalos pero a veces también de la misma longitud, de color castaño, dehiscente con las valvas enteras recurvándose. Semillas elipsoidales, apiculadas, 0.7-1.1 × 0.4-0.6 $\mathrm{mm}$, de color castaño con una cubierta seminal hialina, rugosa. $2 \mathrm{n}=24$ (Beaman et al., 1962).

Distribución general. Luzula racemosa se distribuye en las tierras altas de México y Guatemala y de manera disyunta en Sur América a lo largo de los Andes desde Colombia y Venezuela hasta Chile y Argentina. En México crece en los estados de Chiapas, Distrito Federal, Jalisco, México, Michoacán, Puebla, Tlaxcala y Veracruz.

Hábitat y fenología. Luzula racemosa crece en elevaciones entre 2900-4700 metros sobre el nivel del mar, pero especialmente por encima de los 3500 metros. Se desarrolla en lugares bien drenados y soleados en comunidades herbáceas abiertas y prados alpinos por debajo del cinturón de árboles y a veces en laderas rocosas con grava volcánica o suelos arenosos. La especie ha sido colectada en flor entre junio y noviembre y en fruto entre julio y abril.

Nombres vernáculos y usos. Desconocidos. 
Balslev y Duno de Stefano: Las Juncaceae en México

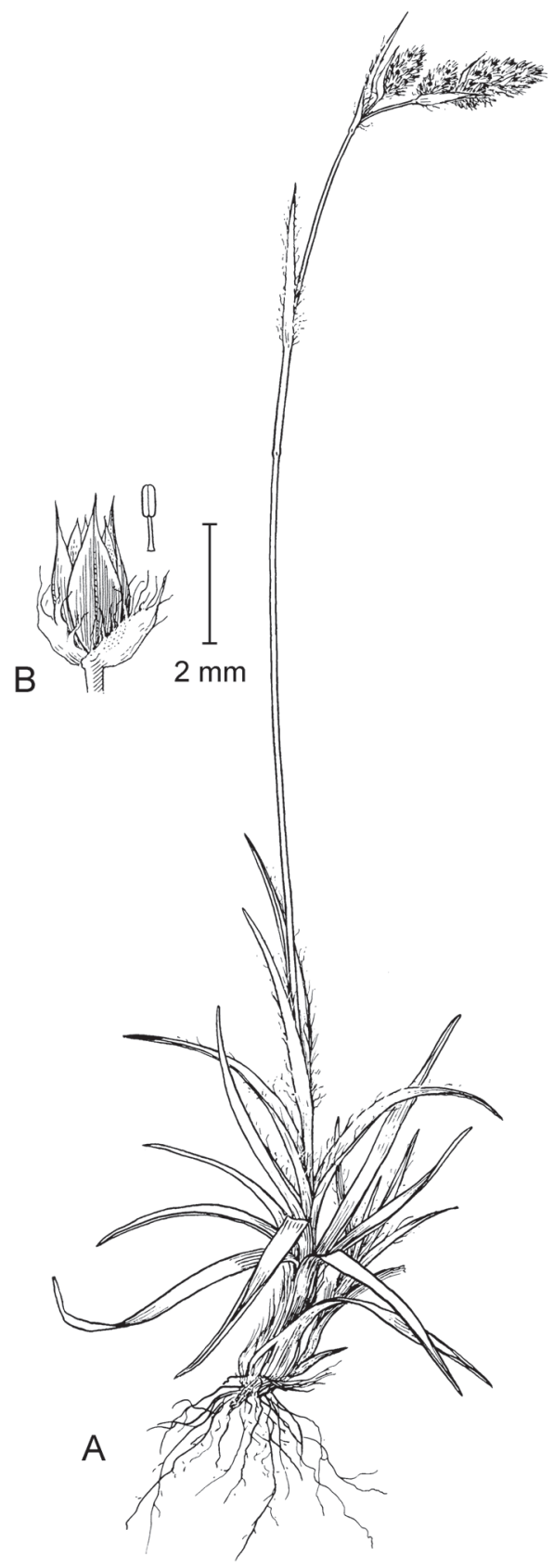

Fig. 12. Luzula racemosa. A. hábito; B. flor y estambre (Bell 78, A). Originalmente publicado en Balslev, 1979. 
Afinidades. Luzula racemosa es junto con L. vulcanica miembro del subgénero Luzula sección Alpinae. Es una especie extremadamente variable en la mayor parte de las características de su hábito (Kirschner, 2002a), pero se diferencia fácilmente de L. vulcanica por carecer de estolones.

Especímenes examinados. CHIAPAS: Unión Juárez, 2200 m, 30.VII.1972, D. E. Breedlove 26722 (F, MO, NY); SE side of Mt. Tacaná, Unión Juarez, 3600 m, 10.XI.1972, D. E. Breedlove 29371 (CHAPA, DS, DUKE, F, LL, MEXU, MICH, MO, NY); summit Volcán Tacaná, 2000-4038 m, VIII.1938, E. Matuda 2355 (GH, MO, NY). DISTRITO FEDERAL: Cerro Ajusco, 3937 m, 12.VII.1959, J. H. Beaman 2786 (GH, UC, US); Ajusco, 3900 m, VIII.1928, E. Lyonnet 263 (MEXU, MO, NY, US); Los Dinamos, Contreras, 3000 m, 16.VIII.1979, A. Ventura A. 3503 (GH, US). JALISCO: Nevado de Colima S of Guzman, 3800 m, 2.VII.1956, D. P. Gregory \& G. Eiten 299 (MO, NY); Nevado de Colima, N slope, Piedra Ancha, 3090 m, 31.III.1951, R. McVaugh 11651 (US); Nevado de Colima, NE slope, Canoa de Leoncito, 3900 m, 13.IX.1952, R. McVaugh 12903 (US); Nevado de Colima, 3300-4340 m, 30.X.1952, $R$. McVaugh 13819 (NY); ESTADO DE MÉXICO: Nevado de Toluca, 4140 m, 8.IX.1957, J. H. Beaman 1691 (GH, NY, US); Nevado de Toluca, 4200 m, 19.X.1952, E. Matuda 26603 (NY); Ixtaccíhuatl, 3500-4300 m, 13.IX.1953, E. Matuda 29032 (US); Chapultepec, Lermas, 2600 m, 10.X.1953, E. Matuda 29466 (US); Ixtaccihuatl, 22.IX.1946, H. E. Moore, Jr. 1245 (GH, UC, US); Toluca, 9.IX.1893, E. W. Nelson 16 (US); Nevado de Toluca, 16.X.1903, J. N. Rose \& J. H. Painter 7984 (US); Nevado de Toluca, 4200 m, 17.IX.1930, M. St. Pierre 910 (US); near Toluca, VIII.1892, C. G. Pringle 4216 (GH, GOET, MO, NY, US). MICHOÁCAN: Mt. Tancítaro, 3500 m, 22.VII.1941, W. C. Leavenworth 1158 (F, GH, MO, NY, US). PUEBLA: N side Popocatépetl, J. H. Beaman 1742 (DUKE, ENCB, GH, TEX, UC, US); N side Mt. Orizaba, Albergue Piedra Grande, 4275 m, 14.VII.1960, J. H. Beaman 3633 (US); Ciudad Serdán, N slope Pico de Orizaba, 4100-4200 m, 7.VII.1982, G. Diggs \& M. Nee 2770 (F, MO, NY); Popocatépetl, 3750 m, 11.IV.1947, E. Miranda \& F. A. Barkley 17M205 (F). TLAXCALA: Malinche, crest of N rim of crater, 4400-4450 m, 10.VIII.1958, J. H. Beaman 2225 (F, GH, NY, TEX, UC, US, WIS); Malinche crest of N rim of crater, 4400-4450 m, 10.VIII.1958, I. H. Beaman 2223 (F, NY, UC, US). VERACRUZ: Pico de Orizaba, S side of Mt. N of Cueva del Muerto, 4000 m, 21.IX.1957, J. H. Beaman 1780 (UC, US); Cofre de Perote, 4150 m, 27.IX.1973, C. Delgadillo \& I. Dorantes 3078 (F); Cofre de Perote, 4100 m, 27.VI.1982, G. Diggs et al. 2582 (F); Pico de Orizaba, 3300 m, 11.X.1980, R. Hernández M. \& R. C. Trigos 1337 (F); La Perla, N side of Pico de Orizaba above Piedra Grande, 4200 m, 21.IX.1986, M. Nee et al. 33188 (MO, NY, UC, XAL). 
5. Luzula vulcanica Liebm., Mexic. Juncac. 44. 1850.

Lectotipo (designado por Balslev, 1996): MÉXICO. Veracruz, Mt. Orizaba, 4250 m, F. M. Liebmann s.n. (C!; iso-: C!, GH!, K!, P!, S!). Figura 13 A, B.

Hierbas perennes, 5-45 cm del alto. Rizomas erectos o ascendentes, 1-2 mm de diámetro, con estolones ascendentes que terminan en una roseta de hojas; culmos erectos, 0.7-2 mm de diámetro, usualmente erectos, a veces curvados en dirección opuesta a la inflorescencia. Hojas basales 3-8 por cada culmo, las internas erectas y algo adpresas al culmo; láminas 3-15 × 0.2-0.5 cm, márgenes pilosos cuando jóvenes y luego glabros. Hojas caulinares dos por cada culmo, 1-5(-11) $\mathrm{cm}$ de largo, insertadas abajo de la mitad del culmo y usualmente cerca de la inflorescencia. Inflorescencia con 3-7 grupos de flores, dispuestos en un racimo en forma de espiga, terminal, 1-4 $\times$ 0.5-1.5 cm, formando $1 / 5$ del total de la altura de la planta, erecto al principio, luego péndulo; grupos de flores $0.5-2 \times 0.5-1 \mathrm{~cm}$, sésiles o los basales a veces cortamente pedunculados y separados unos de otros por un corto segmento del raquis; brácteas membranáceas, los márgenes divididos en lóbulos ciliados, las brácteas basales usualmente cerca de $1 \mathrm{~cm}$ de largo, anchamente lanceoladas, ocasionalmente hasta 2 $\mathrm{cm}$ de largo y algo herbáceas en especímenes grandes. Tépalos casi iguales, membranáceos, de color castaño oscuro en las flores jóvenes, los externos 3-4 mm de largo, los internos 2-3.5 mm de largo. Estambres tres, 1-1.5 $\mathrm{mm}$ de largo; anteras oblongas, 0.2-0.6 mm de largo, más cortas que los filamentos. Ovario con estilo de 0.1-0.2 mm de largo; estigmas 0.5-0.8 mm de largo. Cápsula anchamente elipsoidal, basalmente trilobada, apicalmente trígona, 1.5-2 × 1-1.3 mm, finamente rugosa, de color castaño claro. Semillas elipsoidales, apiculadas, 1-1.2 $\times$ 0.5-0.6 mm, de color castaño abajo de la cubierta seminal, blanca o de color castaño claro, lisa. $2 \mathrm{n}=$ desconocido.

Distribución general. Luzula vulcanica se distribuye en México y de manera de manera disyunta en Sur América, en los Andes desde Colombia hasta Bolivia. En México crece en los estados de México, Puebla y Veracruz.

Hábitat y fenología. Luzula vulcanica crece en elevaciones entre 3850-4700 metros sobre el nivel del mar, mientras que en México lo hace entre 3850-4300 metros. Es más común en lugares húmedos y pantanosos por debajo de límite de crecimiento de la línea de árboles. La especie ha sido colectada en flor entre julio y agosto.

Nombres vernáculos y usos. Desconocidos. 
Acta Botanica Mexicana 111: 61-164 (2015)

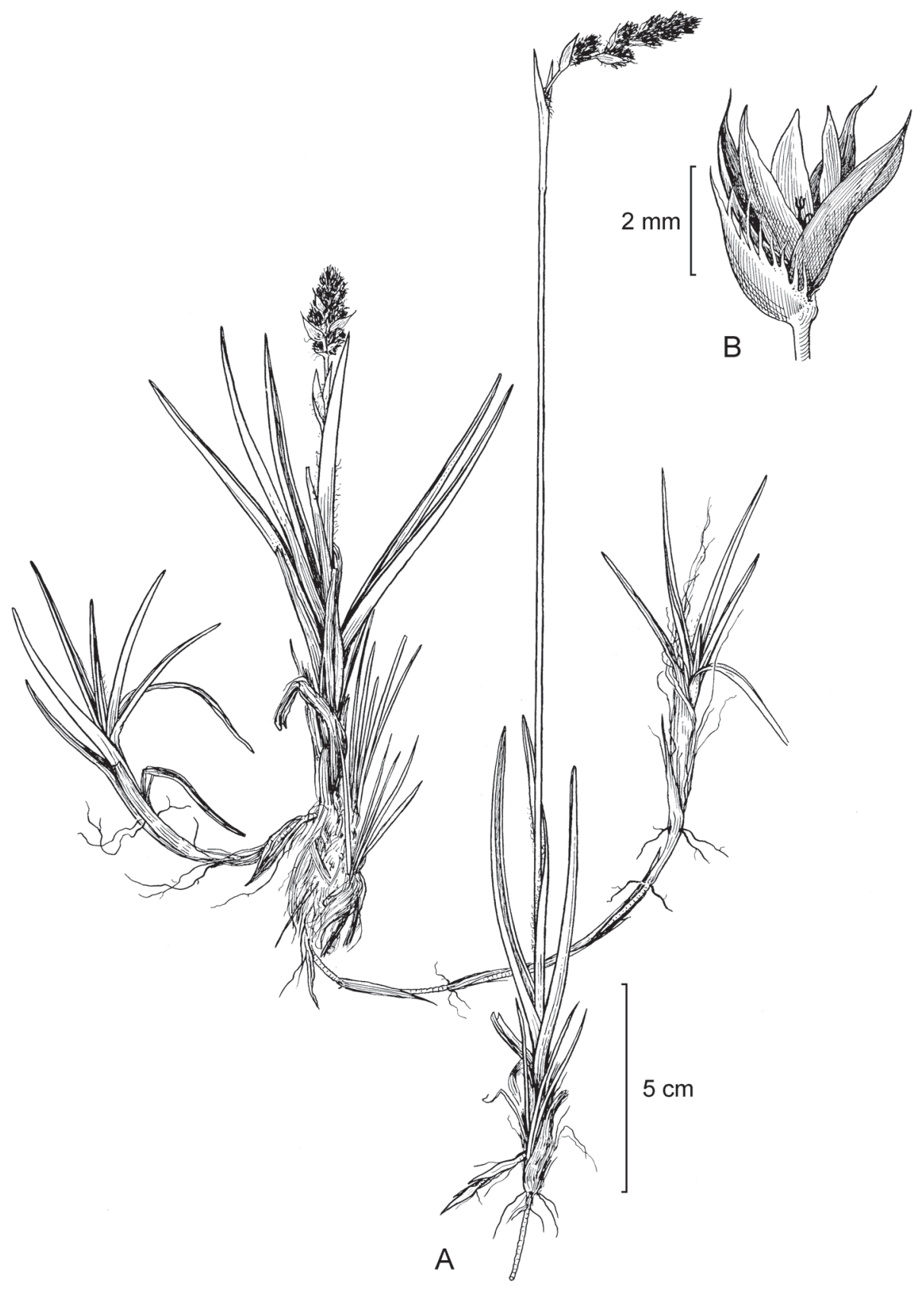

Fig. 13. Luzula vulcanica. A. hábito; B. flor y estambre (Øllgaard \& Balslev 9881, AAU). Originalmente publicado en Balslev, 1979. 
Afinidades. Luzula vulcanica se relaciona con L. racemosa. Buchenau (1906) y otros autores las han tratado como coespecíficas. Sin embargo, L. vulcanica tiene estolones, culmos rectos (ausentes en L. racemosa), brácteas inferiores de la inflorescencia anchamente lanceoladas, escariosas y tan largas como las inflorescencias (lineares, herbáceas y más largas que la inflorescencia en L. racemosa) y los grupos de flores son de color oscuro (castaño en L. racemosa).

Especímenes examinados. ESTADO DE MÉXICO: SW side of Mt. Ixtaccihuatl, Cañada de Alcalican, below La Joya, 3850 m, 10.VII.1960, J. H. Beaman 3527 (US). PUEBLA: S side of Mt. Ixtaccihuat1, $0.5 \mathrm{~km}$ NE of summit of Piez, 4300-4350 m, J. H. Beaman 2554 (GH, MEXU). VERACRUZ: E slope Cofre de Perote, 4000 m, 28.VIII.1971, I. Dorantes $338(\mathrm{~F})$.

\section{AGRADECIMIENTOS}

El primer autor desea expresar su agradecimiento a los curadores de todos los herbarios que hicieron posible este estudio. El segundo autor agradece a la Universidad de Aarhus el apoyo de la estancia de tres meses para culminar este tratamiento. Se dan gracias asimismo a la Bióloga Lilia Lorena Can por la revisión del texto.

\section{LITERATURA CITADA}

APG. 1998. An ordinal classification for the families of flowering plants. Ann. Missouri Bot. Gard. 85: 531-553.

APG II. 2003. An update of the Angiosperm Phylogeny Group classification for the orders and families of flowering plants: APG II. Bot. J. Linn. Soc. 141: 399-436.

APG III. 2009. An update of the Angiosperm Phylogeny Group classification for the orders and families of flowering plants: APG III. Bot. J. Linn. Soc. 161(2): 105-121.

Balslev, H. 1979. Juncaceae. In: Harling, G. y L. Andersson (eds.). Flora of Ecuador 11. Department of Systematic Botany, University of Gothenburg and the Section for Botany, Riksmuseum. Stockholm, Sweden. 45 pp.

Balslev, H. 1982. Juncaceae for Flora Neotropica. Ph.D. thesis. City University of New York. New York, USA. pp. 1-495.

Balslev, H. 1983. New taxa and combinations in neotropical Juncus (Juncaceae). Brittonia 35: 302-308.

Balslev, H. 1988. Two new rushes (Juncus, Juncaceae) from Chiapas, Mexico. Ann. Missouri Bot. Gard. 75: 379-382. 
Balslev, H. 1994. Juncaceae. In: Davidse, G., M. Sousa y A. O. Chater (eds.). Flora Mesoamericana 6: Alismataceae a Cyperaceae. Instituto de Biología, Universidad Nacional Autónoma de México, Missouri Botanical Garden y Museo de Historia Natural (Londres). San Louis, USA. 543 pp.

Balslev, H. 1996. Juncaceae. Flora Neotropica Monographs 68: 1-163.

Balslev, H. y S. Lægaard. 1986. Distichia acicularis sp. nov.- a new cushion-forming Juncaceae from the high Andes of Ecuador. Nordic J. Bot. 6: 151-155.

Balslev, H. y A. Zuluaga. 2009. Juncaceae. In: Pinto Escobar, P. y P. M. Ruiz (eds.). Flora de Colombia 26. Instituto de Ciencias Naturales, Universidad Nacional de Colombia. Bogotá D.C., Colombia. 80 pp.

Beaman, J. H., D. C. D. De Jong y W. P. Stoutamire. 1962. Chromosome studies in the alpine and subalpine floras of Mexico and Guatemala. Amer. J. Bot. 49: 41-50.

Britton, N. L. y A. Brown. 1913. An illustrated flora of the Northern United States and Canada. Vol. 1. Charles Scribner's Sons. New York, USA. 680 pp.

Buchenau, F. 1873. Über einige von Liebmann in Mexico gesammelte Pflanzen. Abh. Naturwiss. Ver. Bremen 3: 339-350.

Buchenau, F. 1875. Monographie der Juncaceen vom Cap. Abh. Naturwiss. Ver. Bremen 4: 119-134.

Buchenau, F. 1879. Kritische Zusammenstellung der bis jetzt bekannten Juncaceen aus SüdAmerika. Abh. Naturwiss. Ver. Bremen 6: 353-431.

Buchenau, F. 1880. Die Verbreitung der Juncaceae über die Erde. Bot. Jahrb. Syst. 1: 104-141.

Buchenau, F. 1886. Die Juncaceen aus Mittelamerika. Flora 69: 145-155, 161-170.

Buchenau, F. 1890. Monographia Juncacearum. Bot. Jahrb. Syst. 12: 1-495.

Buchenau, F. 1902. Juncus textilis Buchenau. Abh. Naturwiss. Ver. Bremen 17: 336-340.

Buchenau, F. 1906. Juncaceae. Das Pflanzenreich IV. 36 (Heft 25): 1-284.

Cope, T. A. y C. A. Stace. 1978. The Juncus bufonius L. aggregate in western Europe. Watsonia 12: 112-128.

Cope, T. A. y C. A. Stace. 1985. Cytology and hybridization in the Juncus bufonius L. aggregate in western Europe. Watsonia 15: 309-320.

Coville, F. V. 1893. Juncus marginatus and its varieties. Proc. Biol. Soc. Wash. 8: 121-127.

Cronquist, A. 1981. An integrated system of classification of flowering plants. Houghton Mifflin. Boston, USA. 1262 pp.

Cronquist, A., A. H. Holmgren, N. H. Holmgren, J. L. Reveal y P. K. Holgren. 1977. Intermountain Flora. Vol. 6. The monocotyledons. The New York Botanical Garden \& Columbia University Press. New York, USA. 584 pp.

Dalgaard, V. 1991. Chromosome studies in flowering plants from Macaronesia II. Willdenowia 20: 139-152.

Drábková, L. y Č. Vlček. 2007. The phylogenetic position of Oxychloë (Juncaceae): evidence from one nuclear, three plastid regions and morphology. Taxon 56: 95-102.

Drábková, L. y Č. Vlček. 2009. Mitochondrial DNA variation within Juncaceae: Comparison of impact of organelles regions on phylogeny. Pl. Syst. Evol. 278: 169-186.

Drábková, L., J. Kirschner y Č. Vlček. 2006. Phylogenetic relationships within Luzula DC. and Juncus L. (Juncaceae): a comparison of phylogenetic signals of trnL-trnF intergenic spacer, trnL intron and rbcL plastome sequence data. Cladistics 22: 132-143. 
Drábková, L., J. Kirschner, O. Seberg, G. Petersen y Č. Vlček. 2003. Phylogeny of the Juncaceae based on rbcL sequences, with special emphasis on Luzula DC. and Juncus L. Pl. Syst. Evol. 240: 133-147.

Drábková, L., J. Kirschner, Č. Vlček y V. Pačes. 2004. TrnL-trnF intergenic spacer and trnL intron define clades within Luzula and Juncus (Juncaceae). J. Molec. Evol. 59: 1-10.

Druskovic, B. 1995. IOPB chromosome data 9. Newslett. Int. Organ. Pl. Biosyst. Oslo 24: 11-14.

Engelmann, G. 1866. A revision of the North American species of the genus Juncus, with a description of a new and imperfectly known species. Trans. Acad. Sci. St. Louis 2: 424-458.

Engelmann, G. 1868. A revision of the North American species of the genus Juncus, with a description of a new and imperfectly known species. Trans. Acad. Sci. St. Louis 2: 459-499.

Ertter, B. 1986. The Juncus triformis complex. Mem. New York Bot. Gard. 39: 1-90.

Fernández-Carvajal, M. C. 1981. Revisión del género Juncus L. en la Península Ibérica. I. Categorías supraespecíficas y clave para las especies. Anales Jard. Bot. Madrid 38: 79-89.

Fernández-Carvajal, M. C. 1983. Revisión del género Juncus L. en la Península Ibérica. IV: Subgéneros Juncinella (Fourr.) Krecz. \& Gontsch., Septati Buchenau y Alpini Buchenau. Anales Jard. Bot. Madrid 39: 301-379.

Galván-Villanueva, R. 2002. Juncaceae. Flora del Bajío y de Regiones Adyacentes 104: 1-41. Gleason, H. A. 1968. The new Britton and Brown Illustrated Flora of the Northeastern United States and adjacent Canada. Vol. 1. Lancaster Press, Lancaster, USA. 486 pp.

Gleason, H. A. y A. Cronquist. 1991. Manual of the vascular plants of Northeastern United States and adjacent Canada. 2nd ed. New York Botanical Garden. Bronx, USA. 910 pp.

Hämet-Ahti, L. 1971. A synopsis of the species of Luzula, subgenus Anthelaea Griseb. (Juncaceae) indigenous in North America. Ann. Bot. Fenn. 8: 368-381.

Hämet-Ahti, L. 1980. The Juncus effusus aggregate in eastern North America. Ann. Bot. Fenn. 17: 183-191.

Harriman, N. A. 1979. IOPB chromosome number reports LXIV. Taxon 28: 405-406.

Harriman, N. A. y D. Redmond. 1976. Somatic chromosome numbers for some North American species of Juncus L. Rhodora 78: 727-738.

Hermann, F. J. 1975. Manual of the rushes (Juncus spp.) of the Rocky Mountains and Colorado Basin. US Dep. Agric. Gen. Techn. Rep. 18.

Holm, T. 1899. Juncus repens Michx.- a morphological and anatomical study. Bull. Torrey Bot. Club 26: 359-364.

Kirschner, J. (comp.). 2002a. Juncaceae 1: Rostkovia to Luzula. Species Plantarum, Flora of the World 6: 1-237.

Kirschner, J. (comp.). 2002b. Juncaceae 2: Juncus subg. Juncus. Species Plantarum, Flora of the World 7: 1-336.

Kirschner, J. (comp.). 2002c. Juncaceae 3: Juncus subg. Agathryon. Species Plantarum, Flora of the World 8: 1-192.

Liebmann, F. 1850. Mexico's Juncaceer. Vidensk. Meddel. Dansk Naturhist. Foren. Kjøbenhavn 1850: 36-48. 
Linnaeus, C. 1753. Species plantarum. Bay Society (1957). Londres, UK.

Love, A. y D. Love. 1980. Chromosome number reports LXIX. Taxon 29: 707-709.

Love, A. y D. Love. 1981. Chromosome number reports LXXIII. Taxon 30: 845-851.

Matuda, E. 1960. Las Juncaceae del Estado de México. Dirección de Recursos Naturales, Gobierno del Estado de México. Toluca, México. 15 pp.

McVaugh, R. 1993. Juncaceae. In: Anderson, W. R. (ed.). Flora Novo Galiciana. Vol. 13. University of Michigan Press. Ann Arbor, USA. 480 pp.

Munro, S. L. y H. P. Linder. 1998. The phylogenetic position of Prionium (Juncaceae) within the order Juncales based on morphological and rbcL sequence data. Syst. Bot. 23: 43-55.

Plunkett, G. M., D. E. Soltis, P. S. Soltis y R. E Brooks. 1995. Phylogenetic relationships between Juncaceae and Cyperaceae: Insights from rbcL sequence data. Amer. J. Bot. 82: $520-525$.

Rzedowski, J. 1978. Vegetación de México. Limusa. México, D.F., México. 432 pp.

Small, J. K. 1903. Flora of southeastern United State. Published by the author. New York, USA. 1370 pp.

Snogerup, S. 1963. Studies in the genus Juncus III. Observations on the diversity of chromosome numbers. Bot. Not. 116: 142-156.

Snogerup, S. 1971. Juncaceae. Flora Iranica 75: 1-35.

Snogerup, S. 1980. Juncaceae. In: Tutin, T. G., V. H. Heywood, N. A. Burges, D. M. Moore, D. H. Valentine, S. M. Walters y D. A. Webb (eds.). Flora Europea. Vol. 5: Alismataceae to Orchidaceae. Cambridge University Press. Cambridge, UK. 452 pp.

Snogerup, S. 1993. A revision of Juncus subgen. Juncus (Juncaceae). Wildenowia 23: 23-73. Standley, P. C. 1937. Juncaceae. Flora of Costa Rica. Field. Bot. 18: 167-168.

Standley, P. C. y J. A. Steyermark. 1952. Juncaceae. Flora of Guatemala. Field. Bot. 24: 5259.

Uhrikova, A. 1974. Index to chromosome numbers of Slovakian flora. Part 4. Acta Fac. Rerum Nat. Univ. Comenianae, Bot. 23: 1-23.

Weimarck, H. 1946. Studies in Juncaceae. With special reference to the species in Ethiopia and the Cape. Svensk Bot. Tidskr. 40: 141-178.

Wiegand, K. M. 1900. Juncus tenuis Willd. and some of its North American allies. Bull. Torrey Bot. Club. 27: 511-527. 